\title{
Reversible switching between nonporous and porous phases of a new SIFSIX coordination network induced by a flexible linker ligand
}

Bai-Qiao Song ${ }^{\dagger}$, Qing-Yuan Yang ${ }^{\ddagger}$, Shi-Qiang Wang ${ }^{\dagger}$, Matthias Vandichel ${ }^{\dagger}$, Amrit Kumar $^{\dagger}$, Clare Crowley ${ }^{\dagger}$, Naveen Kumar ${ }^{\dagger}$, Cheng-Hua Deng ${ }^{\dagger}$, Victoria GasconPerez ${ }^{\dagger}$, Matteo Lusi ${ }^{\dagger}$, Hui Wu ${ }^{\S}$, Wei Zhou ${ }^{\S}$ and Michael J. Zaworotko*,†

'Department of Chemical Sciences and Bernal Institute, University of Limerick, Limerick V94 T9PX, Republic of Ireland.

'School of Chemical Engineering and Technology, Xi'an Jiaotong University, Xi'an 710049, China ${ }^{\S}$ NIST Center for Neutron Research, National Institute of Standards and Technology, Gaithersburg, Maryland 20899-6102, United States 


\section{Materials and Synthesis}

The ligand 1,4-Bis(1-imidazolyl)benzene (L) was synthesized according to the literature method. ${ }^{1}$ Other reagents and solvents were commercially available and used without further purification.

$\left[\mathrm{Cu}\left(\mathrm{SiF}_{6}\right)(\mathrm{L})_{2}\right] \cdot \mathbf{x M e O H} \cdot \mathbf{y H}_{2} \mathrm{O}(\mathrm{SIFSIX}-23-\mathrm{Cu}-\boldsymbol{\alpha})$. A $5 \mathrm{~mL}$ water solution containing of $\mathrm{CuSiF}_{6} \cdot \mathrm{H}_{2} \mathrm{O}$ (22 $\left.\mathrm{mg}, 0.1 \mathrm{mmol}\right)$ was placed in the bottom of a glass tube, on which $6 \mathrm{~mL}$ of mixed $\mathrm{MeOH} /$ water (1:1) buffer was layered. Finally a $5 \mathrm{~mL} \mathrm{MeOH}$ solution containing bi-imidazolyl ligand (42 $\mathrm{mg}, 0.2 \mathrm{mmol}$ ) was carefully layered on the top. After several days, purple needle/rod shaped crystals were formed on the glass wall. The crystals were collected after three weeks to optimize the yield. The harvested crystals were washed with $\mathrm{MeOH}$ before drying (Yield: ca. 61\%). IR ( $\left.\mathrm{cm}^{-1}\right): 3419(w)$, 3129(m), 1631(m), 1526(s), 1309(s), 1272(w), 1255(w), 1137(w), 1108(w), 1066(s), 957(m), 843(m), 695(s).

SIFSIX-23-Cu- $\boldsymbol{\gamma}$ 1. Single crystals of SIFSIX-23-Cu- $\boldsymbol{\alpha}$ are prone to lose guest molecules in air at RT. When fresh crystals of SIFSIX-23-Cu- $\boldsymbol{\alpha}$ were filtered from reaction solution and dried in air for about 1 day, SCXRD demonstrated the formation of a new phase, SIFSIX-23-Cu- $\boldsymbol{\gamma} \mathbf{1}$.

SIFSIX-23-Cu- $\boldsymbol{\gamma} 2$ and SIFSIX-23-Cu- $\boldsymbol{\gamma}$ 3. Heating the air dried sample at $60{ }^{\circ} \mathrm{C}$ for about 2 hours, SIFSIX-23-Cu- $\boldsymbol{\gamma} \mathbf{2}$ was isolated. Further heating this phase or the air dried sample at $80{ }^{\circ} \mathrm{C}$ for 2 hours produced SIFSIX-23-Cu- $\boldsymbol{\gamma}$ 3. It is worth to note that the SIFSIX-23-Cu- $\boldsymbol{\gamma} \mathbf{3}$ form can capture water from air very quickly to return back to the SIFSIX-23-Cu- $\boldsymbol{\gamma} \mathbf{2}$ phase.

SIFSIX-23-Cu- $\boldsymbol{\beta 1}$. Heating the air dried sample or the isolated intermediate phases at $120{ }^{\circ} \mathrm{C}$ for 3 hours resulted in the generation of the titled phase, which was accompanied by a color change from light purple to light green. 
SIFSIX-23-Cu- $\boldsymbol{\beta 2}$. Heating the air dried sample or the isolated intermediate phases at $160{ }^{\circ} \mathrm{C}$ overnight produced the titled phase.

\section{Single-crystal X-ray diffraction measurements.}

Single crystals of SIFSIX-23-Cu- $\boldsymbol{\alpha}$ are prone to lose guest molecules in air at RT. Therefore, the crystals of SIFSIX-23-Cu- $\boldsymbol{\alpha}$ were sealed in a glass capillary with mother liquor from the reaction tubes and the single-crystal refection data were collected at room temperature on a Bruker Quest diffractometer equipped with a CMOS detector and $\mathrm{I} \mu \mathrm{S}$ microfocus X-ray source $\left(\mathrm{Cu} \mathrm{K}_{\alpha}, \lambda=1.54178 \AA\right)$. The crystals of SIFSIX-23-Cu- $\boldsymbol{\gamma} \mathbf{1}$ were measured under liquid $\mathrm{N}_{2}$ flow at temperature of $150 \mathrm{~K}$ to avoid the phase transformation caused by guest molecules escape in air. For SIFSIX-23-Cu- $\boldsymbol{\gamma}$ 2, SIFSIX-23-Cu- $\boldsymbol{\gamma}$ and SIFSIX-23-Cu- $\boldsymbol{\beta} 1$, the crystal can capture the water in air to undergo back-transformation. As a result, the crystals picked were dipped immediately in paraffin oil to prevent contact with water in air, and subsequently quickly mounted on the instrument and kept under liquid $\mathrm{N}_{2}$ flow at $150 \mathrm{~K}$. Even so, we found SIFSIX-23-Cu-\$1 capturing a water molecule from air during our SCXRD measurements. The fast water capture matches with the water sorption isotherm which shows steep water sorption at very low humidity. Based on the VT-PXRD measurements, there are no other phases between $\boldsymbol{\beta 1}$ and $\boldsymbol{\beta 2}$ phases, confirming no other "closed" phase exists, and the TGA curve showed the phase transformation from $\boldsymbol{\beta 1}$ to $\boldsymbol{\beta 2}$ phases was accompanied by no weight loss, indicating no water molecule accommodating in $\boldsymbol{\beta 1}$ phase. As a result, we can conclude that the closed form $\boldsymbol{\beta} 1$ contains no solvent but small cavity suitable for one water molecule and it can capture this water molecule very fast at very low humidity. The remaining small cavity in $\boldsymbol{\beta} 1$ is negligible and in fact the calculated pore volume in the closed phase $(1.3 \%)$ is lower than that of most other reported structures considered as nonporous phases (Ref. 11 in main text).

In all cases, data was indexed, integrated and scaled in APEX3. ${ }^{2}$ Absorption correction was performed by multi-scan method using in SADABS. ${ }^{3}$ Space group was determined using XPREP ${ }^{4}$ implemented in APEX3. Structures were solved using 
intrinsic phasing method (SHELXT) $)^{5}$ and refined on $F^{2}$ using nonlinear least-squares techniques with SHELXL $^{6}$ programs incorporated in OLEX2 graphical user interface. ${ }^{7}$ Anisotropic thermal parameters were applied to all non-hydrogen atoms. The structure model of SIFSIX-23-Cu- $\boldsymbol{\gamma} \mathbf{3}$ was first solved and refined in space group P1. The obtained structure was finally examined by using the ADDSYM algorithm from the program PLATON, which showed the suggested space group should be P-1, i.e., the existing of inversion centers in the structure. However, after we changed the space group from P1 to P-1, the resulted structure model displayed many anomalous thermal parameters even after we tried our best to deal with the disorders. More importantly, The $\mathrm{R}$ factors of refinements in space group $\mathrm{P}-1$ were very high $\left(\mathrm{R}_{1}>\right.$ $\left.0.12, \mathrm{WR}_{2}>0.25\right)$ and unacceptable. On the contrary, the thermal parameters from the structure model refined in P1 without any restraints and constrains were very good and the $\mathrm{R}$ factors were reasonable $\left(\mathrm{R}_{1}<0.12, \mathrm{WR}_{2}<0.25\right)$. By carefully checking the structure model, we found that the structure is intrinsically asymmetric. The $\mathrm{Cu}$ atoms and SIFSIX pillars in the structure were possible to be related by inversion center within the error range (in fact the inversion centers locate on the $\mathrm{Cu}$ atoms in $\mathrm{P}-1$ space group). There also existed a possible inversion center on the middle point of the phenyl group of each anti-conformational ligand. However, the two syn-conformational ligands couldn't be related by inversion center and no possible inversion centers on the ligand could be found. As a result, no inversion center couldn't be located in the sql net formed by $\mathrm{Cu}$ atom and syn-/anti-conformational bi-imidazolyl ligands. Perhaps this is reason why we couldn't refine the structure in P-1 reasonably. Anyway, we present the crystal structure of SIFSIX-23-Cu- $\boldsymbol{\gamma} \mathbf{3}$ in space group P1 which didn't affect the structure features. The reported refinement for SIFSIX-23-Cu- $\alpha$, SIFSIX-23-Cu- $\gamma 1$, SIFSIX-23-Cu- $\gamma 2$ and SIFSIX-23-Cu- $\gamma 3$ are of the guest-free structures using the *.hkl file produced using the SQUEEZE ${ }^{8}$ routine because the guests are highly disordered in the frameworks. The void volume (excluding solvent guest molecules) in the crystal cell was calculated using the program PLATON. ${ }^{9}$ Due to the disorder of organic bi-imidazolyl ligands in SIFSIX-23-Cu- $\boldsymbol{\alpha}$, the accessible void volume has been calculated considering an 
average value from each disordered part. Crystallographic data and structural refinement information are listed in Tables S1. Crystallographic data for the structures reported in this paper have been deposited with the Cambridge Crystallographic Data Centre as CCDC number 1961593 (SIFSIX-23-Cu- $\boldsymbol{\alpha}$ ), 1961596 (SIFSIX-23-Cu- $\boldsymbol{\gamma} \mathbf{1}$ ), $1961597 \quad$ (SIFSIX-23-Cu- $\boldsymbol{\gamma}$ 2), $1961598 \quad$ (SIFSIX-23-Cu- $\boldsymbol{\gamma 3}$ ), 1961594

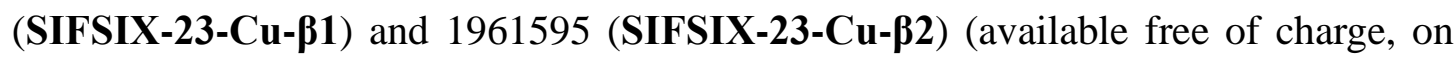
application to the CCDC, 12 Union Rd., Cambridge CB2 1EZ, U.K.; e-mail deposit@ccdc.cam.ac.uk).

\section{IR spectra}

Fourier Transform Infrared (FTIR) Spectroscopy A drop of peptide hydrogel (2 wt $\%$ ) was dropped onto the ATR plate by syringe delivery. Afterwards, the droplet was allowed to be completely air dry. Spectra were obtained by using a FTIR spectrometer (Agilent technologies, Cary 630) in the range of $4000-650 \mathrm{~cm}^{-1}$.

\section{Raman Spectra}

Raman spectra were recorded on an InVIA Reflex micro-spectrometer (Renishaw, Wotton under Edge, UK) coupled to a DM2500 Leica microscope with the laser spot being focused onto the sample, via mirrors and a notch filter, through the objective lens and the Raman scattering collected in a $180^{\circ}$ backscattered geometry. Instrument calibration was performed daily using the $\mathrm{Si}$ (100) peak $(520.5 \pm 1 \mathrm{~cm}-1)(50 \mathrm{x}$ objective, laser power $10 \mathrm{~mW}$, acquisition time 10 secs, 1 accumulation). Powder samples were dispersed on a glass slide and $\geq 10$ spectra were collected by point mapping (785 $\mathrm{nm}$ excitation laser, laser power $0.5 \mathrm{~mW}$, acquisition time $10 \mathrm{secs}, 20 \mathrm{x}$ objective and $\geq 5$ accumulations). For the measurement of activated phase, the sample was activated in a long quartz tube used for gas sorption experimental. After the activation, the open side of the tube was tightly sealed to prevent sample contact with air. The tube was used directly for measurements. 


\section{Thermogravimetric analysis (TGA) and DSC analyses (DSC)}

Thermogravimetric analyses (TGA) were performed under $\mathrm{N}_{2}$ using a TA Instruments Q50 system. Samples were loaded into aluminium sample pans and heated at $5 \mathrm{~K}$ $\mathrm{min}^{-1}$ from room temperature to $550{ }^{\circ} \mathrm{C}$. Differential scanning calorimetry (DSC, Q2000 TA Instruments, USA) analysis was performed at heating rates of $5{ }^{\circ} \mathrm{C} / \mathrm{min}$ from room temperature to $300{ }^{\circ} \mathrm{C}$ under $\mathrm{N}_{2}$ atmosphere.

\section{Powder X-ray diffraction measurements}

Powder X-ray diffraction patterns were recorded on a PANalytical X'Pert MPD Pro $(\mathrm{Cu} \mathrm{Ka}, \lambda=1.5418 \AA)$ with a 1D X'Celerator strip detector. Experiments were conducted in continuous scanning mode with the goniometer in the theta-theta orientation. Incident beam optics included the Fixed Divergences slit with anti-scatter slit PreFIX module, with a $1 / 8^{\circ}$ divergence slit and a $1 / 4^{\circ}$ anti-scatter slit, as well as a $10 \mathrm{~mm}$ fixed incident beam mask and a Soller slit (0.04 rad). Divergent beam optics included a P7.5 anti-scatter slit, a Soller slit (0.04 rad), and a Ni $\beta$ filter. The data were collected in the range of $2 \theta=3-50$. Raw data was then evaluated using the X'Pert HighScore Plus ${ }^{\mathrm{TM}}$ software V 4.1 (PANalytical, The Netherlands).

\section{In-situ Variable Temperature Powder X-ray Diffraction (VT-PXRD)}

Diffractograms at different temperature were recorded using a PANalytical X'Pert Pro-MPD diffractometer equipped with a PIXcel3D detector operating in scanning line detector mode with an active length of 4 utilizing 255 channels. Anton Paar TTK 450 stage coupled with the Anton Paar TCU 110 Temperature Control Unit was used to record the variable temperature diffractograms. The diffractometer is outfitted with an Empyrean Cu LFF (long fine-focus) HR (9430 033 7300x) tube operated at $40 \mathrm{kV}$ and $40 \mathrm{~mA}$ and $\mathrm{CuK} \alpha$ radiation $\left(\lambda_{\alpha}=1.54056 \AA\right)$ was used for diffraction experiments. Continuous scanning mode with the goniometer in the theta-theta orientation was used to collect the data. Incident beam optics included the Fixed Divergences slit, with a $1 / 4^{\circ}$ divergence slit and a Soller slit (0.04 rad). Divergent beam optics included a P7.5 
anti-scatter slit, a Soller slit (0.04 rad), and a Ni- $\beta$ filter. In a typical experiment, 20 $\mathrm{mg}$ of sample was ground into a fine powder, and was loaded on a zero background sample holder made for Anton Paar TTK 450 chamber. The data was collected from $5^{\circ}-45^{\circ}(2 \theta)$ with a step-size of $0.0167113^{\circ}$ and a scan time of 50 seconds per step. Crude data were analyzed using the X'Pert HighScore Plus ${ }^{\mathrm{TM}}$ software V 4.1 (PANalytical, The Netherlands). Each sample was heated up to $515 \mathrm{~K}$ under $\mathrm{N}_{2}$ atmosphere and then cooling at the room temperature.

\section{In-situ $\mathrm{CO}_{2}$ and $\mathrm{N}_{2}$-loaded Neutron Powder Diffraction (NPD)}

In-situ $\mathrm{CO}_{2}$ and $\mathrm{N}_{2}$-loaded Neutron powder diffraction (NPD) data were collected using the BT-1 neutron powder diffractometer at the National Institute of Standards and Technology (NIST) Center for Neutron Research. A Ge(311) monochromator with a $75^{\circ}$ take-off angle, $\lambda=2.0787(2) \AA$, and in-pile collimation of 60 minutes of arc was used. Data were collected over the range of $1.3-166.3^{\circ}(2 \theta)$ with a step size of $0.05^{\circ}$. Fully activated SIFSIX-23-Cu- $\boldsymbol{\beta 1}$ sample obtained by heating at $80{ }^{\circ} \mathrm{C}$ under vacuum for 2 hours was loaded in a vanadium can equipped with a capillary gas line. A closed-cycle He refrigerator was used to control the sample temperature. The bare $\boldsymbol{\beta 1}$ sample was measured first at room temperature $(298 \mathrm{~K})$. To investigate $\mathrm{CO}_{2}$ and $\mathrm{N}_{2}$ adsorption, the sample was charged with corresponding gas molecules at pre-determined pressures and temperatures, and allowed enough time to reach equilibrium. Diffraction data were then collected on the gas-loaded samples at various temperatures. Finally, the gas loaded sample was allowed to desorption at $298 \mathrm{~K}$ (high temperature is beneficial for the gas release) until the corresponding pressure in the can reaches 0 bar, and a diffraction pattern was recorded.

\section{Accelerated stability protocol}

The accelerated stability test was conducted by exposing the samples to $40{ }^{\circ} \mathrm{C}$ at $95 \%$ relative humidity for a stipulated amount of time in a desiccator. 95\% relative humidity was achieved by using a supersaturated aqueous solution of potassium sulfate $\left(\mathrm{K}_{2} \mathrm{SO}_{4}\right)$ maintained at $40{ }^{\circ} \mathrm{C}$ by placing the solution in an enclosed desiccator, 
which was subsequently placed in an oven held at $40{ }^{\circ} \mathrm{C}$. The time frame used for our studies was 3 months. Once the sample was subjected to the desired amount of time, it was removed from the desiccator and characterized by PXRD and sorption experiments in order to detect if the sample had been affected by exposure to humidity.

\section{Low-pressure gas adsorption measurements}

The sorption isotherms for $\mathrm{N}_{2}$ at $77 \mathrm{~K}$ and $\mathrm{CO}_{2}$ at $195 \mathrm{~K}$ were measured using Micromeritics Tristar II 3030 instrument. Before gas sorption experiment, the freshly prepared sample of SIFSIX-23-Cu was placed in the quartz tube and degased under high vacuum at $80{ }^{\circ} \mathrm{C}$ for 2 hours to remove the remnant solvent molecules prior to measurements. We recorded the other consecutive cycles of $\mathrm{CO}_{2}$ sorption at $195 \mathrm{~K}$ without the reactivation process after the first cycle. All the $\mathrm{CO}_{2}$ isotherms at $195 \mathrm{~K}$ were tested with the maximum operating pressure at $752 \mathrm{mmHg}$ (close to $1 \mathrm{bar}$ ). The surface areas of the $\boldsymbol{\gamma} \mathbf{3}$ phase in the first step and the $\boldsymbol{\alpha}$ phase in the second step were determined from the $\mathrm{CO}_{2}$ adsorption isotherm of $\boldsymbol{\beta} 1$ collected at $195 \mathrm{~K}$ by applying the Langmuir models (in the range of $2.6-27 \mathrm{mmHg}$ and 30.5 to $752 \mathrm{mmHg}$ respectively). Note that Brunauer-Emmett-Teller (BET) surface areas cannot be accurately determined for either framework because of the switching $\mathrm{CO}_{2}$ adsorption isotherms at $195 \mathrm{~K}$.

The sorption isotherms for $\mathrm{CO}_{2}$ at $263 \mathrm{~K}, 268 \mathrm{~K}, 273 \mathrm{~K}, 278 \mathrm{~K}$ and $298 \mathrm{~K}$ were measured using Micromeritics 3 Flex surface area and pore size analyser. A Julabo temperature controller was used to maintain a constant temperature in the bath through the duration of the experiment. Samples were degassed under high vacuum at $80{ }^{\circ} \mathrm{C}$ for 2 hours on a Smart VacPrep instrument prior to the analysis. We consecutively recorded the multiple $\mathrm{CO}_{2}$ adsorption/desorption cycles at $273 \mathrm{~K}$ without the reactivation process after the first cycle.

\section{Calculation of the Langmuir surface areas}

The well-known Langmuir isotherm model can be expressed by the following 
equation:

$$
\frac{Q}{Q_{0}}=\frac{b P}{1+b P}
$$

Where $\mathrm{Q} /\left(\mathrm{cm}^{-3} \mathrm{~g}^{-1}\right)$ is the amount adsorbed; $\mathrm{Q}_{0} /\left(\mathrm{cm}^{3} \mathrm{~g}^{-1}\right)$ is the saturated amount adsorbed; $\mathrm{P} / \mathrm{mmHg}$ is the equilibrium pressure; and $\mathrm{b} / \mathrm{mmHg}^{-1}$ is the adsorption affinity.

A line expression for the Langmuir equation can be written as following:

$$
\frac{P}{Q}=\frac{1}{b Q_{0}}+\frac{1}{Q_{0}} P
$$

A least-squares fit is performed on the $\left(\frac{P}{Q}, P\right)$ designated pairs where $\frac{P}{Q}$ is the independent variable and $P$ is the dependent variable. The following are calculated:

a) Slope $\left(\frac{1}{Q_{0}}, \mathrm{~g} / \mathrm{cm}^{3} \mathrm{STP}\right)$

b) Y-intercept $\left(\frac{1}{b Q_{0}}, \mathrm{~g} \cdot \mathrm{mmHg} / \mathrm{cm}^{3} \mathrm{STP}\right)$

c) Error of the slope $\left(\mathrm{g} / \mathrm{cm}^{3} \mathrm{STP}\right)$

d) Error of the y-intercept $\left(\mathrm{g} \cdot \mathrm{mmHg} / \mathrm{cm}^{3} \mathrm{STP}\right)$

Using the results of the above calculations, the Langmuir surface area can be calculated as following:

$$
S_{g}=A_{m} \times N_{A} \times \frac{Q_{0}}{22414} \times 10^{-18}
$$

Where $S_{g}$ is the Langmuir surface area $\left(\mathrm{m}^{2} / \mathrm{g}\right) ; A_{\mathrm{m}}=$ molecular cross-sectional area $\left(\mathrm{nm}^{2}\right)$ of adsorbate i.e. $0.1700 \mathrm{~nm}^{2}$ for $\mathrm{CO}_{2}$, and $N_{A}=6.02 \times 10^{23}$.

\section{High-pressure $\mathrm{CO}_{2}$ adsorption measurements}

High-pressure $\mathrm{CO}_{2}$ adsorption isotherms $(0-30$ bar) were performed using the Particulate Systems HPVA-II 100 at Micromeritics Instrument Corporation, a static 
volumetric system, connected to a high vacuum source. For cycle 1 of $\mathrm{CO}_{2}$ sorption, the samples were loaded into a tared stainless-steel sample holder and degassed on Micromeritics Smart VacPrep instrument until the outgas rate was less than 0.005 mbar $\min ^{-1}$. The sample holder with degassed sample $(\sim 0.3 \mathrm{~g})$ was then transferred to the HPVA-II-100, connected to the instrument's analysis port via an OCR fitting, and evacuated at room temperature for 1 hour before the measurements. Free spaces were determined at 0.7 bar Helium $(\mathrm{He})$ and $25^{\circ} \mathrm{C}$. For other consecutive cycles of $\mathrm{CO}_{2}$ sorption, the same batch of samples was degased for $0.3 \mathrm{~h}$ under high vacuum at the room temperature without the reactivation process before gas sorption experiments. The uptake and gate-opening for SIFSIX-23-Cu- $\mathbf{\beta 1}$ are temperature dependent. As the temperature is raised, the onset pressures for the first and second steps shifted higher and but the latter was more obviously, which resulted in the increased width of the first step. The cyclic sorption studies for SIFSIX-23-Cu-ß1 obtained at $298 \mathrm{~K}$ because the uptake can almost reach the saturation. To optimize the time efficiency, limited data points were set for consecutive cycles. Due to the limitation of the equipment, the 32 cycles of consecutive sorption of $\mathrm{CO}_{2}$ were collected by 8 runs ( 4 cycles per run). Because every 4 cycles were collected continuously, i.e. the last data point of previous cycle is the start data point of next cycle, the background will increase gradually which was subtracted for each cycle.

\section{Computational Methods}

\section{Linker and rotational potential energy scans}

The linker structures are fully optimized at the DFT level of theory using the B3LYP hybrid $^{10}$ functional as implemented within the Gaussian16 package. ${ }^{11}$ Furthermore, the triple-zeta Pople basis set $6-311+\mathrm{g}(\mathrm{d}, \mathrm{p})$ is used for all the atoms. In order to estimate the rotational energy barrier for the ligand during configurational changes, a conformational scan of the ligand was performed to obtain energy information at different possible conformational states of the linker. The dihedral angles were defined to control the rotation and were based on four coordinates and indicated as $(a, b, c, d)$ within $\mathrm{d} 1$ and $\mathrm{d} 2$. Two different scan methods were conducted. First, a 
rotational potential energy scan on one dihedral angle (d1) between one imidazole plane and central phenyl plane was defined to undergo a $180^{\circ}$ sweep with a step size of $5^{\circ}$ while the other one (d2) was free. The optimized ligand with minimum energy was chosen as the starting point. As a result, a 1D rotational potential energy profile was obtained. Second, a rotational potential energy scan on the two dihedral angles was defined to undergo a $180^{\circ}$ sweep with a step size of $5^{\circ}$. The anti-conformational linker with $\mathrm{d} 1=\mathrm{d} 2=0^{\circ}$ was taken as the starting point.

To evaluate the distortion of ligand (bending between imidazolyl group and phenyl group) during structure transformation, the energies of linkers in different phases are compared. Constrained optimizations were performed at the B3LYP/6-311+g(d,p) level of theory by keeping the outer $\mathrm{C} 3$ and N2 positions on imidazolyl groups fixed at their crystallographic positions.

To study the energetics of structural transitions within the SIFSIX-class of materials systematically, periodic DFT-D calculations using the projected augmented wave (PAW) formalism are performed with the Vienna Ab Initio Simulation Package (VASP 5.4.4). ${ }^{12}$ The gradient-corrected (GGA) exchange-correlation functional according to Perdew, Burke and Ernzerhof $(\mathrm{PBE})^{13}$ is combined with the $\mathrm{dDsC}$ dispersion correction method (PBE-dDsC) to include van der Waals interactions in the stacking energies of the framework with organic 1,4-Bis(1-imidazolyl)benzene) linkers. ${ }^{14}$ The one-electron Kohn-Sham orbitals are expanded in a plane wave basis set with a kinetic energy cut-off of $450 \mathrm{eV}$ for all calculations. PAW potentials are employed to describe the interaction between the valence electrons and the core. ${ }^{15}$ Reciprocal space integration over the Brillouin zone is approximated with finite sampling using Monkhorst-Pack grids using $3 \times 3 \times 3$ k-point grids. ${ }^{16}$ The systems are structurally optimized until the largest force is smaller than $0.02 \mathrm{eV} / \AA$. 


\section{Traditional rigid SIFSIX nets}

SIFSIX $\left(\right.$ SiF $\left._{6}{ }^{2-}\right)$ pillaring sql net through two trans $F$ atoms

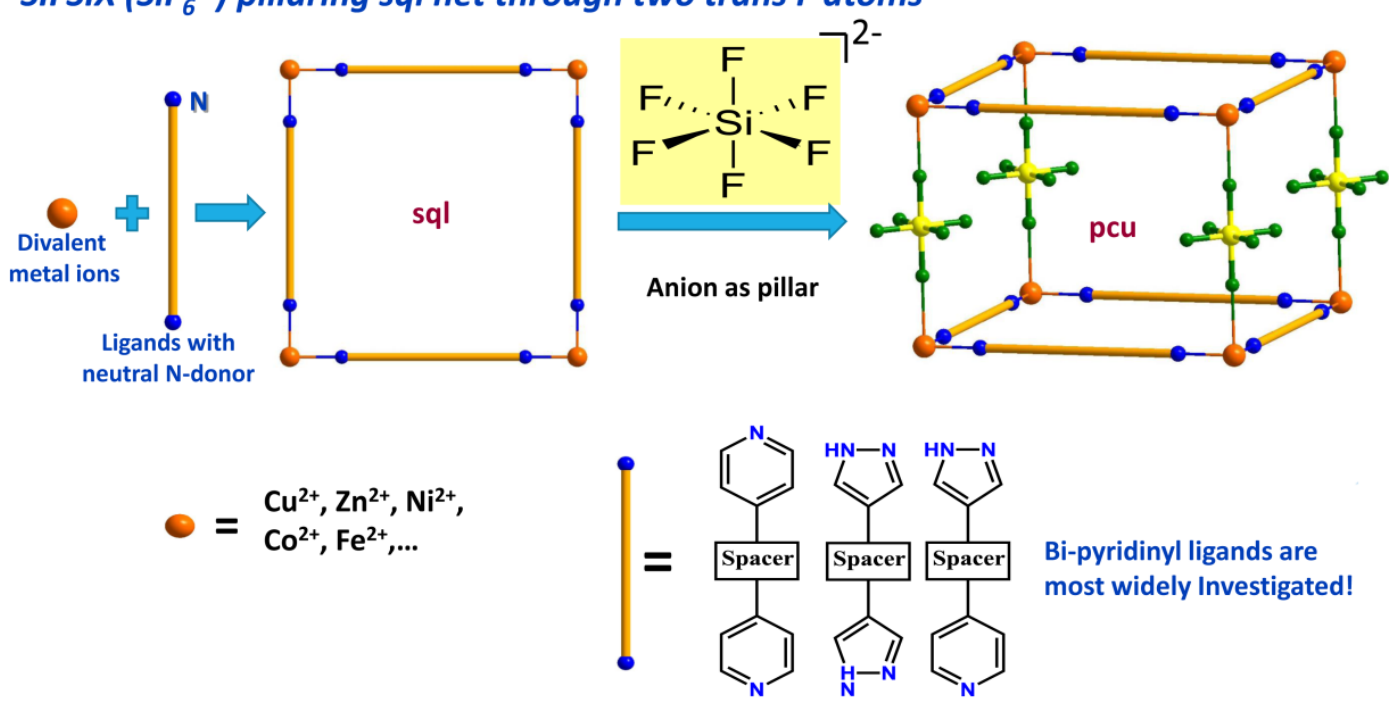

\section{Flexible SIFSIX net}

SIFSIX $\left(\mathrm{SiF}_{6}{ }^{2-}\right)$ pillaring sql net through two cis $\mathrm{F}$ atoms
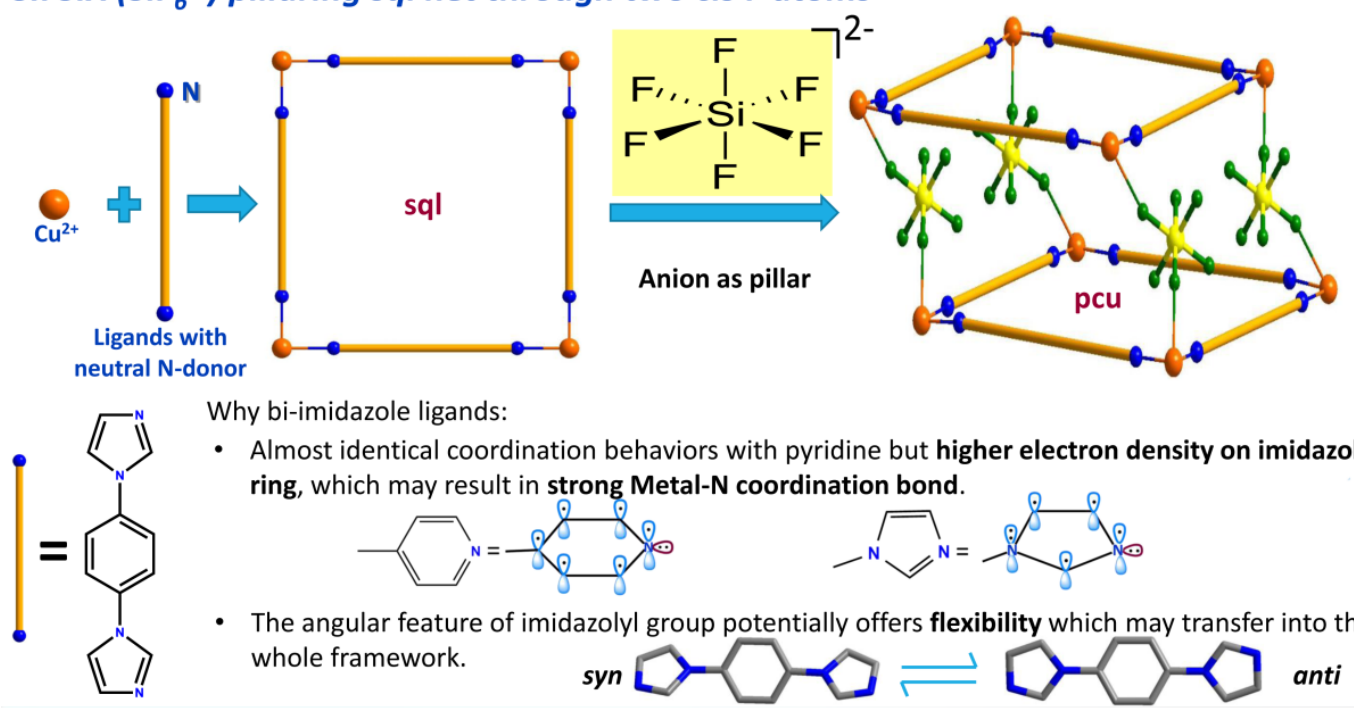

Why bi-imidazole ligands:

- Almost identical coordination behaviors with pyridine but higher electron density on imidazole ring, which may result in strong Metal-N coordination bond.
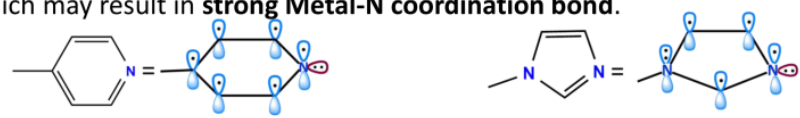

- The angular feature of imidazolyl group potentially offers flexibility which may transfer into the whole framework.
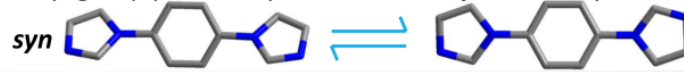

anti

Figure S1. Comparising construction strategies for traditional rigid SIFSIX nets (top) and flexible SIFSIX net (bottom) reported in this work. Noting the obvious different trans-bridging and cis-bridging coordination mode of $\mathrm{SiF}_{6}{ }^{2-}$ (SIFSIX) anions. 


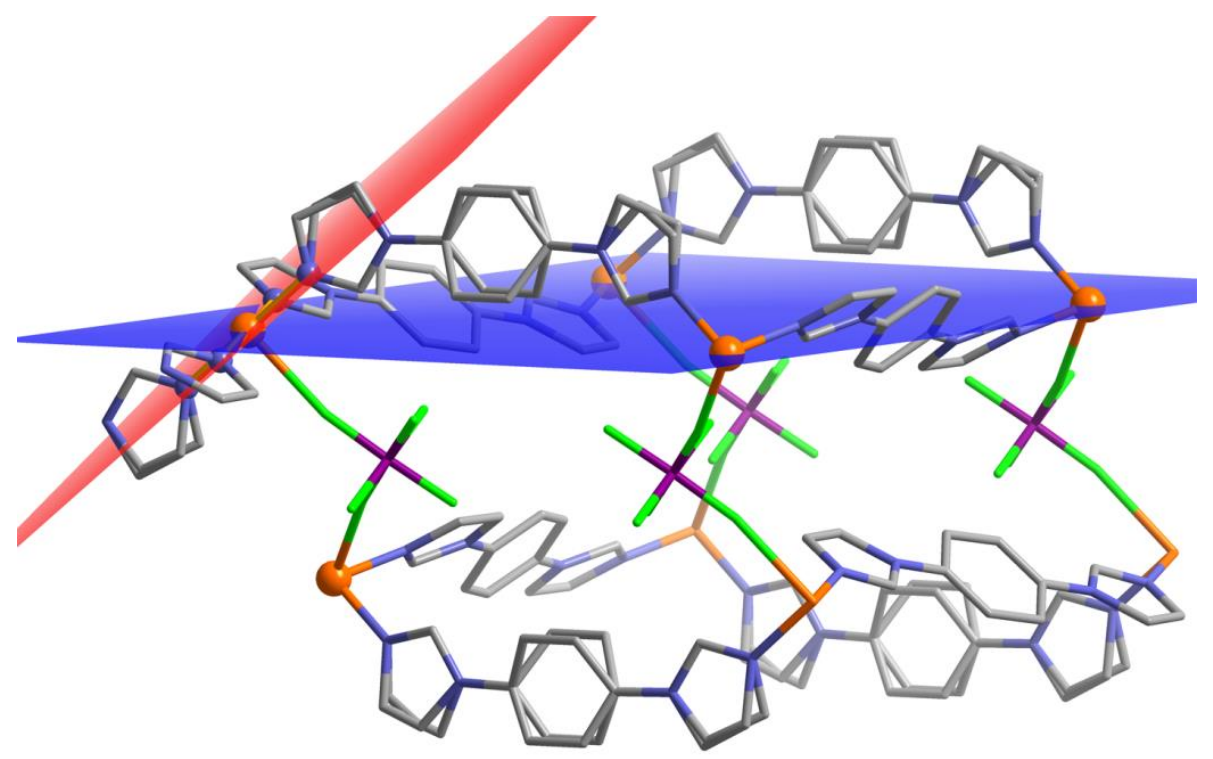

Figure S2. Structural origin of cis-bridging coordination mode of SIFSIX anions in SIFSIX-23-Cu- $\boldsymbol{\alpha}$. The angular syn-conformational ligands (L(syn)) lie out of the $\mathrm{Cu}$ ions plane (blue plane) which results in an undulated sql net. The imidazolyl plane of $\mathrm{L}($ syn) is almost perpendicular to the $\mathrm{Cu}$ ions plane, as a result, the equatorial plane of $\mathrm{Cu}$ ion (four coordinated $\mathrm{N}$ and central $\mathrm{Cu}$ ) is not coplanar with the $\mathrm{Cu}$ ions plane. In addition, two adjacent equatorial planes of two $\mathrm{Cu}$ ions are not parallel, which forces the $\mathrm{SiF}_{6}{ }^{2-}$ (SIFSIX) anions to adopt the cis-bridging coordination mode. Theoretically it is possible for SIFSIX anions to adopt cis-bridging coordination mode because there is no difference between the six fluorine atoms.

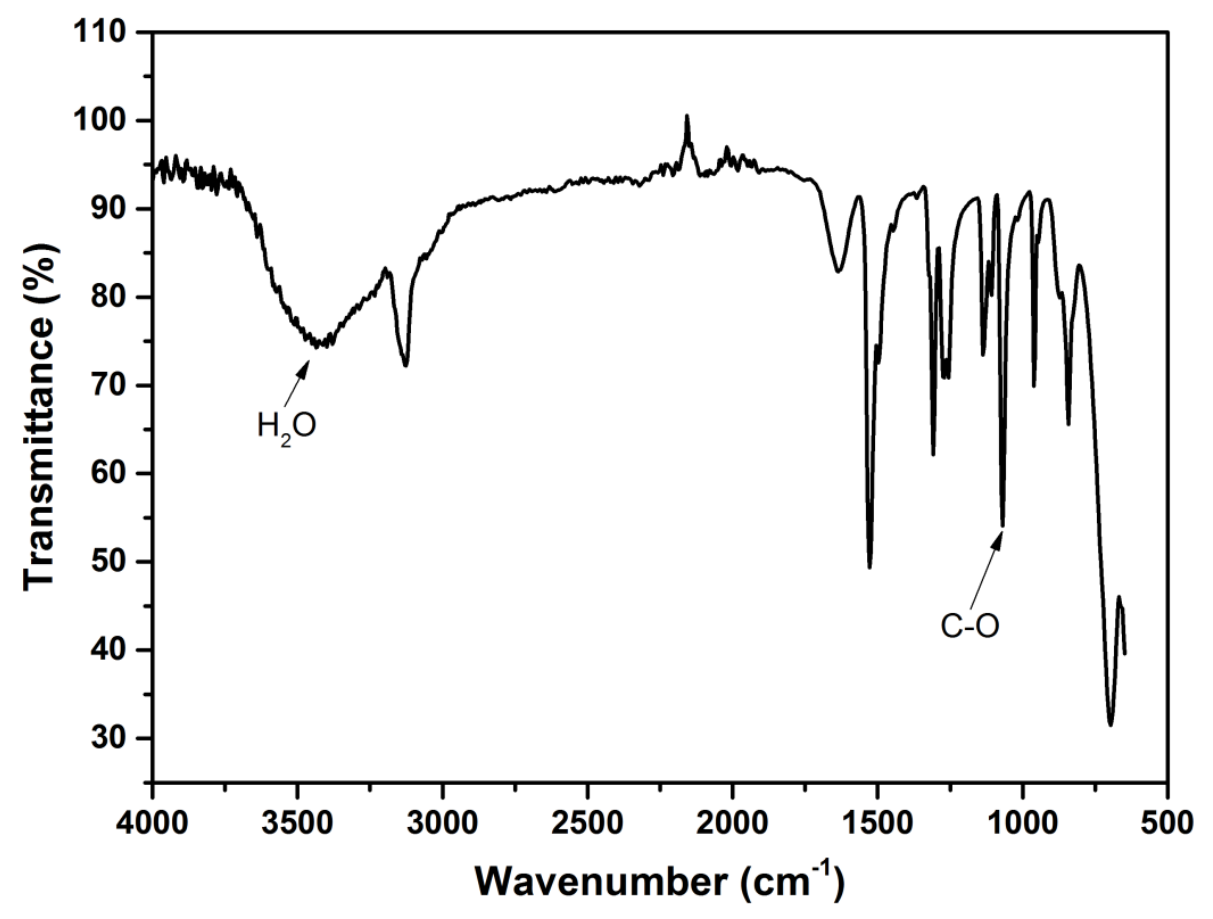


Figure S3. IR spectra of SIFSIX-23-Cu- $\alpha$ measured immediately after collected from the reaction tube.

Table S1. Crystallographic data and structure refinement summary for SIFSIX-23-Cu

\begin{tabular}{|c|c|c|c|}
\hline Compounds & $\begin{array}{l}\text { SIFSIX-23-Cu-a } \\
\text { (Fully open })\end{array}$ & $\begin{array}{l}\text { SIFSIX-23-Cu- } \gamma 1 \\
\text { (Less open) }\end{array}$ & $\begin{array}{c}\text { SIFSIX-23-Cu- } \gamma 2 \\
\text { (Less open) }\end{array}$ \\
\hline Formula & $\mathrm{C}_{24} \mathrm{H}_{20} \mathrm{CuF}_{6} \mathrm{~N}_{8} \mathrm{Si}$ & $\mathrm{C}_{24} \mathrm{H}_{20} \mathrm{CuF}_{6} \mathrm{~N}_{8} \mathrm{Si}$ & $\mathrm{C}_{48} \mathrm{H}_{40} \mathrm{Cu}_{2} \mathrm{~F}_{12} \mathrm{~N}_{16} \mathrm{Si}_{2}$ \\
\hline Formula weight & 626.11 & 626.11 & 1252.22 \\
\hline Temperature (K) & 298 & 125 & 150 \\
\hline Crystal system & monoclinic & monoclinic & triclinic \\
\hline Space group & $C 2 / \mathrm{m}$ & $P 2_{1} / \mathrm{c}$ & $P 1$ \\
\hline$a(\AA)$ & $12.827(5)$ & $12.8841(9)$ & $12.1965(3)$ \\
\hline$b(\AA)$ & $25.552(12)$ & $25.240(2)$ & $12.5066(4)$ \\
\hline$c(\AA)$ & $13.336(7)$ & $12.5623(9)$ & $12.5675(4)$ \\
\hline$\alpha(\mathrm{deg})$ & 90 & 90 & $60.7210(10)$ \\
\hline$\beta(\mathrm{deg})$ & $118.418(14)$ & $116.413(2)$ & $79.864(2)$ \\
\hline$\gamma(\operatorname{deg})$ & 90 & 90 & $64.958(2)$ \\
\hline$V\left(\AA^{3}\right)$ & $3844(3)$ & $3658.7(5)$ & $1513.76(8)$ \\
\hline$Z$ & 4 & 4 & 1 \\
\hline$D_{c}\left(\mathrm{~g} \cdot \mathrm{cm}^{-3}\right)$ & 1.082 & 1.137 & 1.374 \\
\hline$\mu\left(m m^{-1}\right)$ & 0.650 & 0.683 & 1.980 \\
\hline$R_{\text {int }}$ & 0.0610 & 0.0607 & 0.0600 \\
\hline $\begin{array}{c}\text { Data } \\
\text { collected/unique }\end{array}$ & $15827 / 3483$ & $30404 / 6493$ & $25991 / 9910$ \\
\hline$R_{1}[I>2 \sigma(I)]^{[\mathrm{a}]}$ & 0.0445 & 0.0522 & 0.0648 \\
\hline$w R_{2}[\text { all data }]^{[\mathrm{b}]}$ & 0.1281 & 0.1282 & 0.1946 \\
\hline GOF & 0.943 & 1.069 & 1.020 \\
\hline
\end{tabular}




\begin{tabular}{|c|c|c|c|}
\hline Compounds & $\begin{array}{l}\text { SIFSIX-23-Cu- } \gamma 3 \\
\text { (Less open) }\end{array}$ & $\begin{array}{l}\text { SIFSIX-23-Cu- } \beta 1 \cdot \mathrm{H}_{2} \mathrm{O} \\
\left(\text { Closed } 1 \cdot \mathrm{H}_{2} \mathrm{O}\right)\end{array}$ & $\begin{array}{l}\text { SIFSIX-23-Cu- } \beta 2 \\
\text { (Closed2) }\end{array}$ \\
\hline Formula & $\mathrm{C}_{24} \mathrm{H}_{20} \mathrm{CuF}_{6} \mathrm{~N}_{8} \mathrm{Si}$ & $\mathrm{C}_{24} \mathrm{H}_{22} \mathrm{CuF}_{6} \mathrm{~N}_{8} \mathrm{OSi}$ & $\mathrm{C}_{24} \mathrm{H}_{20} \mathrm{CuF}_{6} \mathrm{~N}_{8} \mathrm{Si}$ \\
\hline Formula weight & 626.11 & 644.12 & 626.11 \\
\hline Temperature (K) & 150 & 150 & 295 \\
\hline Crystal system & triclinic & triclinic & triclinic \\
\hline Space group & $P-1$ & $P-1$ & $P-1$ \\
\hline$a(\AA)$ & $11.868(3)$ & $10.4165(8)$ & $10.082(5)$ \\
\hline$b(\AA)$ & $12.443(3)$ & $11.6479(8)$ & $10.590(5)$ \\
\hline$c(\AA)$ & $12.524(3)$ & $12.2390(12)$ & $13.103(7)$ \\
\hline$\alpha(\operatorname{deg})$ & $101.947(12)$ & $64.535(4)$ & $84.987(15)$ \\
\hline$\beta(\operatorname{deg})$ & 107.286(13) & $71.549(5)$ & $86.295(15)$ \\
\hline$\gamma(\operatorname{deg})$ & $115.103(11)$ & $74.498(3)$ & $62.063(10)$ \\
\hline$V\left(\AA^{3}\right)$ & $1475.7(6)$ & $1256.77(19)$ & $1230.8(11)$ \\
\hline$Z$ & 2 & 2 & 2 \\
\hline$D_{c}\left(\mathrm{~g} \cdot \mathrm{cm}^{-3}\right)$ & 1.409 & 1.702 & 1.689 \\
\hline$\mu\left(m m^{-1}\right)$ & 2.031 & 2.433 & 1.015 \\
\hline$R_{\text {int }}$ & 0.0649 & 0.1164 & 0.0752 \\
\hline $\begin{array}{c}\text { Data } \\
\text { collected/unique }\end{array}$ & $10985 / 4764$ & $17000 / 17000$ & $4373 / 4373$ \\
\hline$R_{1}[I>2 \sigma(I)]^{[\mathrm{a}]}$ & 0.0774 & 0.1333 & 0.1047 \\
\hline$w R_{2}[\text { all data }]^{[\mathrm{b}]}$ & 0.2127 & 0.3600 & 0.3278 \\
\hline GOF & 1.081 & 1.080 & 1.042 \\
\hline
\end{tabular}




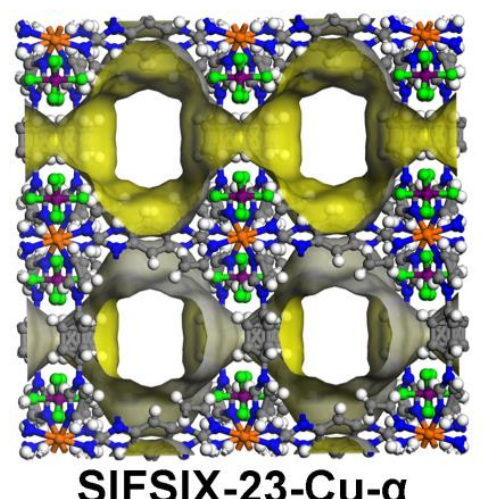

Fully open

Void space: $41.8 \%$

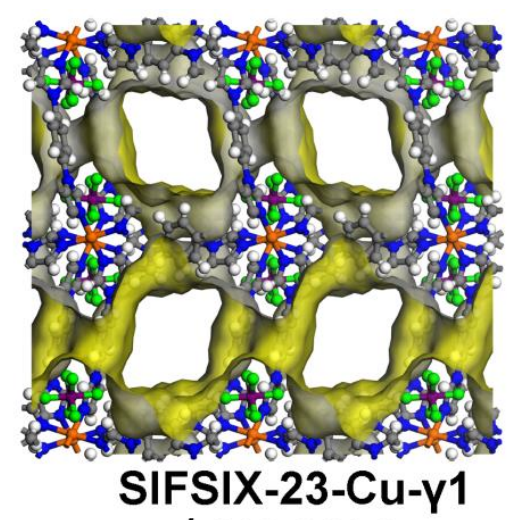

Less open

Void space: $39.6 \%$

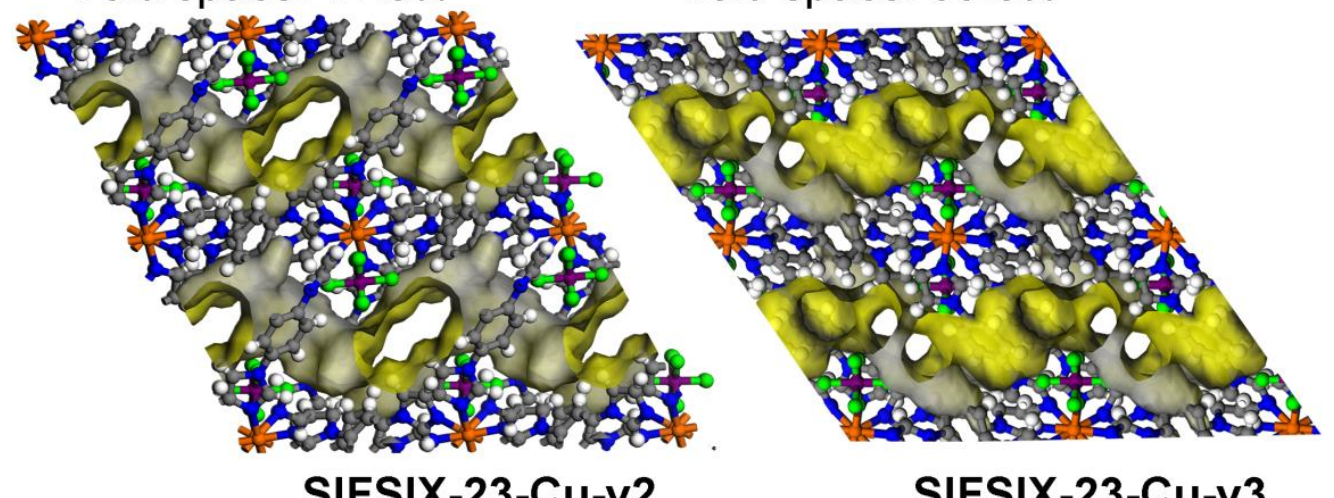

SIFSIX-23-Cu-y2

Less open

SIFSIX-23-Cu-y3

Less open

Void space: $24.7 \%$

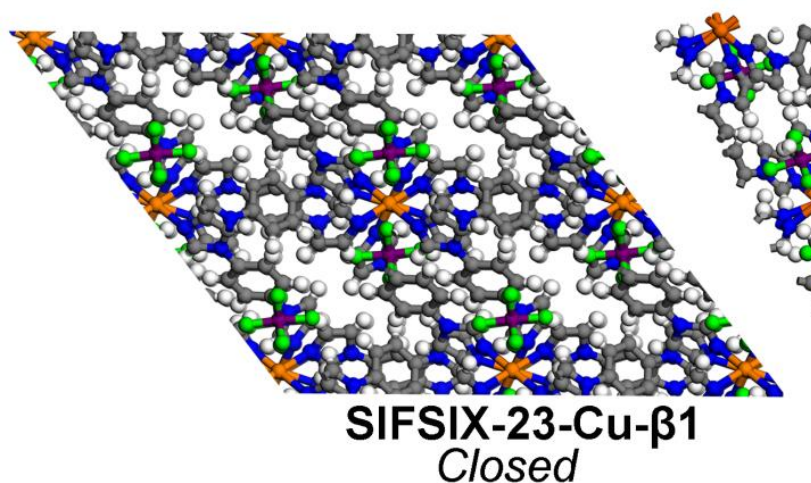

Closed

Void space: $1.3 \%$
Void space: $20.4 \%$

Figure S4. View of the 3D frameworks and channel structures of SIFSIX-23-Cu- $\alpha$,

SIFSIX-23-Cu- $\gamma 1, \quad$ SIFSIX-23-Cu- $\gamma 2, \quad$ SIFSIX-23-Cu- $\gamma 3$, SIFSIX-23-Cu- $\beta 1$ and SIFSIX-23-Cu- $\beta 2$. 

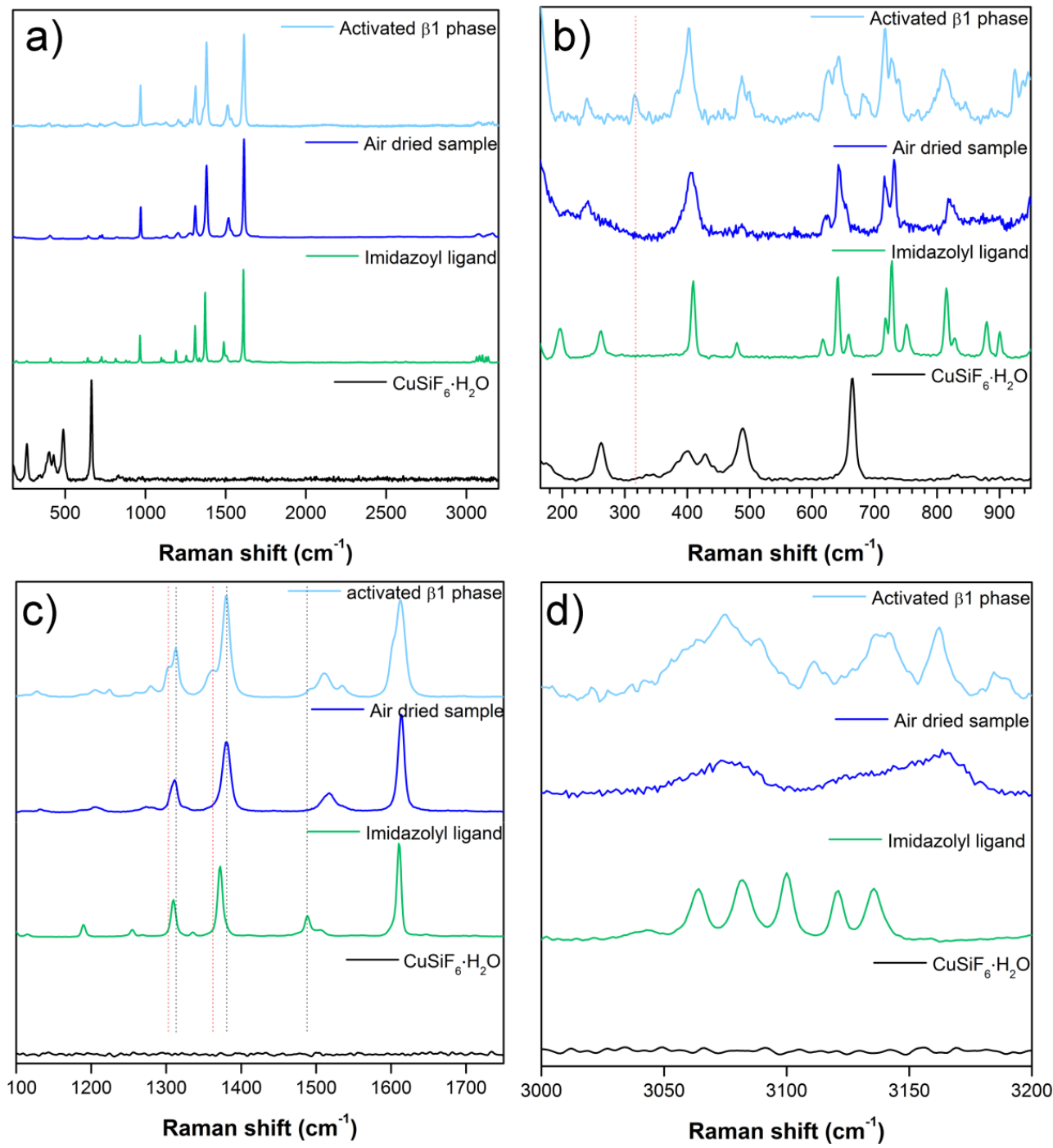

Figure S5. Raman spectra of $\mathrm{CuSiF}_{6} \cdot \mathrm{H}_{2} \mathrm{O}$, imidazolyl ligand $\mathrm{L}$, air dried sample and activated $\boldsymbol{\beta 1}$ phase from $100-3200 \mathrm{~cm}^{-1}$ (a), $100-950 \mathrm{~cm}^{-1}$ (b), $1100-1750 \mathrm{~cm}^{-1}$ (c) and $3000-3200 \mathrm{~cm}^{-1}$ (d).

As shown by the plots, the Raman spectrum is dominated by the vibration modes from imidazolyl ligand as it has high scattering cross section (Figure S5a). In the low wavenumber region, one mode located around $314 \mathrm{~cm}^{-1}$ for activated SIFSIX-23-Cu- $\boldsymbol{\beta} 1$ phase is observed (Figure S5b), which can be assigned to the inter-ring out of plane bending vibrations of imidazolyl ligand. This result matches with the SCXRD outcome, showing one imidazolyl ring of syn-conformational ligand bending relative to the central phenyl group. Modes in the fingerprint region (1000$1700 \mathrm{~cm}^{-1}$ ) can be associated with C-C, C-N or C-H stretching or bending vibrations (Figure S5c). After coordination to $\mathrm{Cu}$ ions to form 3D coordination network, several 
modes shift to low wavenumber region. This is reasonable because $\mathrm{N}$ atom coordinating to $\mathrm{Cu}$ ion will affect the $\mathrm{C}-\mathrm{N}$ stretching vibrations, while the ligand is fixed between two $\mathrm{Cu}$ ions which will affect the inter-ring $\mathrm{C}-\mathrm{N}$ bending vibrations. Several new modes appear in the fingerprint region of SIFSIX-23-Cu-ß1 phase, which arises from the bending of one imidazolyl ring relative to the phenyl ring in syn-conformational ligand. All the $\mathrm{C}-\mathrm{H}$ stretching vibration of phenyl group and imidazolyl group in the free ligand generate well-resolved and distinct peaks at 3064, 3081, 3099, 3121 and $3135 \mathrm{~cm}^{-1}$, suggesting dissimilarity in the $\mathrm{C}-\mathrm{H}$ bond strengths (Figure S5d). However, upon ligand coordination to $\mathrm{Cu}$ ions in 3D framework, these C-H stretching vibration are enveloped under two broad peaks around 3074 and 3165 $\mathrm{cm}^{-1}$, reflecting similar bond strengths have been merged to give two main subgroups. This is in line with the crystal structure of SIFSIX-23-Cu- $\boldsymbol{\gamma} \mathbf{1}$, which consists of equal syn- and anti-conformational ligands in different environments. While one of the two broadened peaks in SIFSIX-23-Cu- $\boldsymbol{\gamma} \mathbf{1}$ is split into several new peaks in SIFSIX-23-Cu- $\boldsymbol{\beta} 1$ after totally removing solvents due to the bending of one imidazolyl ring in syn-conformational ligand. 


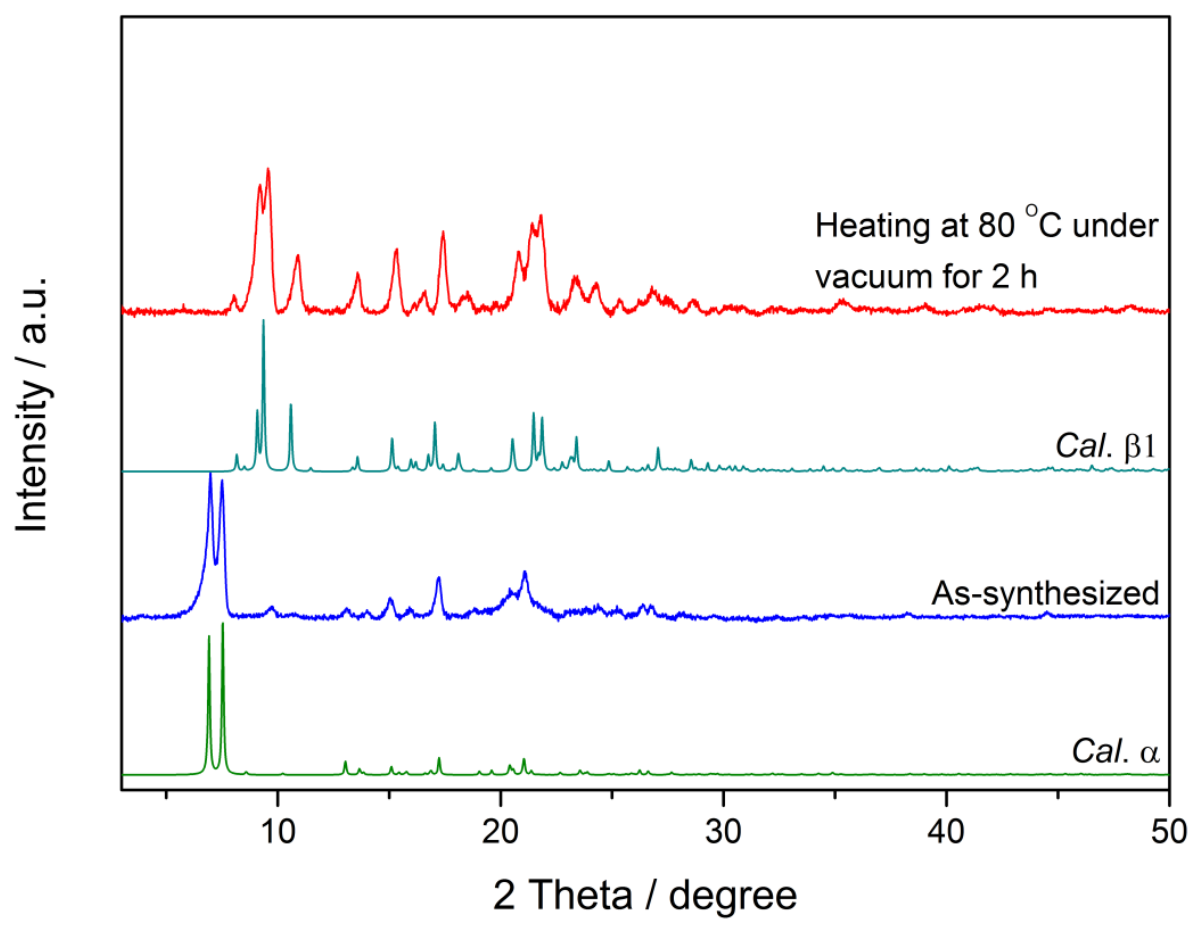

Figure S6. PXRD patterns for as-synthesized SIFSIX-23-Cu- $\boldsymbol{\alpha}$ (measured immediately after harvest from reaction system) and in situ activated sample at $80^{\circ}$ under vacuum for $2 \mathrm{~h}$, demonstrating clearly the activated form is the $\boldsymbol{\beta 1}$ phase.

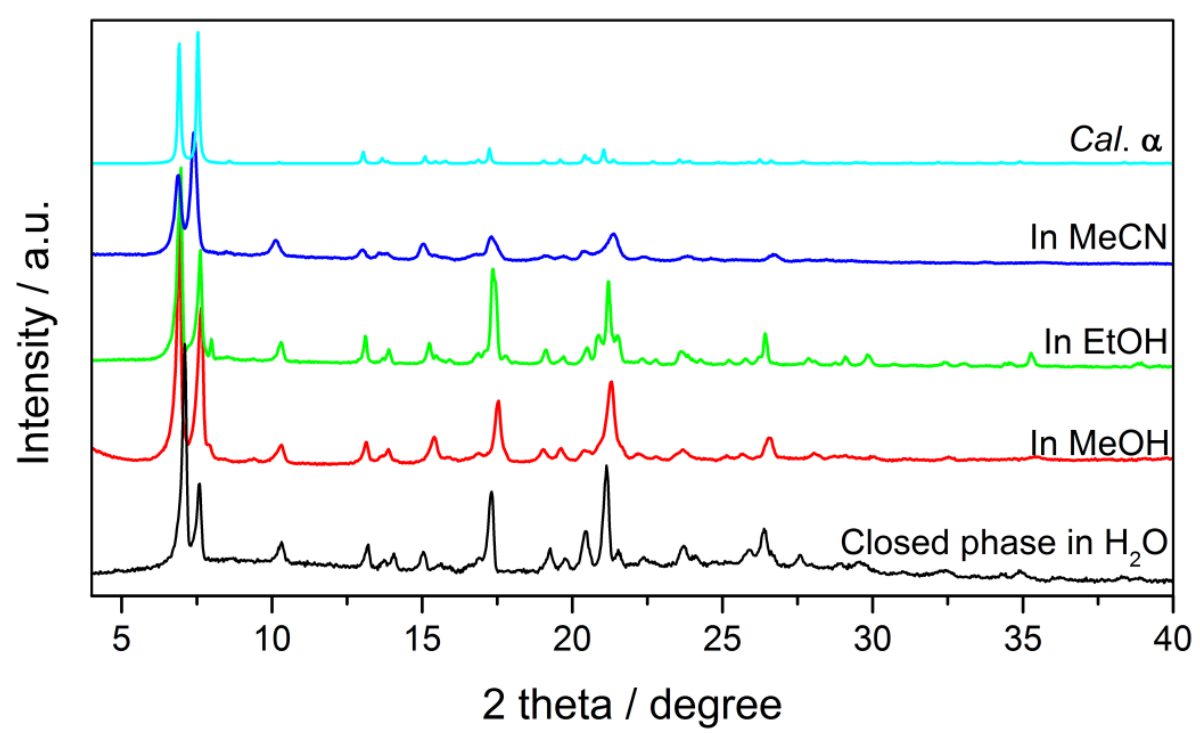

Figure S7. PXRD patterns for activated $\boldsymbol{\beta 1}$ phase in different solvents, showing fast back transformation to $\boldsymbol{\alpha}$ phase. 
Table S2. Comparative analysis of the structural differences between the six isolated phases of SIFSIX-23-Cu

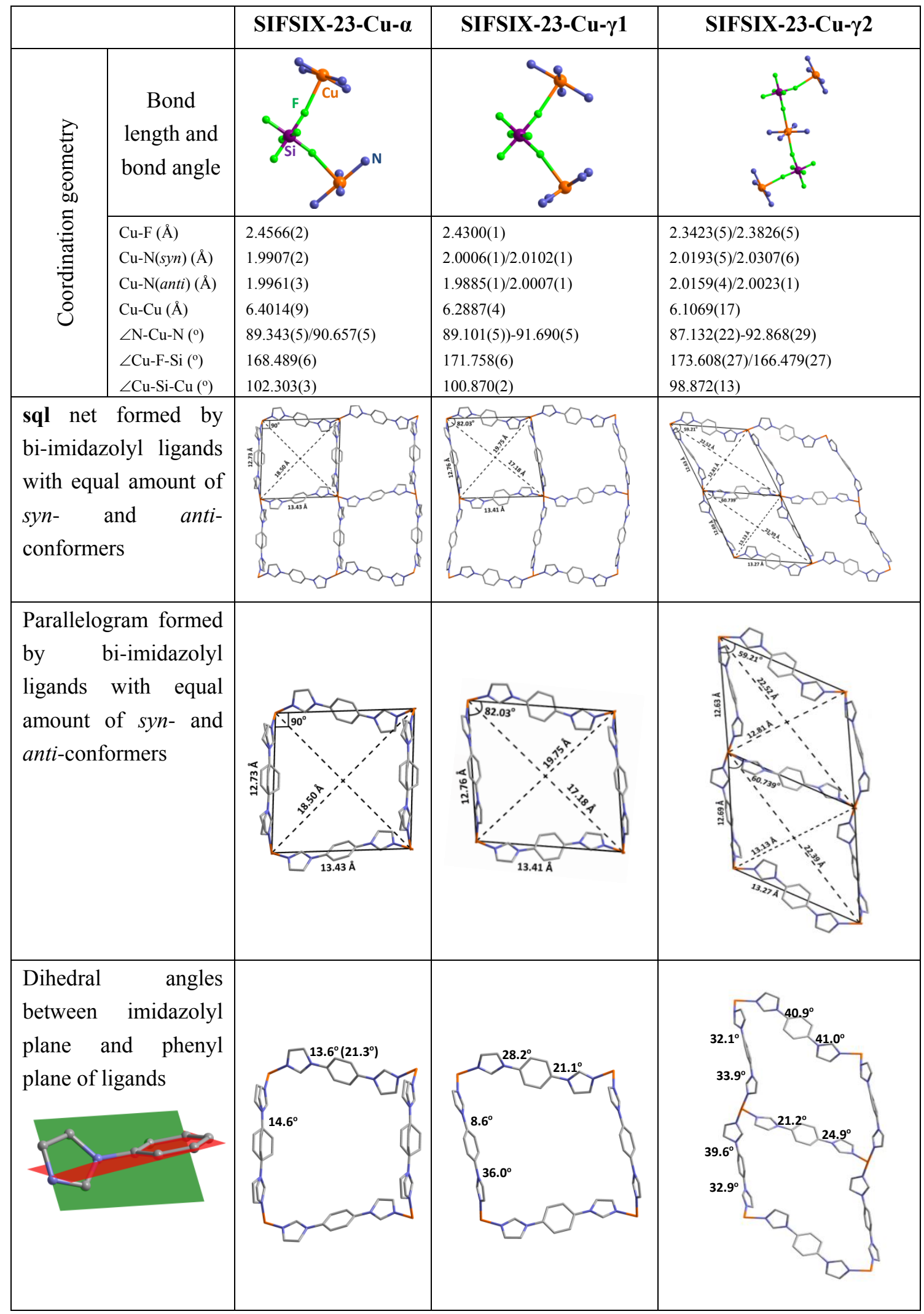




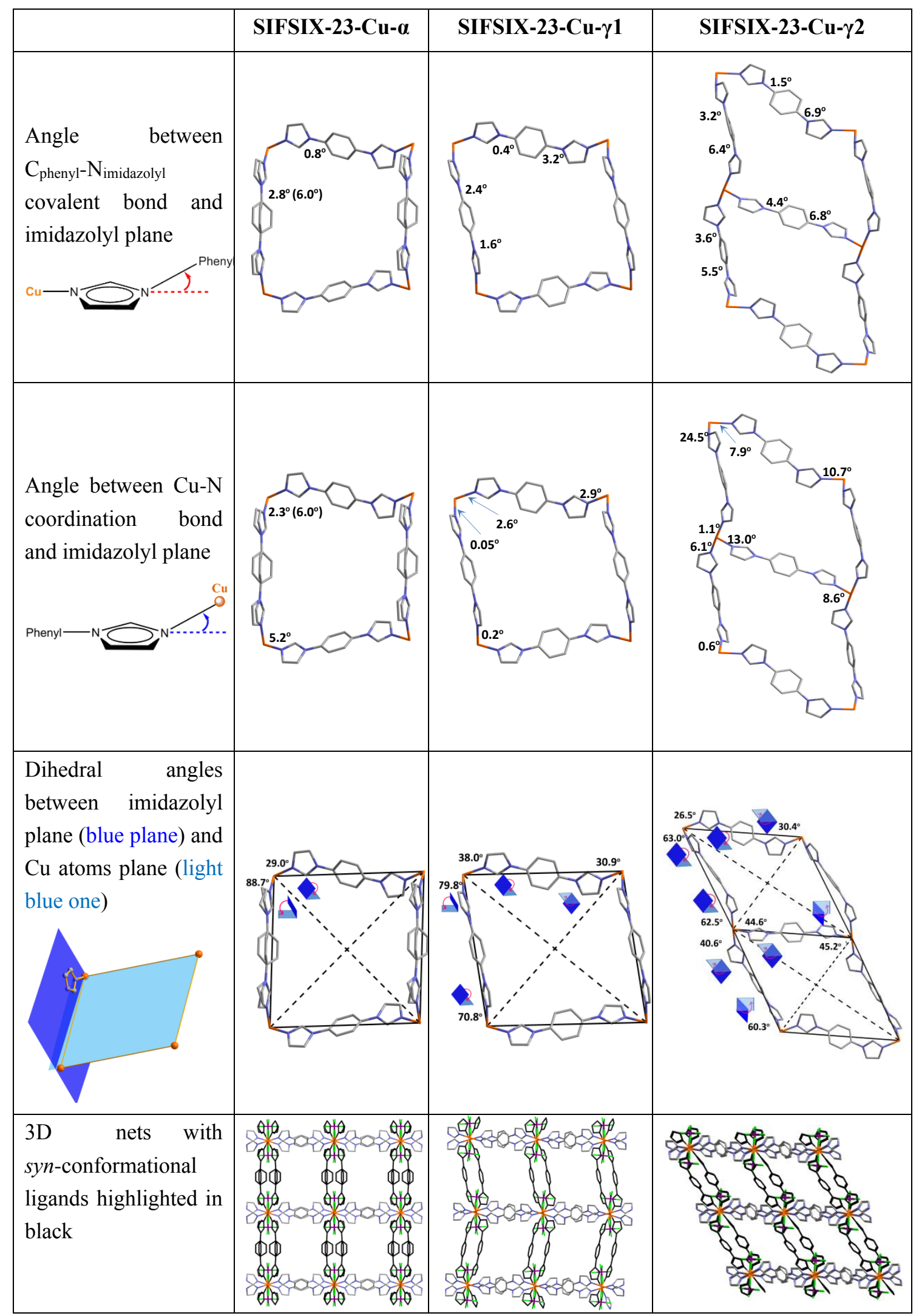




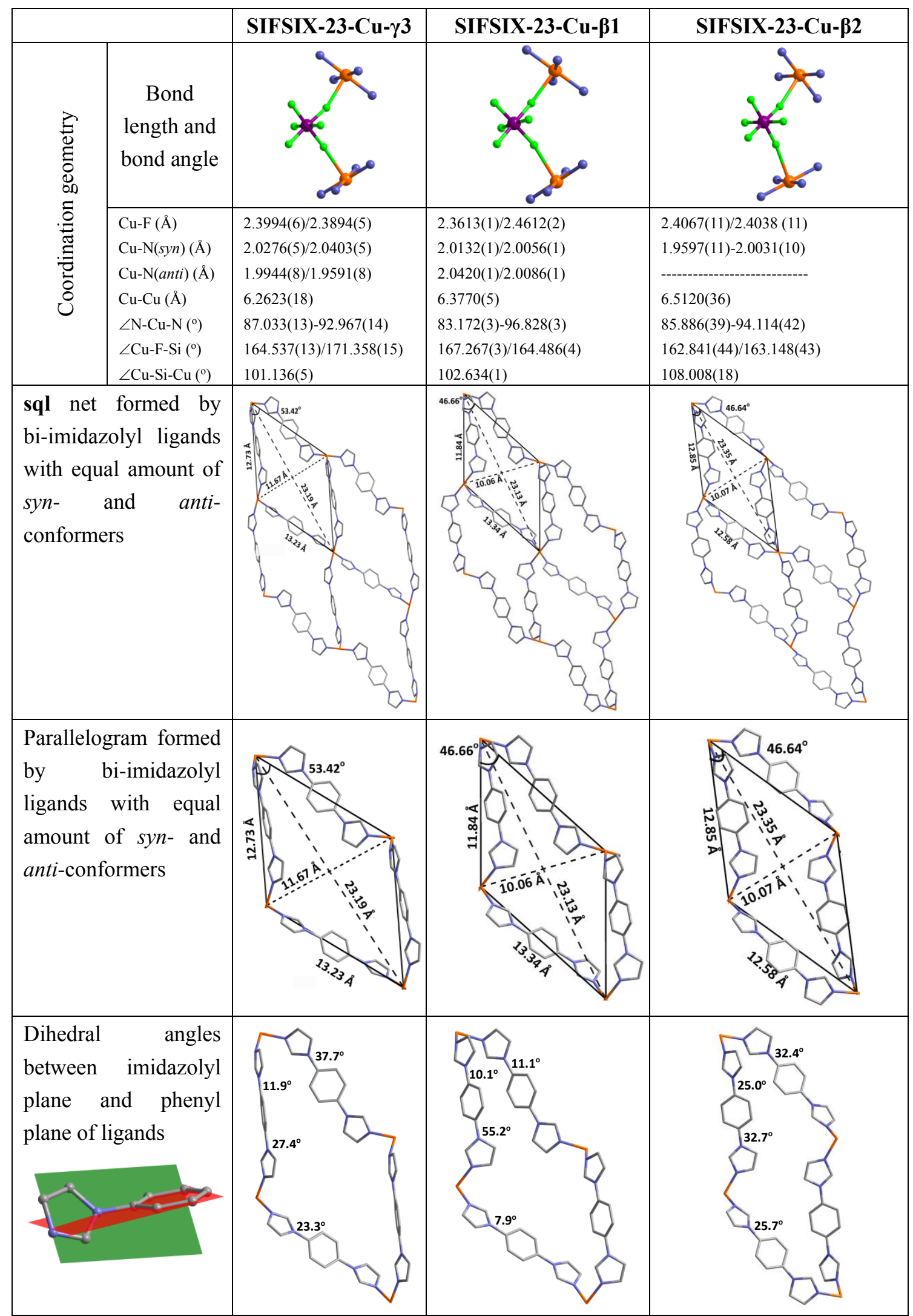




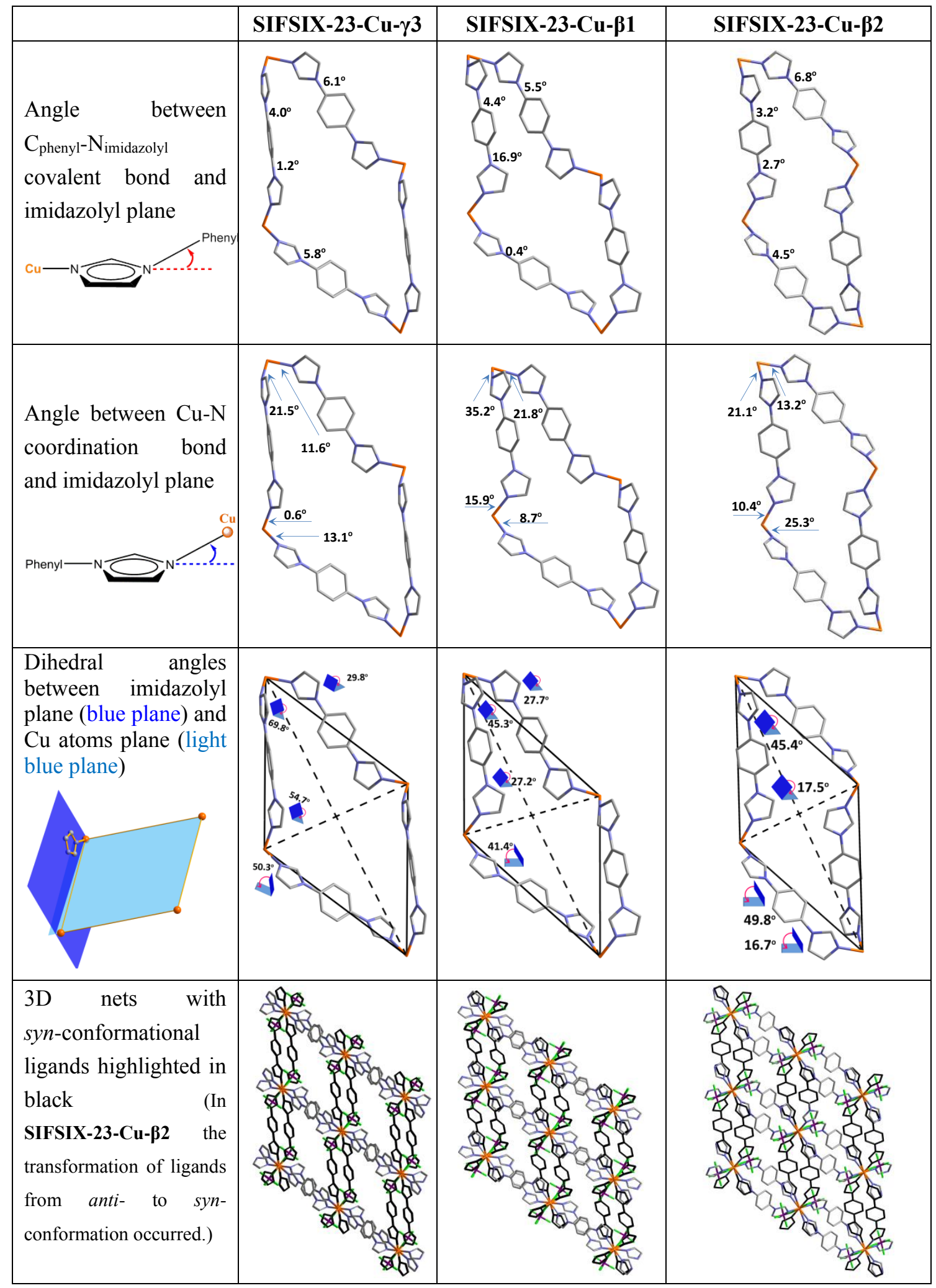



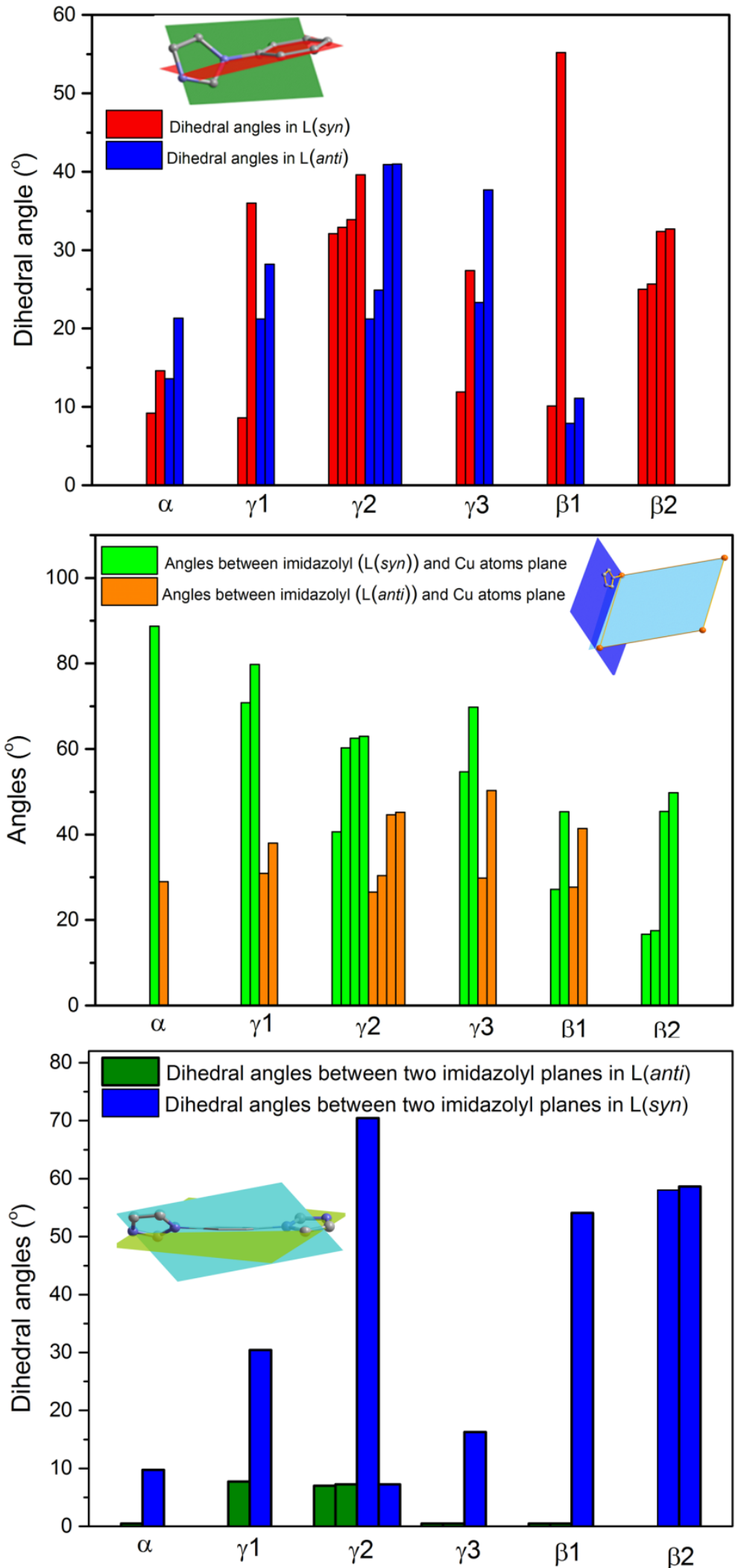

Figure S8. Dihedral angles between imidazolyl plane and phenyl plane (top), between imidazolyl plane and $\mathrm{Cu}$ plane (middle) and between two imidazolyl planes in L (bottom), quantifing the ligand rotation. 


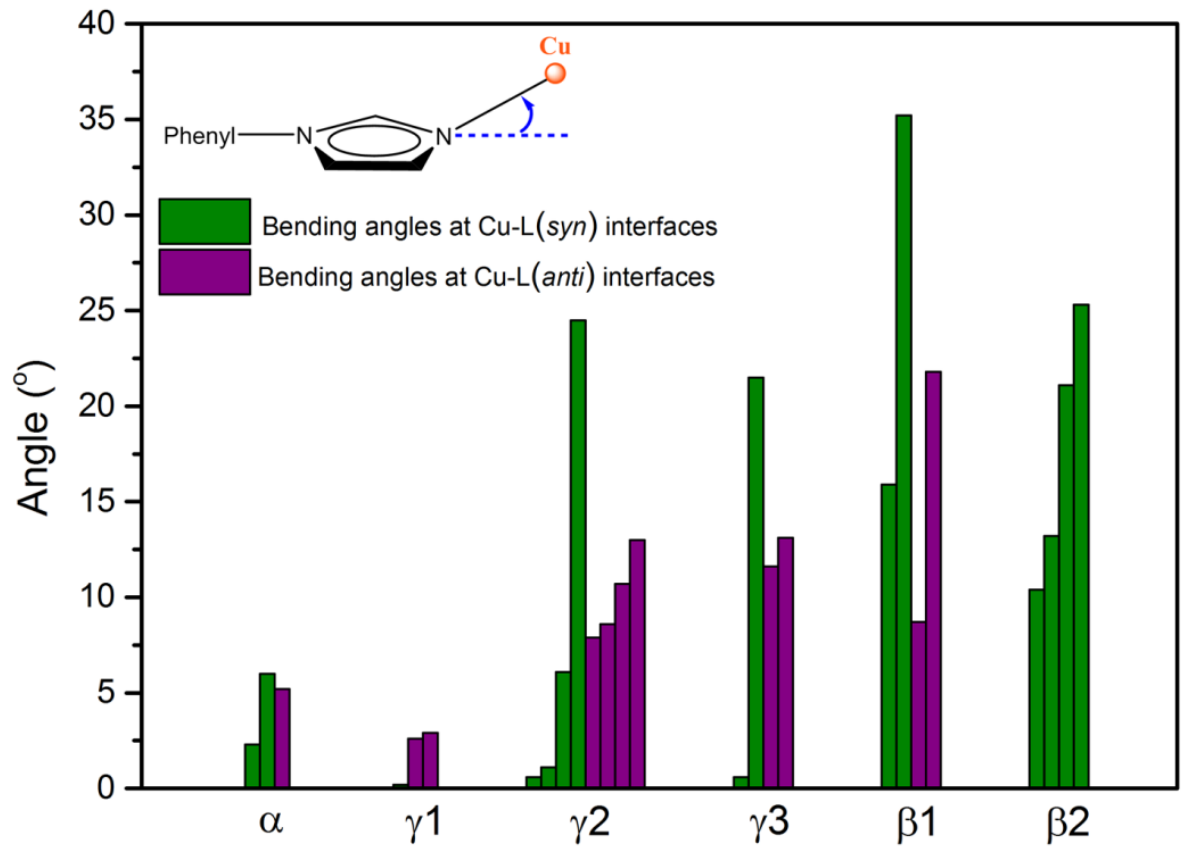

Figure S9. Angles between $\mathrm{Cu}-\mathrm{N}$ coordination bond and imidazolyl plane which quantifies the bending at metal-ligand interfaces.

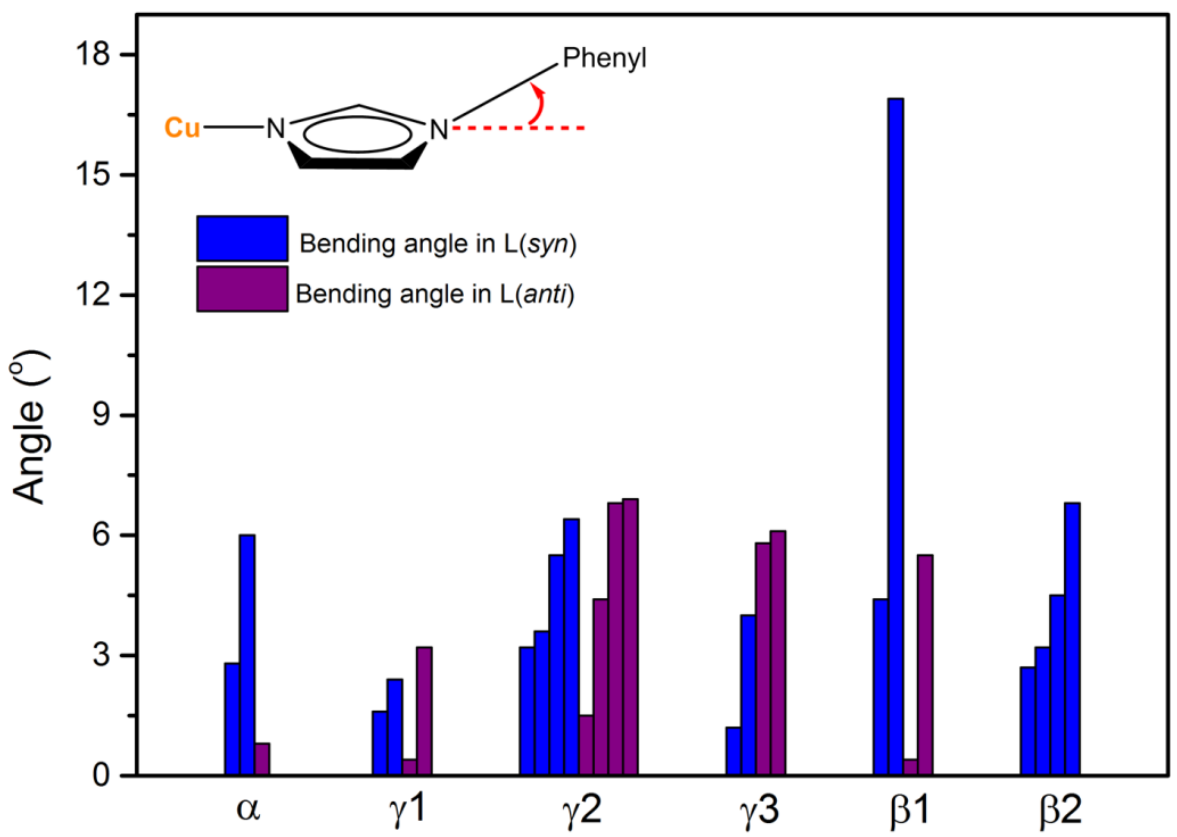

Figure S10. Angles between $\mathrm{C}_{\text {phenyl }}-\mathrm{N}_{\text {imidazolyl }}$ covalent bond and imidazolyl plane which quantifies the bending of ligand scaffold. 

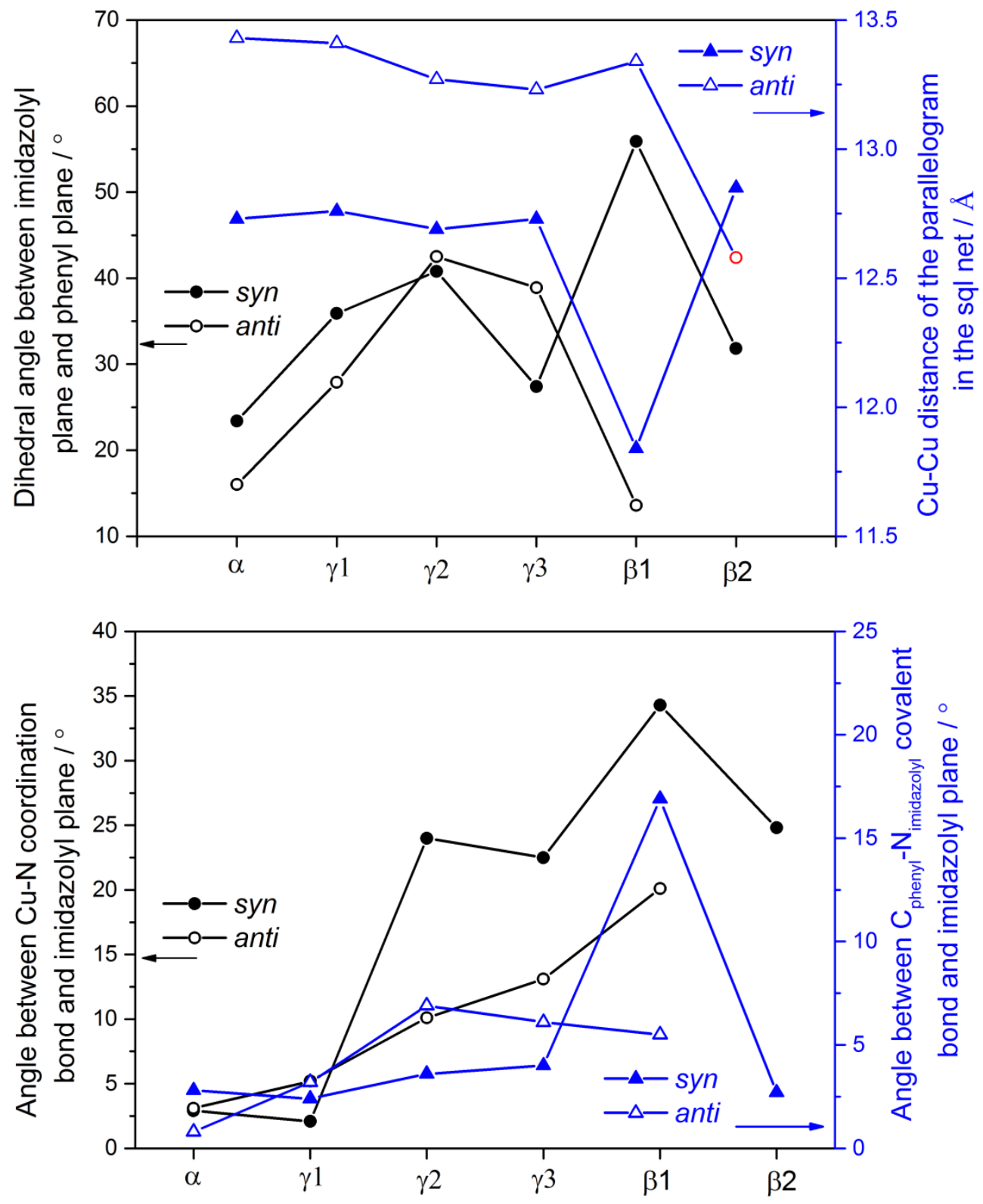

Figure S11. Top left: maximum dihedral angles between imidazolyl plane and phenyl plane in syn-conformational lgiands (L(syn),black solid circle) and anti-conformational ligands (L(anti), black hollow circle) observed in each phase. Top right: Distance between two $\mathrm{Cu}$ centers bridged by $\mathrm{L}($ syn) (blue solid triangle) and $\mathrm{L}$ (anti) (blue hollow triangle) observed in each phase (i.e. the edge length of parallelogram in the sql net). Note: the red hollow circle suggests the distance between $\mathrm{L}($ anti)-bridged $\mathrm{Cu}$ centers decreases after $\mathrm{L}($ anti) isomerizing to $\mathrm{L}($ syn $)$. Bottom left: maximum angles between $\mathrm{Cu}-\mathrm{N}$ coordination bond and imidazolyl plane, quantifying the bending degree of $\mathrm{Cu}$-imidazolyl junction between $\mathrm{Cu}$ ions and $\mathrm{L}($ syn) (black solid circle) and $\mathrm{L}$ (anti) (black hollow circle) in each phase. Bottom right: maximum angles between $\mathrm{C}_{\text {phenyl }}-\mathrm{N}_{\text {imidazolyl }}$ covalent bond and imidazolyl plane in L(syn) (blue solid triangle) and L(anti) (blue hollow triangle) in each phase, quantifying the bending degree of ligands. 
Table S3. Comparative analysis of the structural transformation mechanism between different phase evolution processes

\begin{tabular}{|c|c|c|c|c|}
\hline Transition & $\begin{array}{l}\text { Organic ligand } \\
\text { rotation }\end{array}$ & $\begin{array}{l}\text { Cu-imidazolyl } \\
\text { junction } \\
\text { bending }\end{array}$ & Ligand bending & $\frac{\begin{array}{c}\text { Structure } \\
\text { transformation }\end{array}}{\underline{\text { mechanism }}}$ \\
\hline$\alpha$ to $\gamma 1$ & large & negligible & negligible & Ligand rotation \\
\hline$\gamma 1$ to $\gamma 2$ & large & very large & negligible & $\begin{array}{l}\text { Cu-imidazolyl } \\
\text { junction bending }\end{array}$ \\
\hline$\gamma 2$ to $\gamma 3$ & large & negligible & negligible & Ligand rotation \\
\hline$\gamma 3$ to $\beta 1$ & very large & very large & very large & $\begin{array}{l}\text { Lignand bending } \\
\text { is responsible for } \\
\text { the pore close }\end{array}$ \\
\hline $\boldsymbol{\beta 1}$ to $\boldsymbol{\beta 2}$ & large & decreased & eliminated & $\begin{array}{l}\text { anti-to-syn } \\
\text { isomerization of } \\
\text { ligand and } \\
\text { SIFSIX swing }\end{array}$ \\
\hline
\end{tabular}

As we can see, SIFSIX-23-Cu undergoes a hinge-like motion from $\boldsymbol{\alpha}$ to $\boldsymbol{\beta} 1$ driven by organic ligand rotation, $\mathrm{Cu}$-imidazolyl junction bending and ligand bending. From $\boldsymbol{\alpha}$ to $\boldsymbol{\gamma} \mathbf{1}$, there is negligible $\mathrm{Cu}$-imidazolyl junction bending and ligand bending, as a result, the driving force for structure transformation is the rotation of organic ligand. From $\boldsymbol{\gamma} \mathbf{1}$ to $\boldsymbol{\gamma} \mathbf{2}$, the large $\mathrm{Cu}$-imidazolyl junction bending in $\mathrm{Cu}-\mathrm{L}(\operatorname{syn})-\mathrm{Cu}$ connectivity contributes mainly to the structure contraction; While from $\gamma \mathbf{2}$ to $\gamma \mathbf{3}$, the $\mathrm{Cu}$-imidazolyl junction bending and ligand bending is negligible, thus the rotation of ligand leads to the minor difference between these two forms. From $\boldsymbol{\gamma} \mathbf{3}$ to $\boldsymbol{\beta 1}$, the bending of $\mathrm{Cu}$-imidazolyl junction increase largely (reaching the maximum $\mathrm{Cu}$-imidazolyl junction bending angle of $34.3^{\circ}$ ), which directly results in the decrease of the acute angle of the parralellogram. However, the bending of $\mathrm{L}(\operatorname{syn})\left(16.9^{\circ}\right.$ between $\mathrm{C}_{\text {phenyl }}-\mathrm{N}_{\text {imidazolyl }}$ covalent bond and imidazolyl plane in $\boldsymbol{\beta 1}$ ) is the main contributor to the close of the pore. The ligand bending in $\boldsymbol{\beta 1}$ phase also leads to the maximum dihedral angle between imidazolyl plane and phenyl plane $\left(55.9^{\circ}\right)$ in $\mathrm{L}($ syn $)$ and the minimum dihedral angle $\left(7.9^{\circ}\right)$ in $\mathrm{L}($ anti). In other word, $\mathrm{L}($ syn) shows the most twisted feature while L(anti) displays the most coplanar characteristic in $\boldsymbol{\beta 1}$ phase. From $\boldsymbol{\beta} 1$ to $\boldsymbol{\beta 2}$, the structure evolution arises from the anti-to-syn isomerization 
of L(anti) and swing motion of SIFSIX anions, which causes the decrease of $\mathrm{Cu}$-imidazolyl junction bending angle and the elimination of $\mathrm{L}(\mathrm{syn})$ bending. The elimination of $\mathrm{L}(\mathrm{syn})$ bending enables the related $\mathrm{Cu} \cdots \mathrm{Cu}$ distance to revert to a value close to the beginning while the isomerization from $\mathrm{L}($ anti) to $\mathrm{L}(\mathrm{syn})$ makes the corresponding $\mathrm{Cu} \cdots \mathrm{Cu}$ distance decrease to a value almost equal to the distance between two $\mathrm{Cu}$ centers bridged by inherent $\mathrm{L}(\mathrm{syn})$. Notably, the structure evolution is mostly related to $\mathrm{L}(s y n)$ (Cu-imidazolyl junction bending and ligand bending), as the out-of-plane orientation (relative to the $\mathrm{Cu}$ atoms plane) of 'angular' $\mathrm{L}(\mathrm{syn})$ is far more labile than the in-plane orientation of 'linear' L(anti). 
Table S4. Possible C-F $\cdots \mathrm{H}$ hydrogen bonds with $d_{\mathrm{F} \cdots \mathrm{H}}<2.8 \AA$ (short $\mathrm{F} \cdots \mathrm{H}$ contacts)

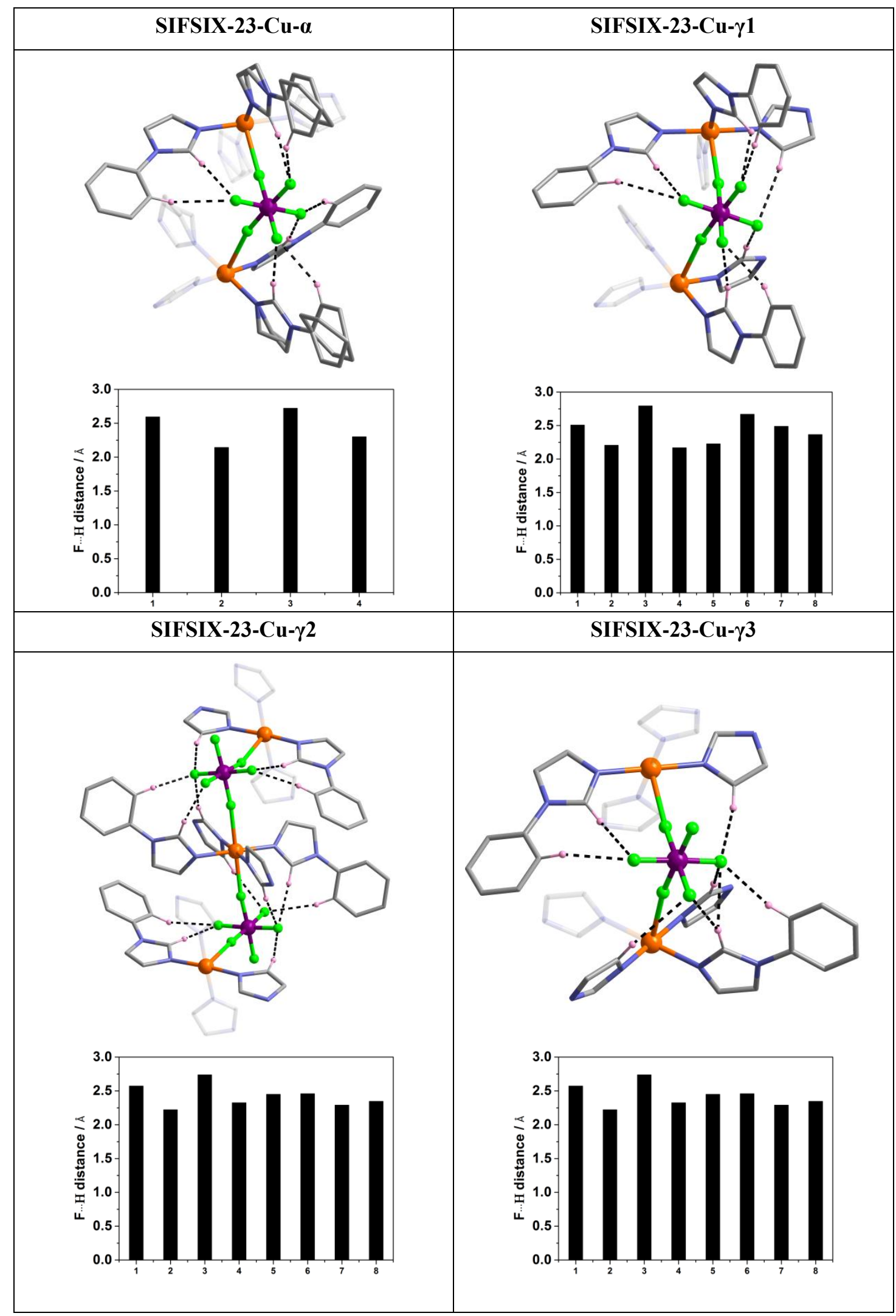




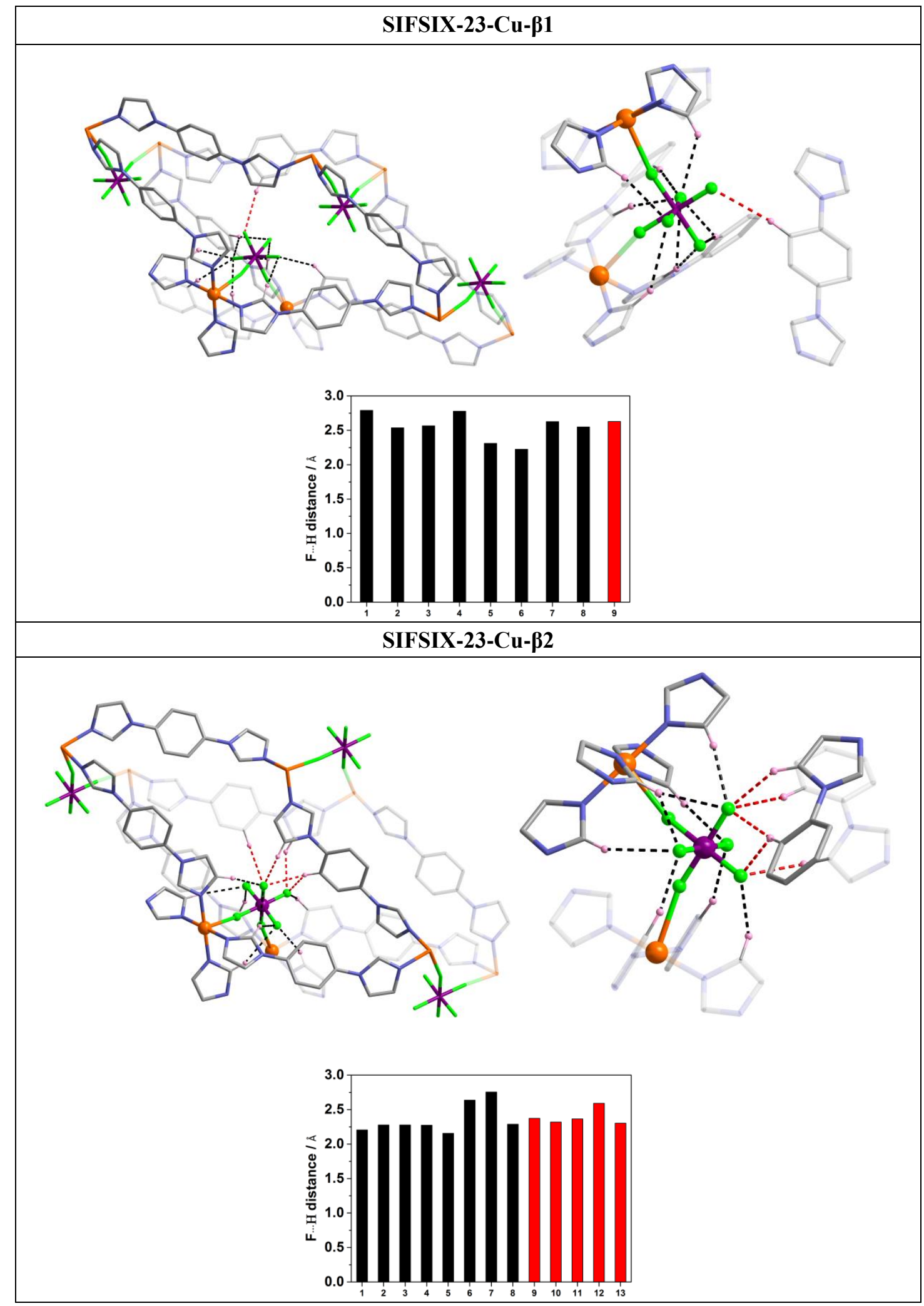

1. $\mathrm{C}-\mathrm{H} \cdots \mathrm{F}$ hydrogen bonds ${ }^{17}$ : the black dash line represent the hydrogen bonds between SIFSIX and organic ligands which share the same $\mathrm{Cu}$ ions with SIFSIX anions. The red one represent the hydrogen bonds between SIFSIX and organic ligands which don't share the same $\mathrm{Cu}$ ion with SIFSIX anions. These hydrogen 
bonds can be considered to lock the channels.

2. The acidity of hydrogen donor from the 2-positioned carbon atom on the imidazolyl ring is high because the strong electron-withdrawing ability of the two bonded nitrogen atoms and the coordinated copper ions can increase the $\mathrm{C}-\mathrm{H}$ acidity. $^{18}$

3. The hydrogen bonds can stablize each phase but not strong enough to prevent the phase transformation.

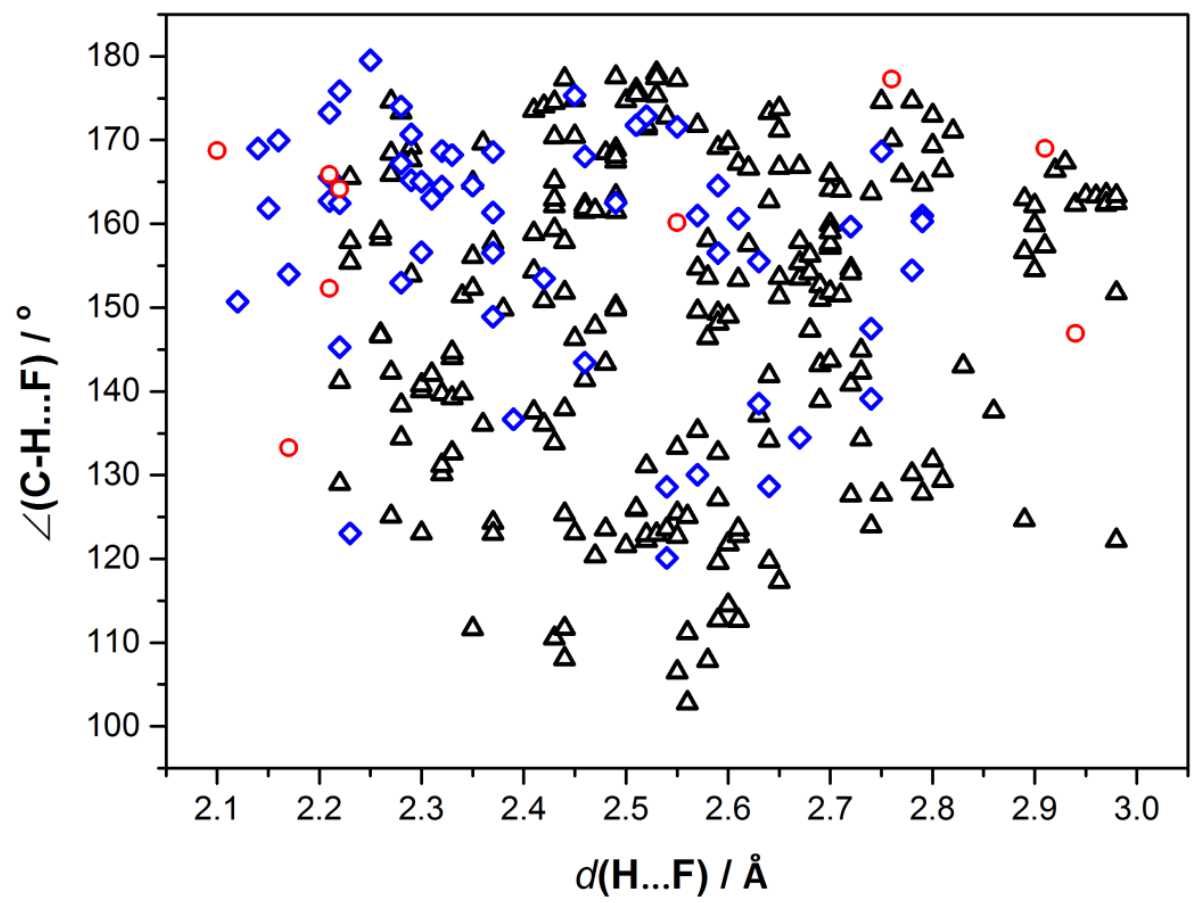

$\Delta \mathrm{C}-\mathrm{H} \cdots \mathrm{F}$ hydrogen bonds in conventional SIFSIX materials

$\diamond \mathrm{C}-\mathrm{H} \cdots \mathrm{F}$ hydrogen bonds in SIFSIX-23-Cu

O $\mathrm{C}-\mathrm{H} \cdots \mathrm{F}$ hydrogen bonds in reported structures composed of other imidazolyl ligands and SIFSIX anions

Figure S12. C-H $\cdots$ F hydrogen bonds in SIFSIX-23-Cu and documented crystal structures based on a survey of Cambridge Crystal Database (CSD, v. 5.40, updated to November 2019). The short hydrogen bonds in SIFSIX-23-Cu come from the interactions between hydrogen atoms on the 2-positioned carbon atoms of imidazolyl groups and SIFSIX anions. The cis-bridging coordination mode of SIFSIX anions, the acidity of the 2-positioned carbon atom of imidazolyl groups and the angular feature of imidazolyl groups enable the stronger hydrogen bonds in SIFSIX-23-Cu compared with those in conventional SIFSIX materials. 
(a)
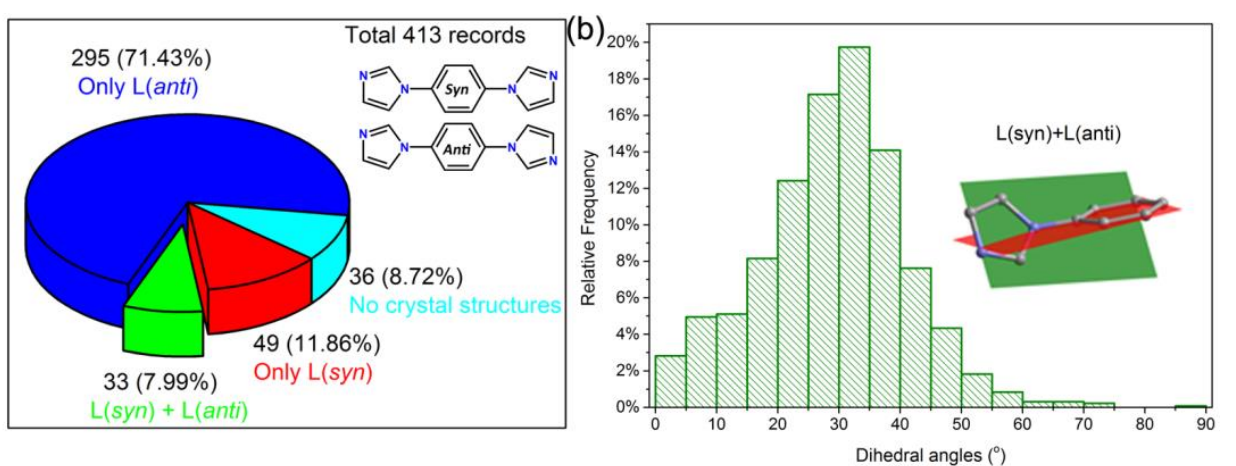

(c)
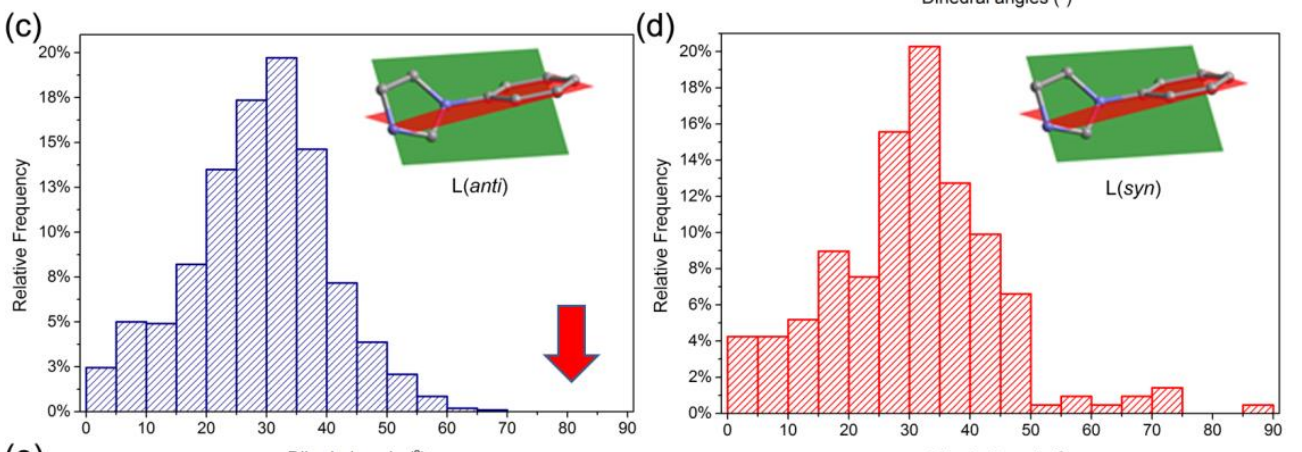

(e)
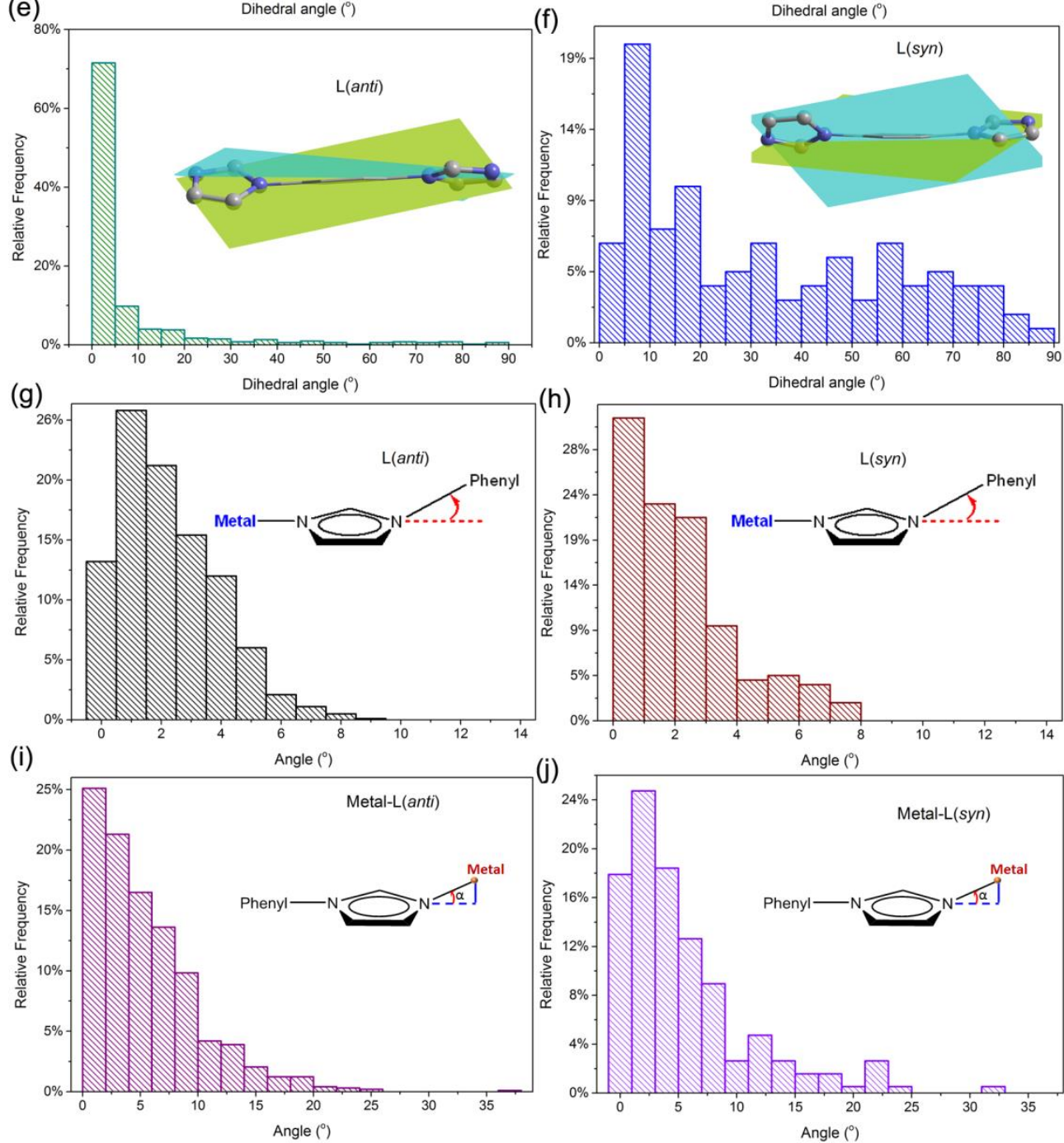

Figure S13. Number of reported crystal structures containing only one conformer or both the two 
conformers of L archived in Cambridge Crystal Database (CSD, v. 5.40, updated to November 2019) (a). The distribution of dihedral angles between imidazolyl planes and phenyl planes in L (L(syn) and $\mathrm{L}($ anti)) (b), in $\mathrm{L}($ anti) (c) and in $\mathrm{L}($ syn) (d). The distribution of dihedral angles between two imidazolyl planes in L(anti) (e) and in $\mathrm{L}(s y n)$ (f). The distribution of angles between $\mathrm{C}_{\text {phenyl- }}-\mathrm{N}_{\text {imidazolyl }}$ covalent bonds and imidazolyl planes in $\mathrm{L}($ anti) (g) and in $\mathrm{L}($ syn) (h). The distribution of angles between Metal- $\mathrm{N}_{\text {imidazolyl }}$ coordination bonds and imidazolyl planes in $\mathrm{L}($ anti) (i) and in $\mathrm{L}($ syn) (j).

Based on the CSD survey on L, we can conclude as following:

1. The recorded crystal structures containing $\mathrm{L}($ anti) are far more than those containing L(syn) (four-fold), perhaps because of the higher symmetry exhibited by $\mathrm{L}($ anti) compared with $\mathrm{L}(s y n)$, which is more suitable for crystallization.

2. In all the reported crystal structures, there are no L(anti) possessing dihedral angles (between imidazolyl plane and phenyl plane) in the region of $70^{\circ}$ to $90^{\circ}$, suggesting the existence of high energy barrier. This is in line with the high temperature (high energy input) controlled anti-to-syn isomerization of L in $\boldsymbol{\beta} 1$ to $\boldsymbol{\beta 2}$ transformation, as the anti-to-syn isomerization of $\mathrm{L}$ needs to overcome the high energy state with dihedral angle of $90^{\circ}$.

3. Although dihedral angles between imidazolyl and phenyl planes in L(anti) and $\mathrm{L}($ syn) exhibited a similar distribution, $\mathrm{L}($ syn) offers more rotational variability than L(anti) does as the two imidazolyl planes in L(anti) are coplanar in most cases. Consequently, the anti-to-syn isomerization of L(anti) should request high energy input which is consistent with the temperature-controlled phase transformation from $\boldsymbol{\beta} 1$ to $\boldsymbol{\beta 2}$.

4. The wide distribution of dihedral angles between imidazolyl plane and phenyl plane suggests the free rotation of the ligand $\mathrm{L}$ is easily available. This is prerequisite for the flexibility of SIFSIX-23-Cu as the rotation of ligand not only drives the deformation of the sql net, but also accommodates the constraints and minimizes the lattice energy. The free rotation of aromatic rings in $\mathrm{L}$ is also essential for the contortion of $\mathrm{L}$ observed in $\boldsymbol{\gamma} \mathbf{3}$ to $\boldsymbol{\beta 1}$ transformation as the 
induced constraints can be released or compensated by the rotation.

5. In all the reported structures, the bending of $\mathrm{L}$ is negligible.

6. The severe bending of metal-imidazolyl junction is rare.
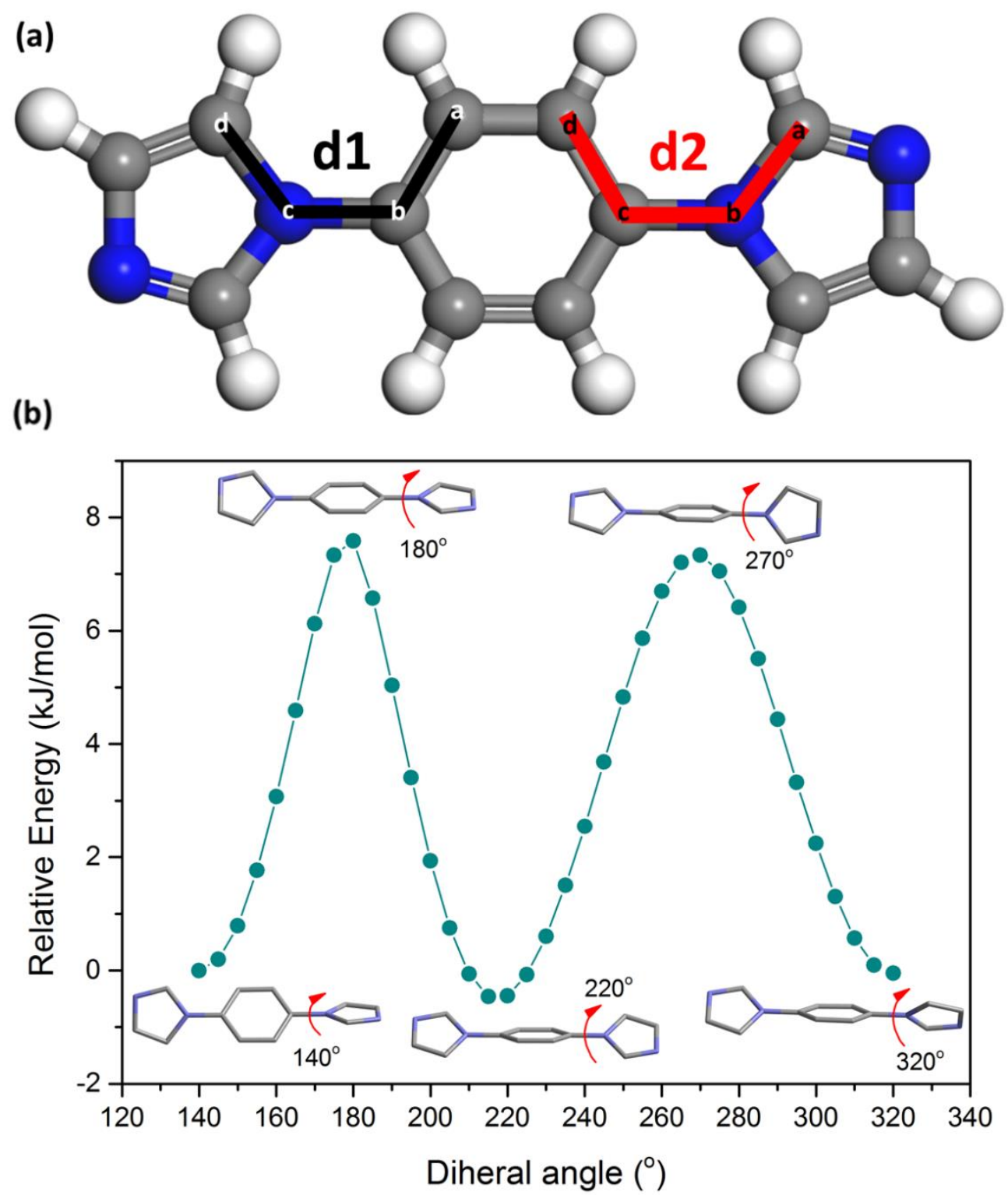

Figure S14. Dihedral angles within the bare linker 1,4-Bis(1-imidazolyl)benzene) are in the anti-conformation in a fully planar configuration $\left(\mathrm{d} 1=\mathrm{d} 2=0^{\circ}\right.$ ) (a). Rotation potential energy scan of bare organic ligand as a function of one dihedral angle between imidazolyl and phenyl planes (b) while the other one (d2) is free. The optimized ligand with minimum energy was chosen as the starting point.

As shown in the plot Figure S14, the ligand with minimum energy is an 
anti-conformer $\left(\mathrm{d} 1 \approx \mathrm{d} 2 \approx 140^{\circ}\left(40^{\circ}\right)\right)$. Along with the increasing of $\mathrm{d} 1$ to $320^{\circ}$, two more minima were identified, one syn- and one anti-conformer with $\mathrm{d} 1 \approx 220^{\circ}\left(40^{\circ}\right)$ and $320^{\circ}\left(40^{\circ}\right)$, respectively. Interestingly, the three obtained minima show the common character with $\mathrm{d} 1 \approx 40^{\circ}$ (acute angle), given the symmetric feature of the ligand we can tentatively conclude that the energy of ligand will reach minimum if the two dihedral angles are around $40^{\circ}$, no matter if the conformation is syn or anti. In addition, two maxima were also identified and both of them are anti-conformers with $\mathrm{d} 1=180^{\circ}\left(0^{\circ}\right)$ and $270^{\circ}\left(90^{\circ}\right)$, respectively. In the former the imidazolyl plane and phenyl plane are coplanar while in the latter, they are perpendicular to each other. Similarly, we can also guess that the energy of ligand will be very high if the imidazolyl plane is coplanar and/or perpendicular to the phenyl plane.

In order to further verify our results, we performed a continuous $180^{\circ}$ sweep with a step size of $5^{\circ}$ on both dihedral angles $\mathrm{d} 1$ and $\mathrm{d} 2$. The corresponding $2 \mathrm{D}$ and $3 \mathrm{D}$ rotational potential energy scan profiles are displayed on Figure S15. Base on the analysis we can conclude as following:

1. The relative energy plot generated from the scan shows minima (blue areas) at d1 $\approx \mathrm{d} 2 \approx 40^{\circ}\left(140^{\circ}\right)$ which confirmed our assumption above. This is interesting because the syn- and anti-conformers with dihedral angles $\mathrm{d} 1$ and $\mathrm{d} 2$ equal to about $40^{\circ}\left(140^{\circ}\right)$ possess the similar energy minimum, perhaps due to the small difference between $\mathrm{N} 2$ and $\mathrm{C} 3$ on the imidazolyl ring.

2. The conformations possess high energy conformation (orange areas) locating at $\mathrm{d} 1$ $=\mathrm{d} 2=0^{\circ}\left(180^{\circ}\right)$ (the corners of the plot), $\mathrm{d} 1=\mathrm{d} 2=90^{\circ}$ (the central point of the plot), and $\mathrm{d} 1=0^{\circ}\left(90^{\circ}\right), \mathrm{d} 2=90^{\circ}\left(0^{\circ}\right)$ (the middle point of the side of the plot). These results verify that the states where the imidazolyl plane is coplanar or perpendicular to the phenyl plane are unstable.

3. Notably, the energy difference between the minimum and maximum is very low $(<14 \mathrm{~kJ} / \mathrm{mol})$, which proves the free rotation of ligand is feasible because of the low rotational energy barrier. In other words, the ligand L indeed has a high degree of intrinsic flexibility.

These outcomes match very well with our statistical results from Cambridge Crystal 
Database (CSD) (Figure S13).
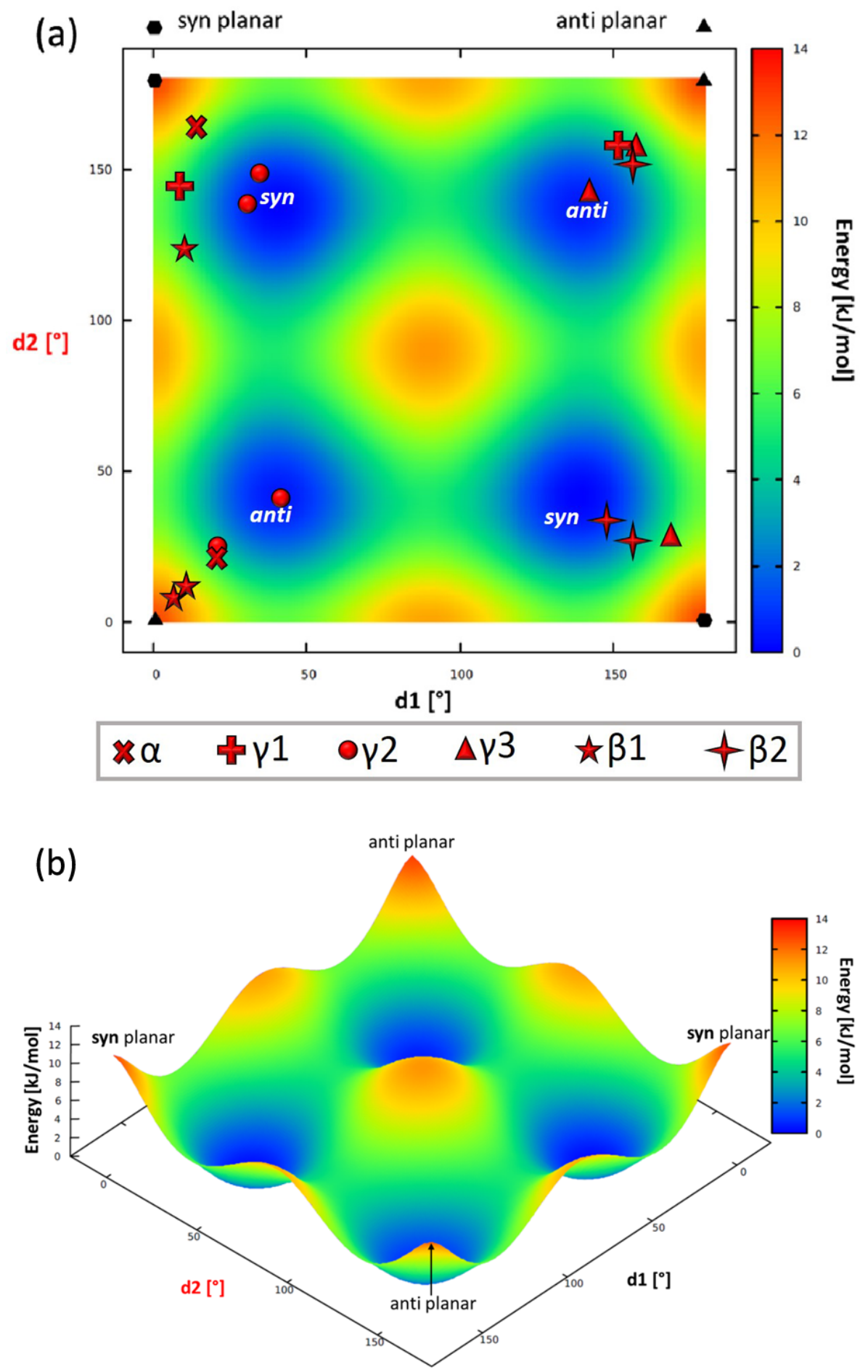

Figure S15. Rotation potential energy scan of bare organic ligand as a function of two dihedral angle between imidazolyl and phenyl planes (a) 2D and (b) 3D plots. All dihedral angles observed in different phases experimentally obtained were marked in (a). Noting because of the symmetry of the plot, we put the symbols separately rather than in one area for clarity. 


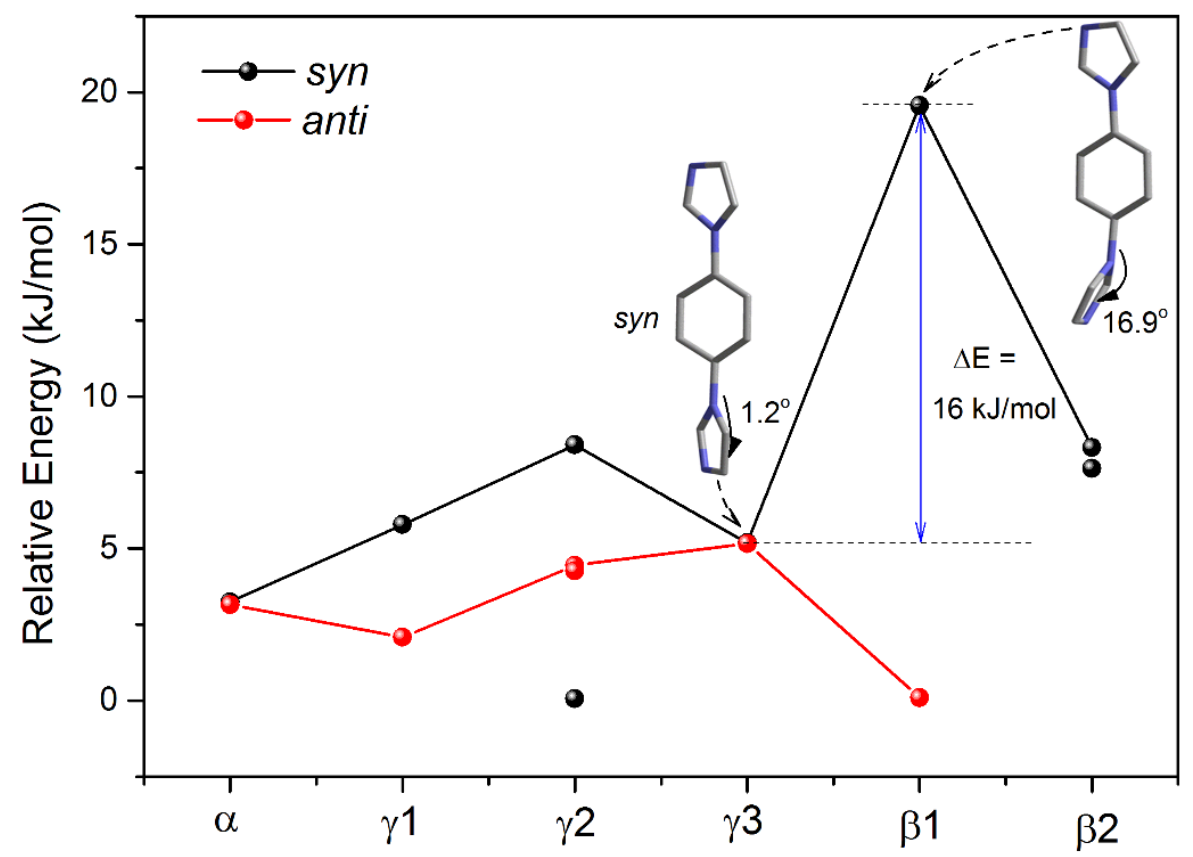

Figure S16. The relative energy of constrained organic ligands as they appeared in the different structural phases. All the energies are zero-point corrected at the B3LYP/6-311+G(d,p) level of theory and are presented with respect to the global minimum configuration of a bare linker.

As we can see from Figure S16, for anti-conformers, the maximum energy change observed during the whole transformation is small $(<5 \mathrm{~kJ} / \mathrm{mol})$, matching with the mild distortion of L(anti) during the structural evolution, while for the syn-conformers, the similar energy change from $\boldsymbol{\alpha}$ to $\gamma 3$ is discovered $(<5 \mathrm{~kJ} / \mathrm{mol})$, but obviously, from $\gamma 3$ to $\boldsymbol{\beta 1}$, the hugely increased energy $(\Delta \mathrm{E} \approx 16 \mathrm{~kJ} / \mathrm{mol})$ is consistent with the increased bending between imidazolyl and phenyl groups. However, the energy difference induced by ligand bending is still very small, which guarantees the flexibility and recyclability of reversible closed-to-open switching from $\gamma \mathbf{3}$ to $\boldsymbol{\beta 1}$ induced by sorption of $\mathrm{CO}_{2}$. On the other side, when $\boldsymbol{\beta} 1$ to $\boldsymbol{\beta 2}$ evolution occurred, the energy of the same ligand decreases, thus indicating the strain constrained in $\boldsymbol{\beta 1}$ phase is released, making $\boldsymbol{\beta 2}$ more stable.

In summary, all of the calculation results confirmed that the rotation, the anti-to-syn interconversion and the bending of organic ligand is feasible because of the low energy barrier, which provide the prerequisite for the flexibility of SIFSIX-23-Cu. 


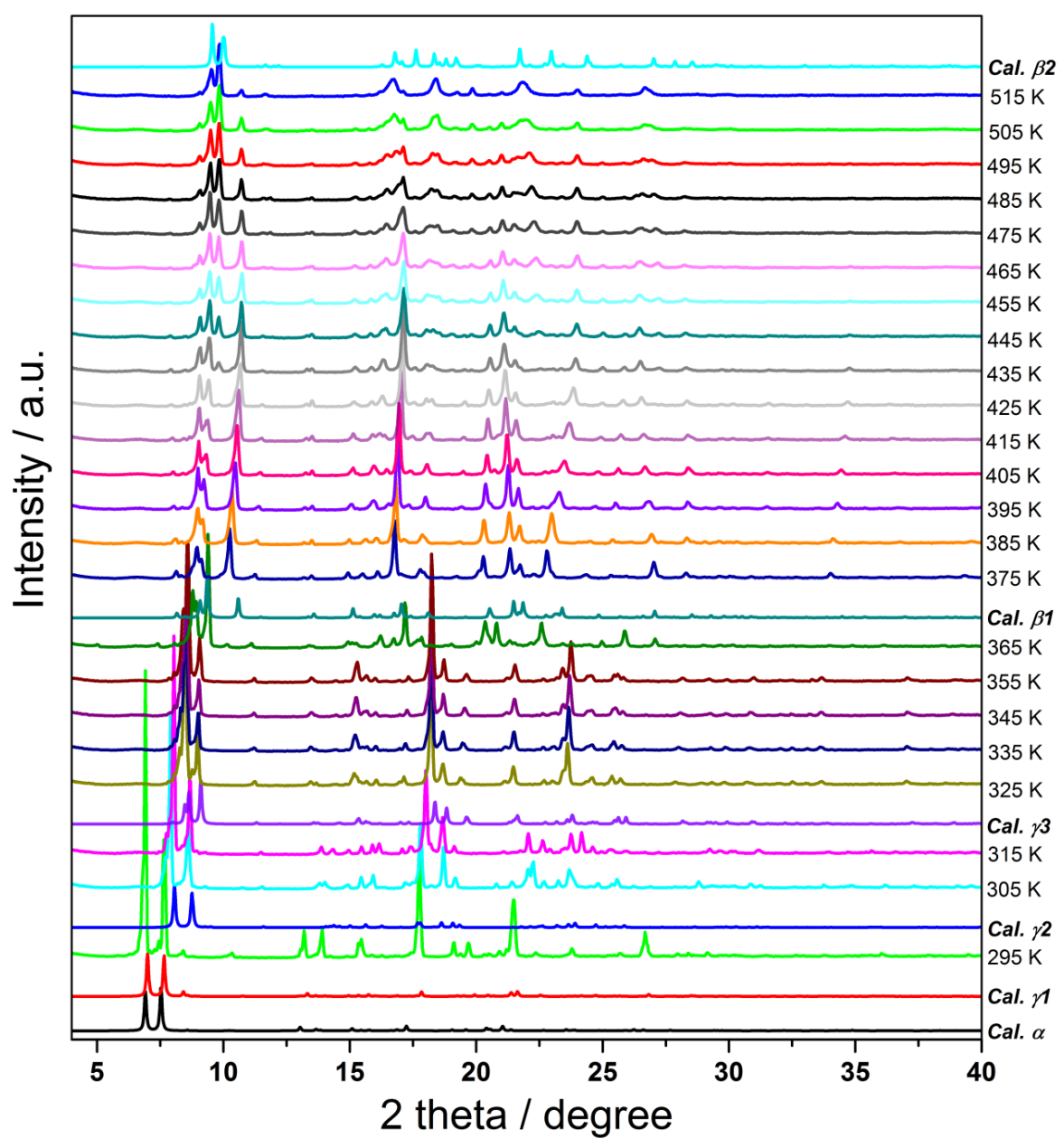

Figure S17. Variable temperature PXRD patterns of air dried sample from 295 to $515 \mathrm{~K}$ under $\mathrm{N}_{2}$ at a step of $10 \mathrm{~K}$. The PXRD pattern at $295 \mathrm{~K}$ demonstrated that the air dried samples are mainly $\gamma \mathbf{1}$ phase with minor part of $\boldsymbol{\alpha}$ phase, which is in accord with the SCXRD results. The rapid phase evolution from $\gamma \mathbf{1}$ to $\gamma \mathbf{2}$ occurring at $305 \mathrm{~K}$ proved the ultra-flexibility of the framework. The variation of the PXRD patterns showed the clear structural transformation tendency from $\boldsymbol{\alpha}$ to $\boldsymbol{\beta 1}$, however, a new phase, $\boldsymbol{\beta 2}$, started to appear slowly from $425 \mathrm{~K}$. 


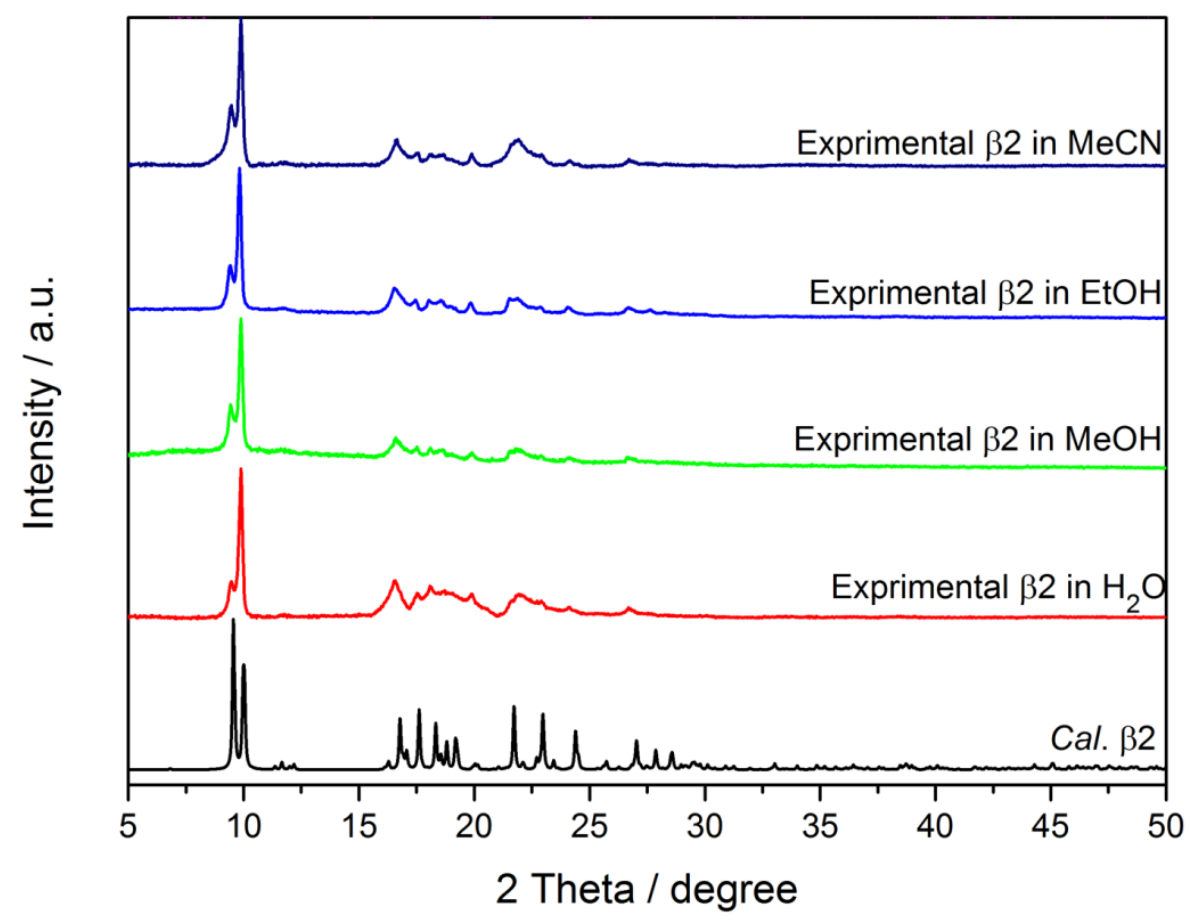

Figure S18. PXRD patterns of SIFSIX-23-Cu- $\beta 2$ phase after soaked in different solvents for 1 month.

Table S5 Relationship between cell volume and relative energies at PBE and PBE-dDsC level of theory. The dispersion contribution increases if the unit cell contracts.

\begin{tabular}{|c|c|c|c|c|}
\hline Phase & $\begin{array}{c}\text { Cell volume } \\
\left(\AA^{3} / \mathbf{C u}_{\mathbf{2}} \mathbf{L}_{\mathbf{4}}\left(\mathbf{S i F}_{\mathbf{6}}\right)_{2} \text {-unit) }\right.\end{array}$ & $\begin{array}{c}\mathbf{E}(\mathbf{P B E}) \\
(\mathbf{k J} / \mathbf{m o l})\end{array}$ & $\begin{array}{c}\mathbf{E}(\mathbf{P B E}-\mathbf{d D s C}) \\
(\mathbf{k J} / \mathbf{m o l})\end{array}$ & $\begin{array}{c}\mathbf{E}(\mathbf{P B E}-\mathbf{d D s C})- \\
\mathbf{E}(\mathbf{P B E}) \\
(\mathbf{k J} / \mathbf{m o l})\end{array}$ \\
\hline $\boldsymbol{\alpha}$ & 1922.12 & 0.0 & 0.0 & 0 \\
\hline $\boldsymbol{\gamma} \mathbf{1}$ & 1829.37 & 14.0 & 5.6 & -8.4 \\
\hline $\boldsymbol{\gamma} \mathbf{2}$ & 1513.76 & 74.5 & -2.0 & -76.5 \\
\hline $\boldsymbol{\gamma} \mathbf{3}$ & 1475.73 & 69.4 & -6.6 & -76.1 \\
\hline $\boldsymbol{\beta 1}$ & 1256.77 & 107.3 & -93.3 & -200.6 \\
\hline $\boldsymbol{\beta 2}$ & 1230.78 & -4.9 & -221.8 & -216.9 \\
\hline
\end{tabular}




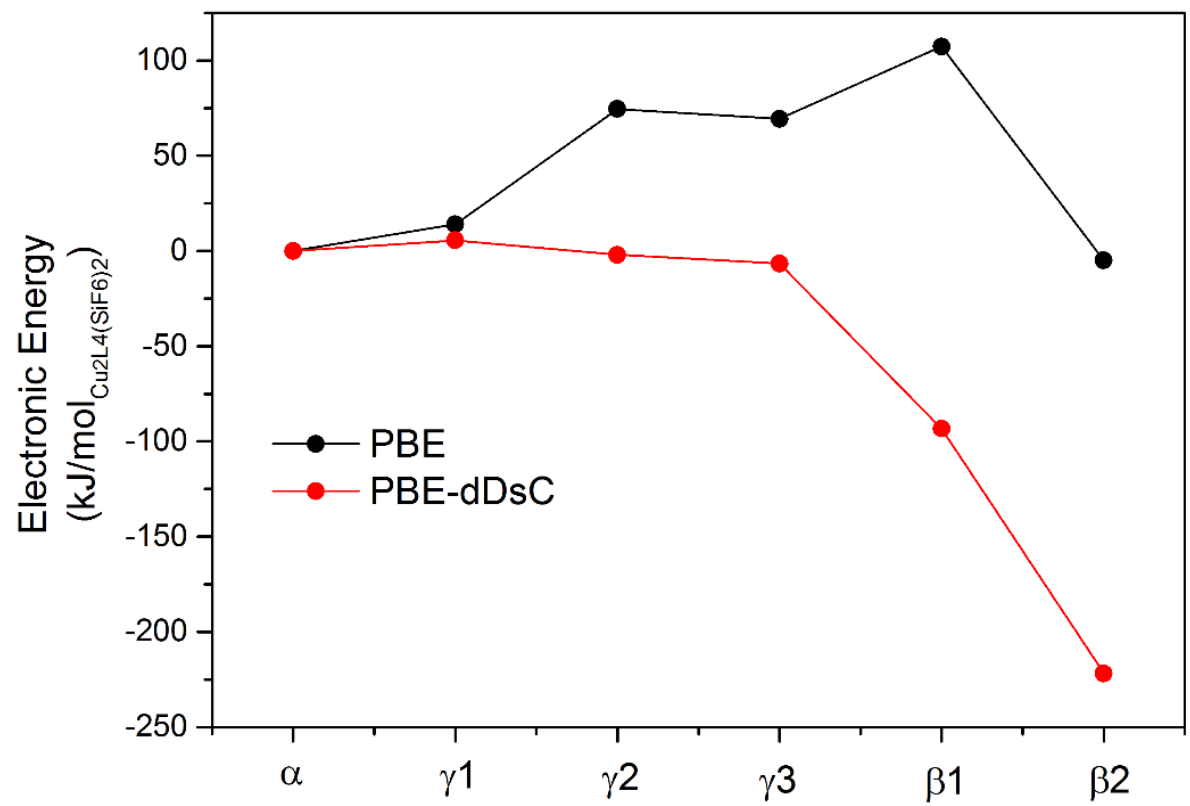

Figure S19. Relative energy diagram of the different phases. Electronic energy differences are given at the PBE (black) and PBE-dDSc (red) level of theory in $\mathrm{kJ} / \mathrm{mol}$.

The relative dispersion contribution increases along with the structural transformation from $\alpha$ to $\boldsymbol{\beta 2}$ (Table S5, Figure S19). This can be rationalized as an effect of unit-cell compression along the structural transformation path. The volume per $\mathrm{Cu}_{2} \mathrm{~L}_{4}\left(\mathrm{SiF}_{6}\right)_{2}$-unit decreases from $1922.12 \AA^{3}$ ( $\alpha$-phase) to $1230.78 \AA^{3}$ ( $\boldsymbol{\beta 2}$-phase). This compression results in (1) increased stacking energies between the organic linkers and (2) hydrogen bonding between the organic linkers and inorganic $\mathrm{SiF}_{6}$ units and is clearly visible in the dispersion contribution. With dispersion corrections (PBE-dDsC), the energy variations from $\boldsymbol{\alpha}$ to $\boldsymbol{\gamma} \mathbf{3}$ are minor, which is an indicator for feasible and reversible structural transformations between these phases. $\boldsymbol{\beta} 1$ is a bit lower in energy on the potential energy surface, about $-93 \mathrm{~kJ}$ per mol $\mathrm{Cu}_{2} \mathrm{~L}_{4}\left(\mathrm{SiF}_{6}\right)_{2}$, but the energy difference between $\boldsymbol{\beta 1}$ and $\boldsymbol{\gamma} \mathbf{3}(86.7 \mathrm{~kJ} / \mathrm{mol})$ is not very high, if 及1-phase is sufficiently loaded with $\mathrm{CO}_{2}$ molecules or other gas and solvent molecules, the adsorption energies can offset the energy penalty caused by the structural expansion and contribute to a reopening of the $\boldsymbol{\beta} 1$-phase $\left(1256.77 \AA^{3}\right)$ to the $\boldsymbol{\gamma}$ 3-phase $\left(1475.73 \AA^{3}\right)$. The $\boldsymbol{\beta 2}$-phase, however, is too stable $(-222 \mathrm{~kJ} / \mathrm{mol}$ vs $\alpha)$ and therefore renders structural transitions from $\boldsymbol{\beta 2}$ to $\boldsymbol{\beta 1}$ unfavorable, which matches our experimental results. 


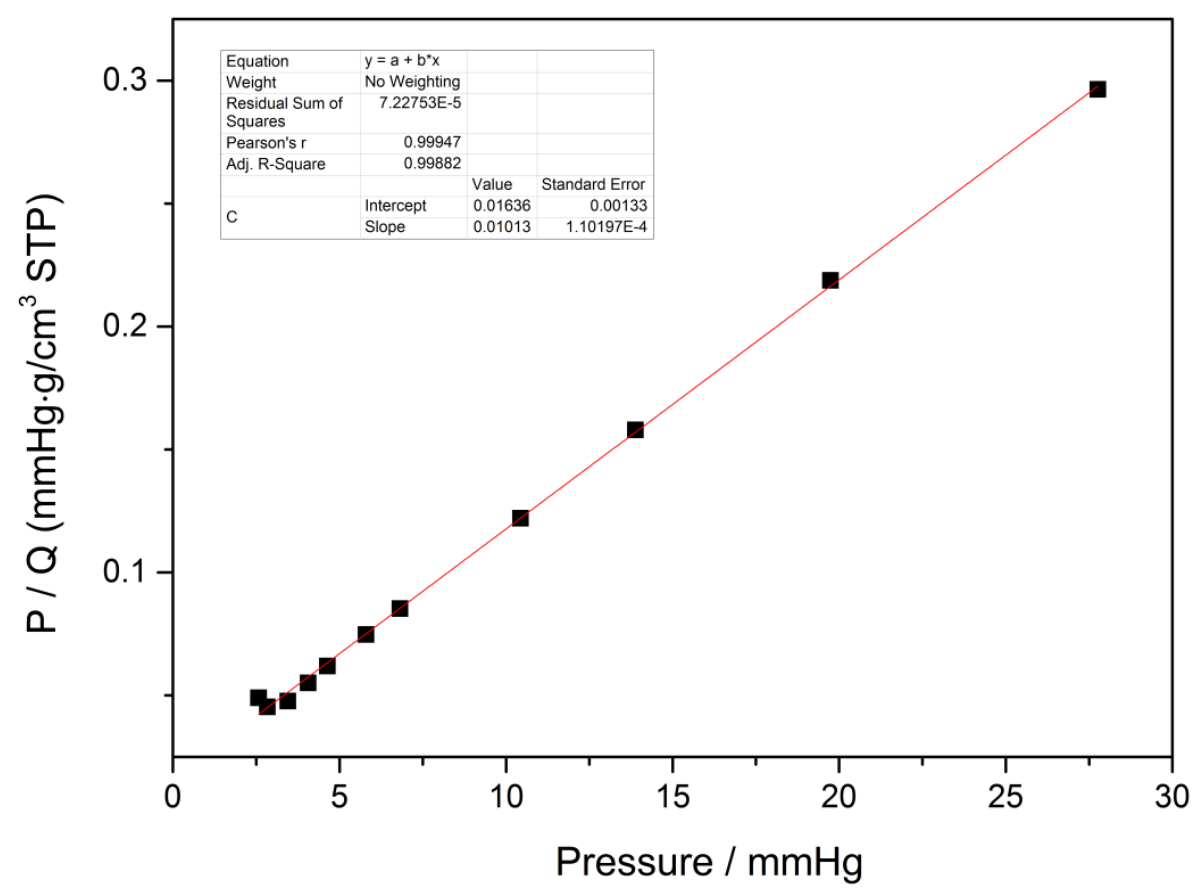

Figure S20. Langmuir fit of data corresponding to the first step on the $195 \mathrm{~K} \mathrm{CO}_{2}$ adsorption isotherm of SIFSIX-23-Cu- $\boldsymbol{\beta 1}$. Squares and line represent the experimental and fitted data respectively.

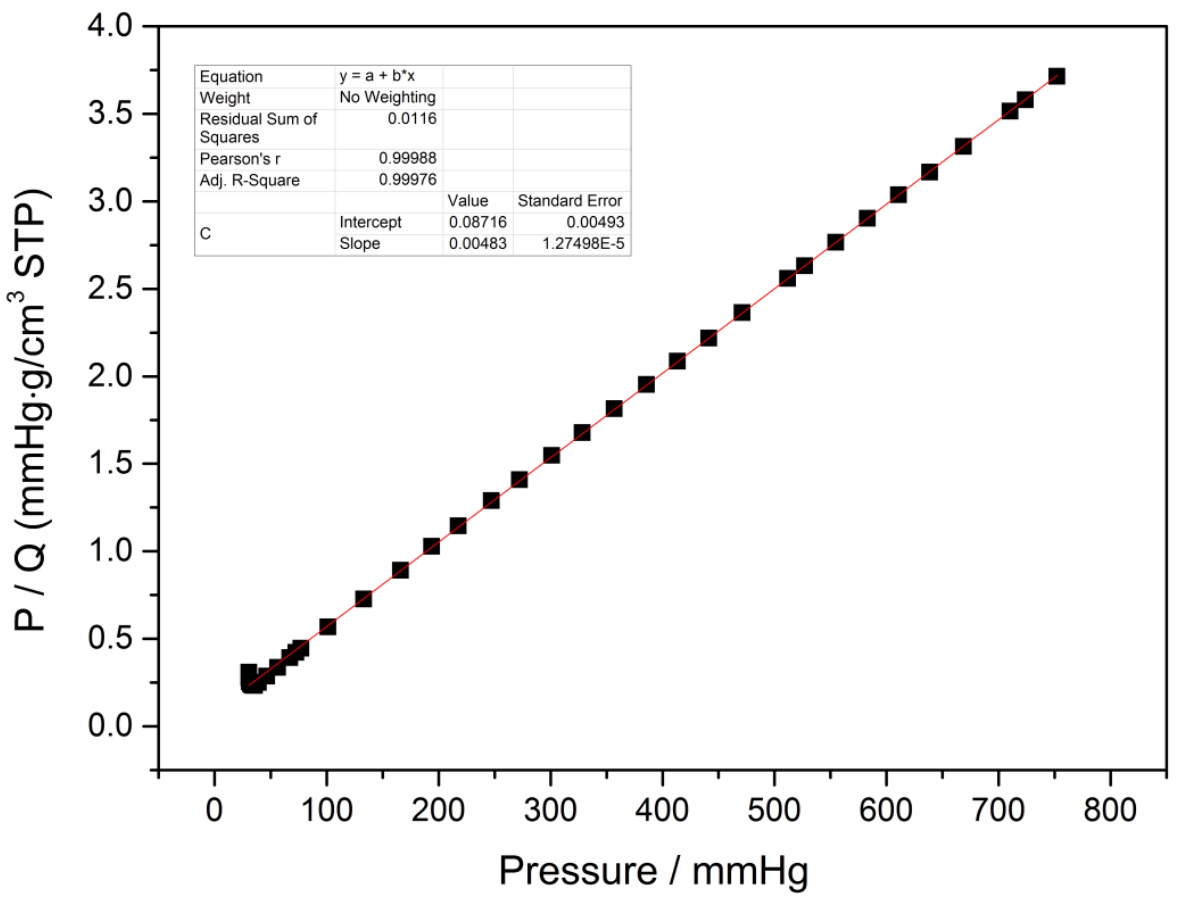

Figure S21. Langmuir fit of data corresponding to the second step on the $195 \mathrm{~K} \mathrm{CO}_{2}$ adsorption isotherm of SIFSIX-23-Cu-p1. Squares and line represent the experimental and fitted data respectively. 


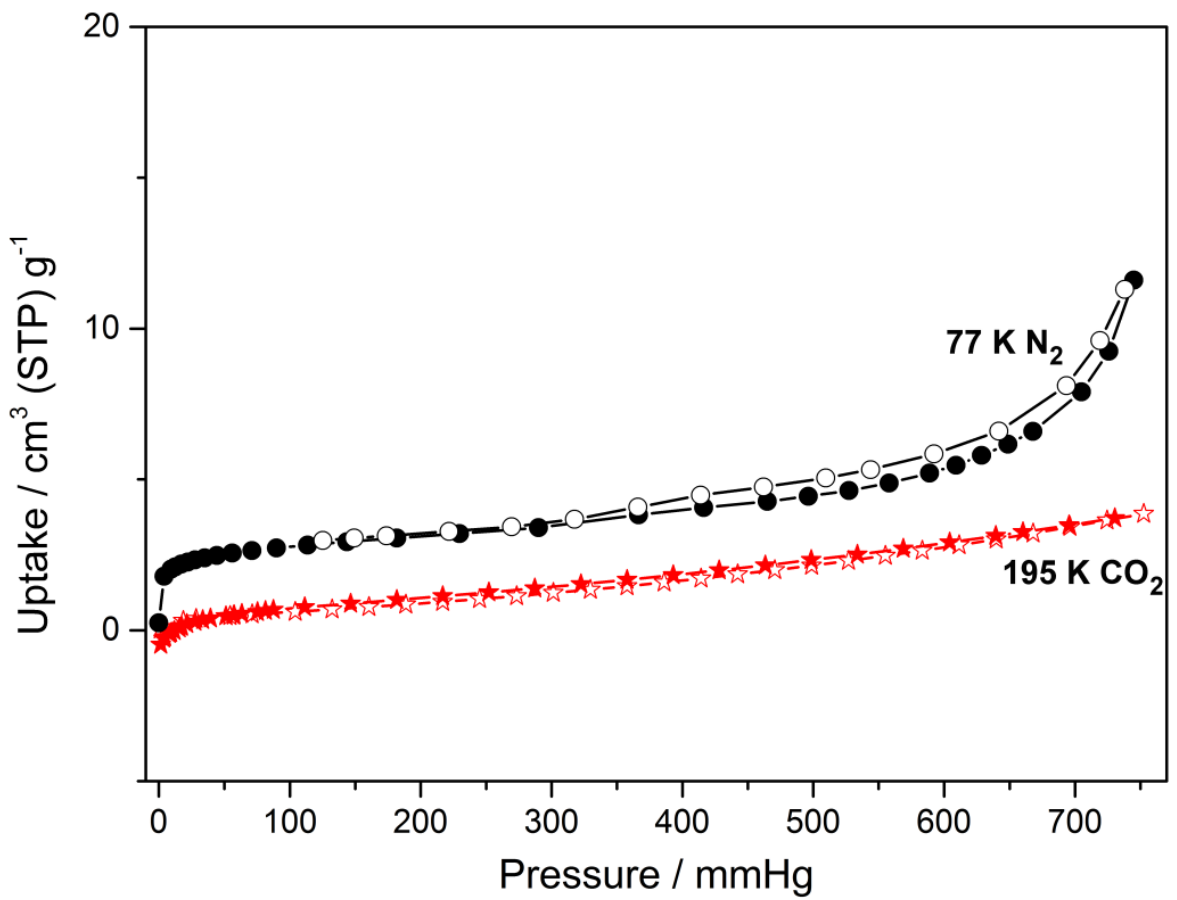

Figure S22. The $\mathrm{CO}_{2}(195 \mathrm{~K})$ and $\mathrm{N}_{2}(77 \mathrm{~K})$ sorption isotherms for SIFSIX-23-Cu-p2, indicating no reversible closed-to-open switching.

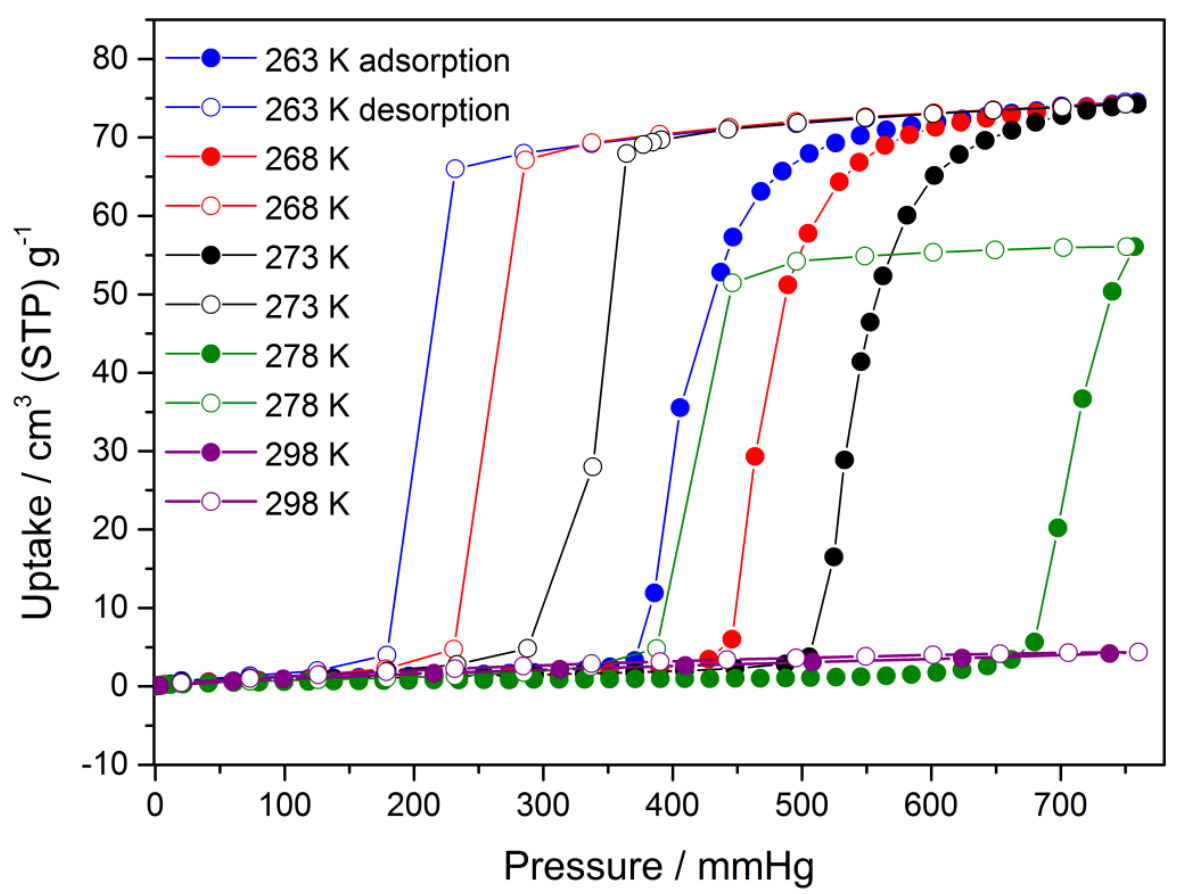

Figure S23. Low pressure $\mathrm{CO}_{2}$ sorption isotherms for SIFSIX-23-Cu- $\beta 1$ measured at $263 \mathrm{~K}, 268$ $\mathrm{K}, 273 \mathrm{~K}, 278 \mathrm{~K}$ and $298 \mathrm{~K}$. The open pressure is highly temperature dependent. The uptakes from $263 \mathrm{~K}$ to $273 \mathrm{~K}$ keep the same, suggesting that the uptake at $273 \mathrm{~K}$ got saturated. 


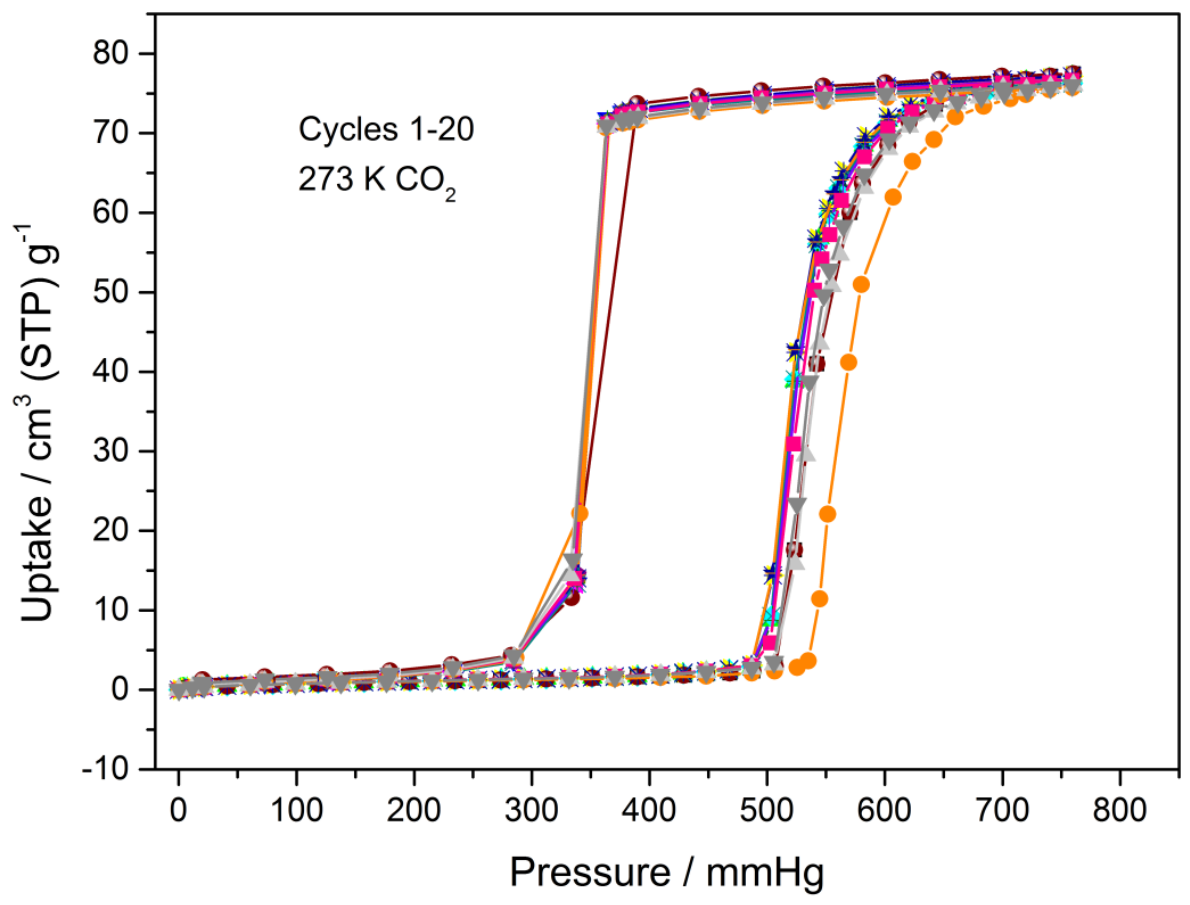

Figure S24. Low pressure $\mathrm{CO}_{2}$ sorption isotherms for SIFSIX-23-Cu- $\mathbf{\beta 1}$ measured at $273 \mathrm{~K}$ for cycles 1-20.

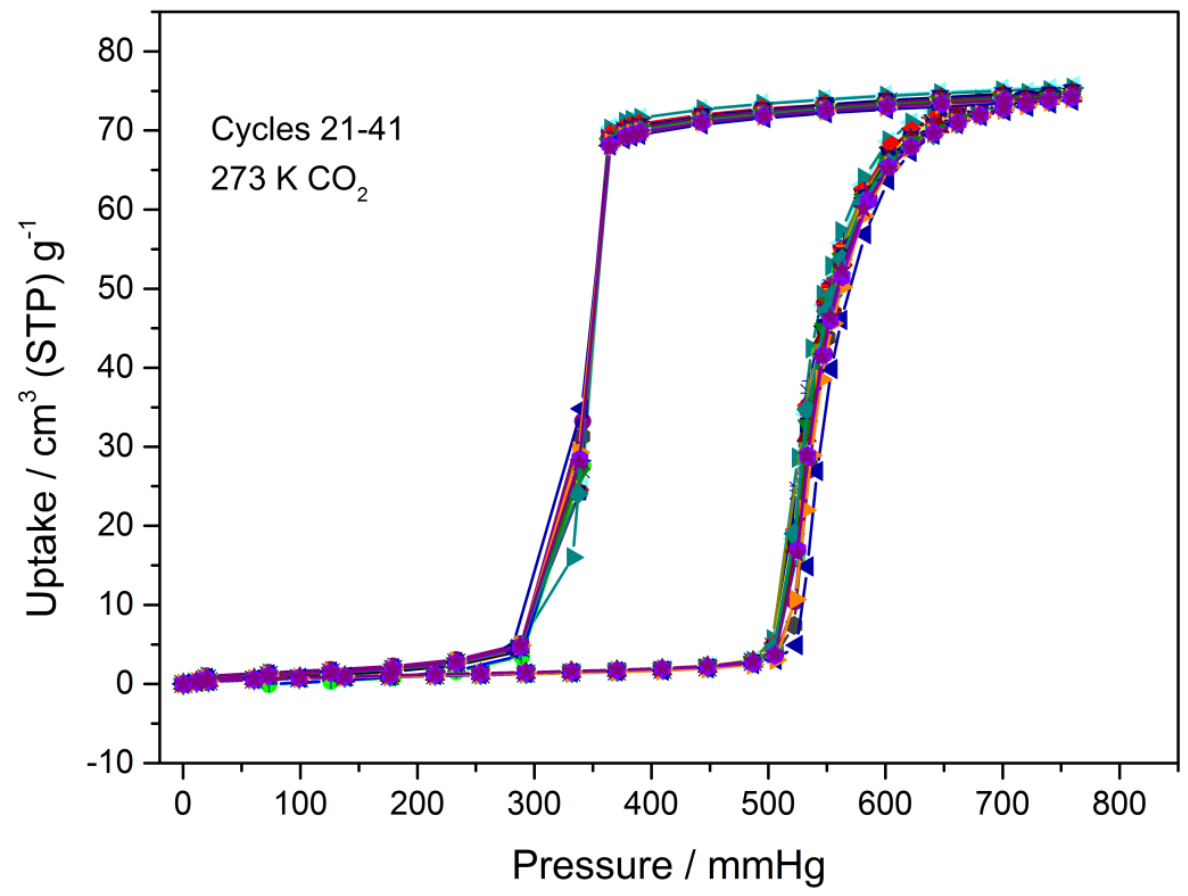

Figure S25. Low pressure $\mathrm{CO}_{2}$ sorption isotherms for SIFSIX-23-Cu- $\mathbf{\beta 1}$ measured at $273 \mathrm{~K}$ for cycles $21-41$. 


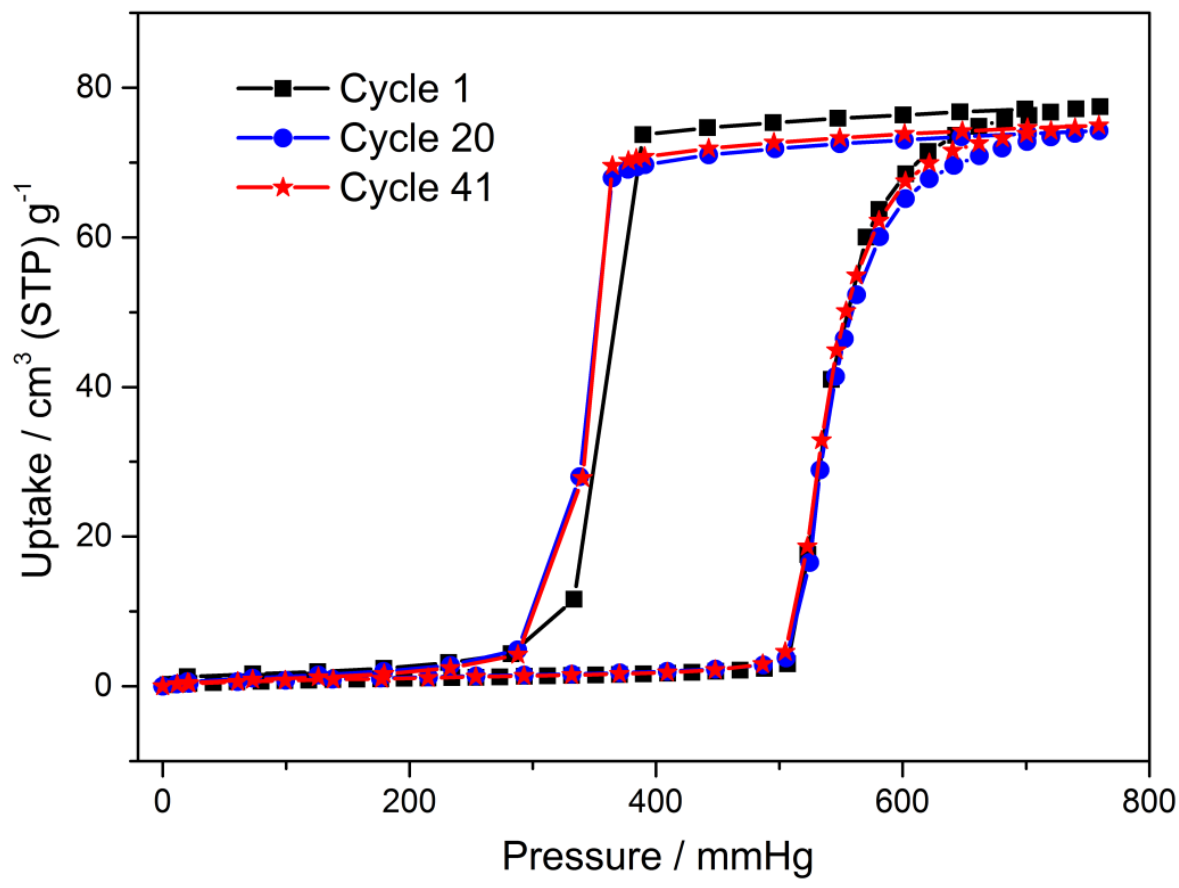

Figure S26. Low pressure $\mathrm{CO}_{2}$ sorption isotherms for SIFSIX-23-Cu- $\mathbf{\beta 1}$ measured at $273 \mathrm{~K}$ for cycle 1 , cycle 20 and cycle 41 , respectively.

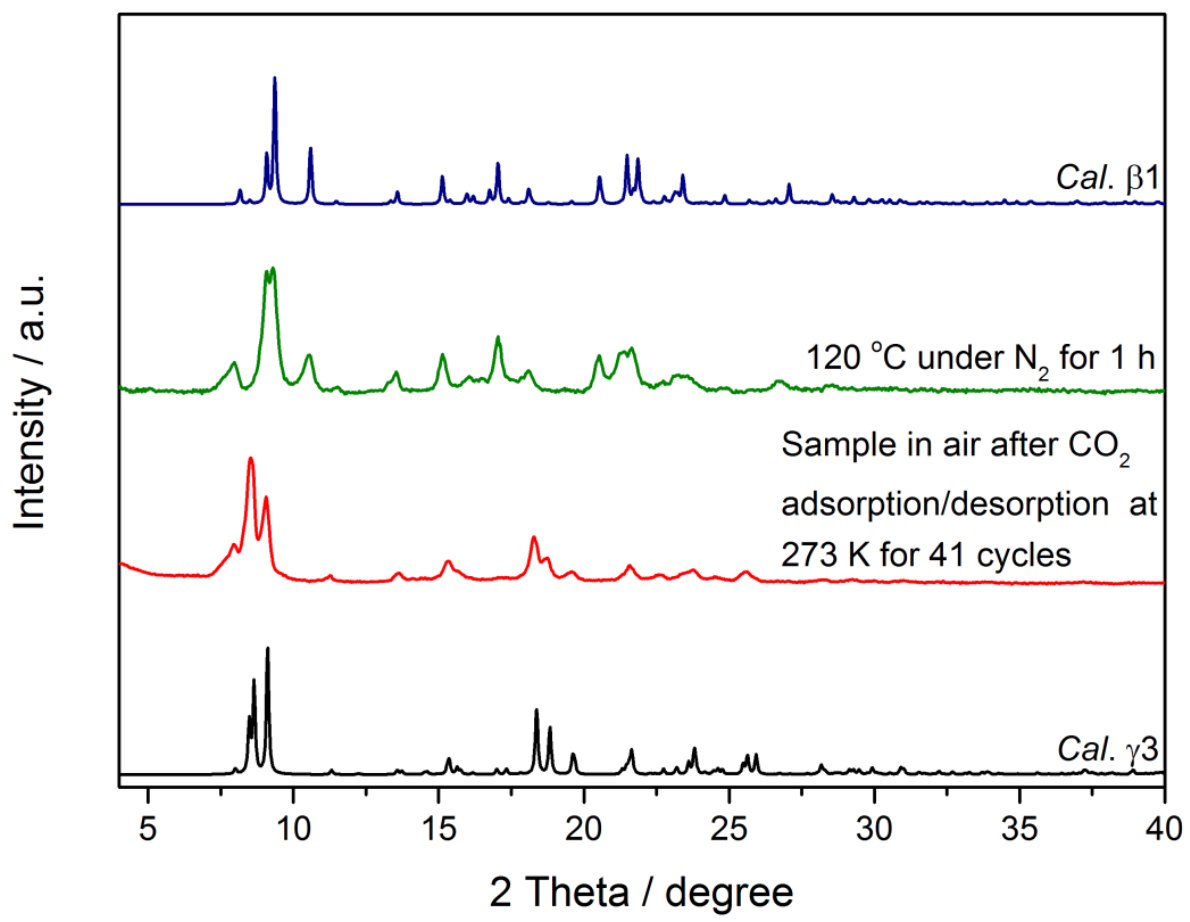

Figure S27. PXRD patterns for sample recycled after multiple sorption of $\mathrm{CO}_{2}$ at $273 \mathrm{~K}$ below 1 bar. Note: once the sample contacted with air, the color will change from light green to light pink, which implied the occurrence of structure transformation by capturing water from air. The 
measured PXRD patterns show similar pattern with SIFSIX-23-Cu- $\boldsymbol{\gamma}$ 3, matching with the PXRD results if the activated $\boldsymbol{\beta 1}$ phase was put in air for a short period of time. By reactivating the hydrated sample, the $\boldsymbol{\beta} 1$ phase can be recovered.

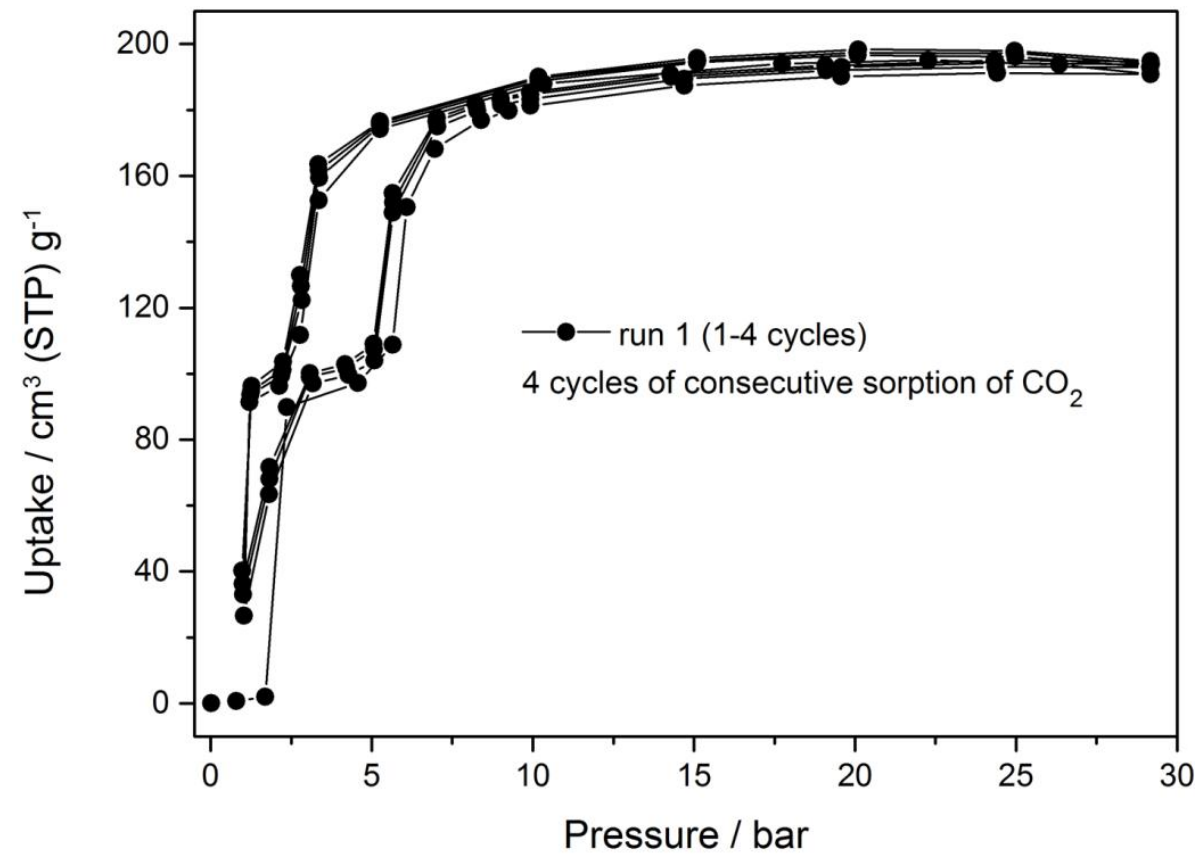

Figure S28. The first run of 4 consecutive cycles of $\mathrm{CO}_{2}$ sorption for SIFSIX-23-Cu- $\boldsymbol{\beta 1}$ at $298 \mathrm{~K}$ from 0 to 30 bar.

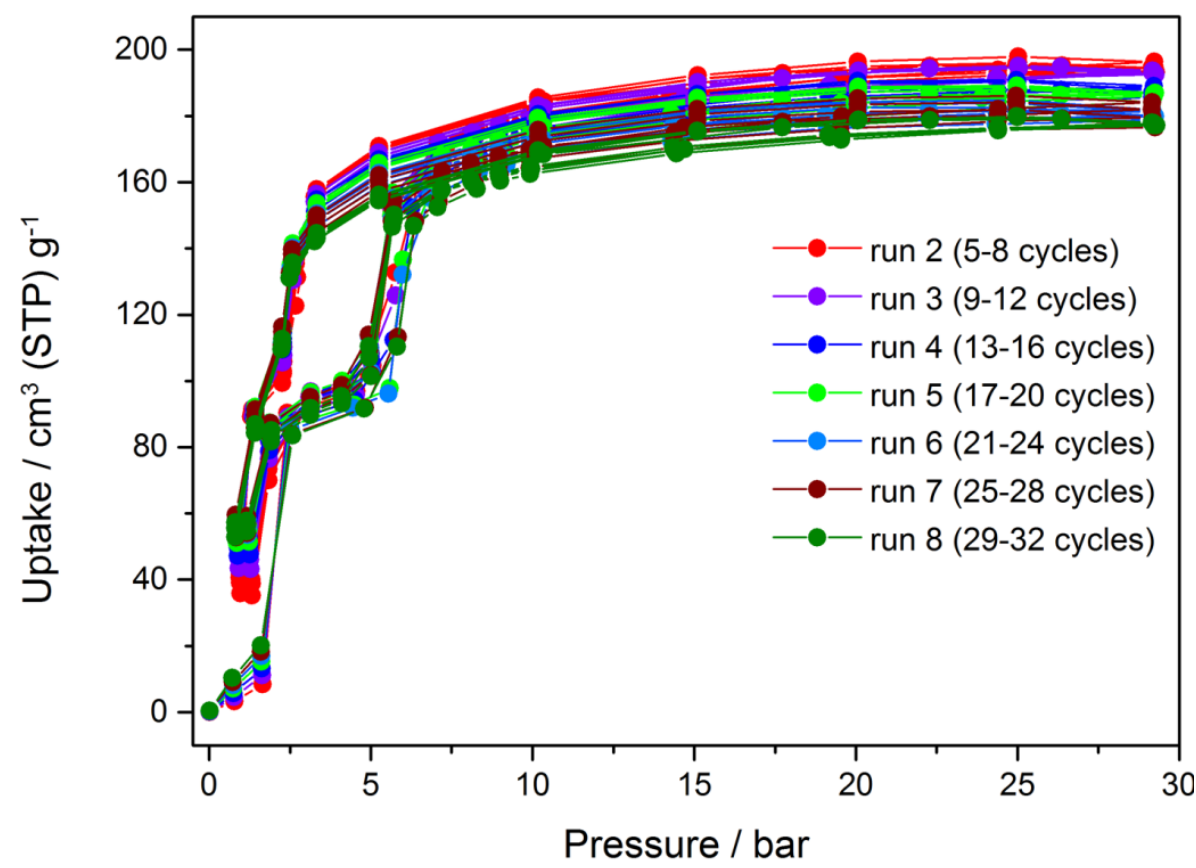

Figure S29. The 7 runs of $\mathrm{CO}_{2}$ sorption (each run containing 4 consecutive cycles) for SIFSIX-23-Cu- $\boldsymbol{\beta} 1$ at $298 \mathrm{~K}$ from 0 to 30 bar. 


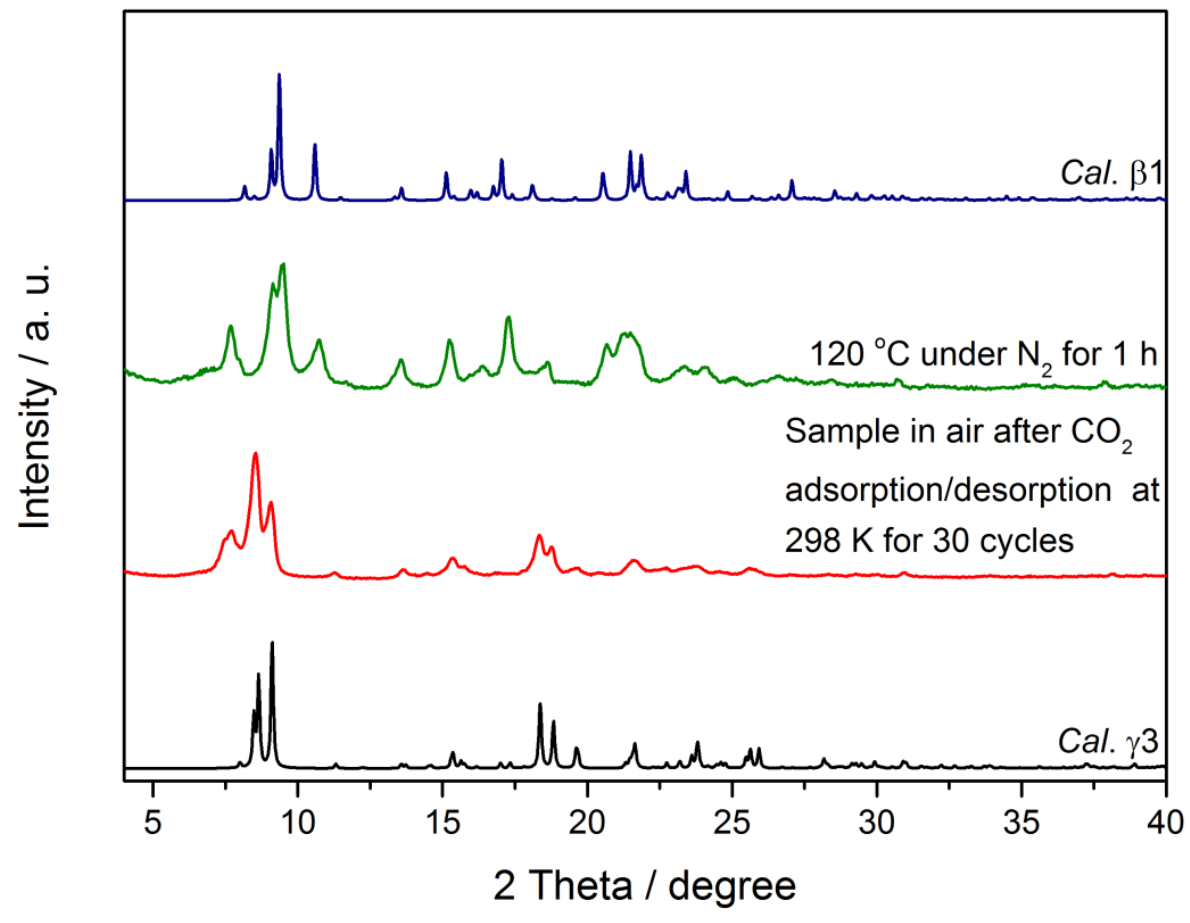

Figure S30. PXRD patterns for sample recycled after multiple high pressure sorption of $\mathrm{CO}_{2}$ at $298 \mathrm{~K}$ from 0 to 30 bar. Note: once the sample contacted with air, the sample color will change from light green to light pink, which in fact implied the structure transformation by capturing water from air. The measured PXRD patterns show similar pattern with SIFSIX-23-Cu- $\boldsymbol{\gamma}$, matching with the PXRD results if the activated $\boldsymbol{\beta} 1$ phase was put in air for a short period of time. By reactivating the hydrated sample, the $\boldsymbol{\beta 1}$ phase can be recovered. 


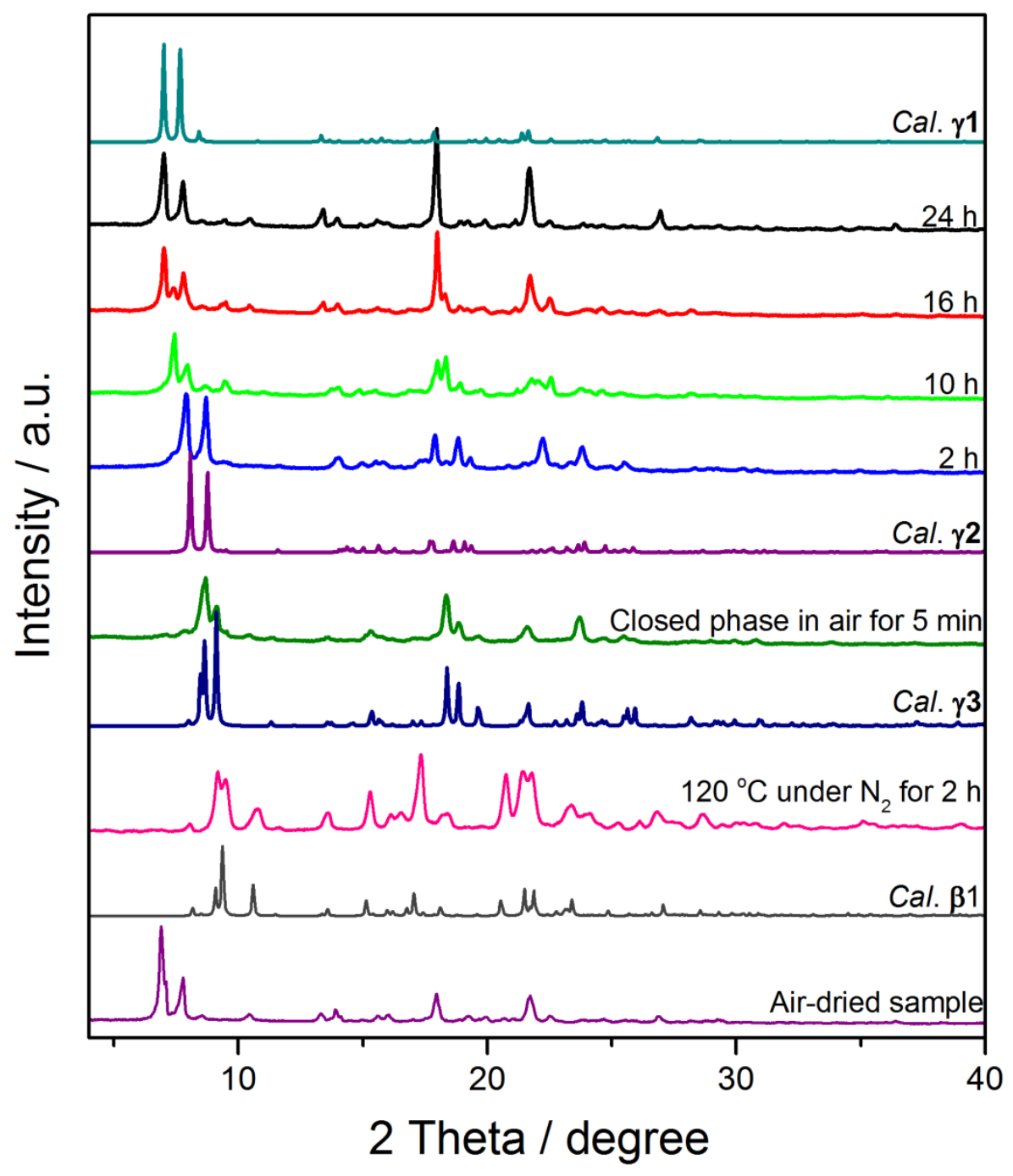

Figure S31. PXRD patterns for measurements testing structural transformation when in situ activated $\boldsymbol{\beta} 1$ phase was exposed in humid air at different time internal $\left(18{ }^{\circ} \mathrm{C}\right.$ and $40-50 \%$ relative humidity in our lab). 


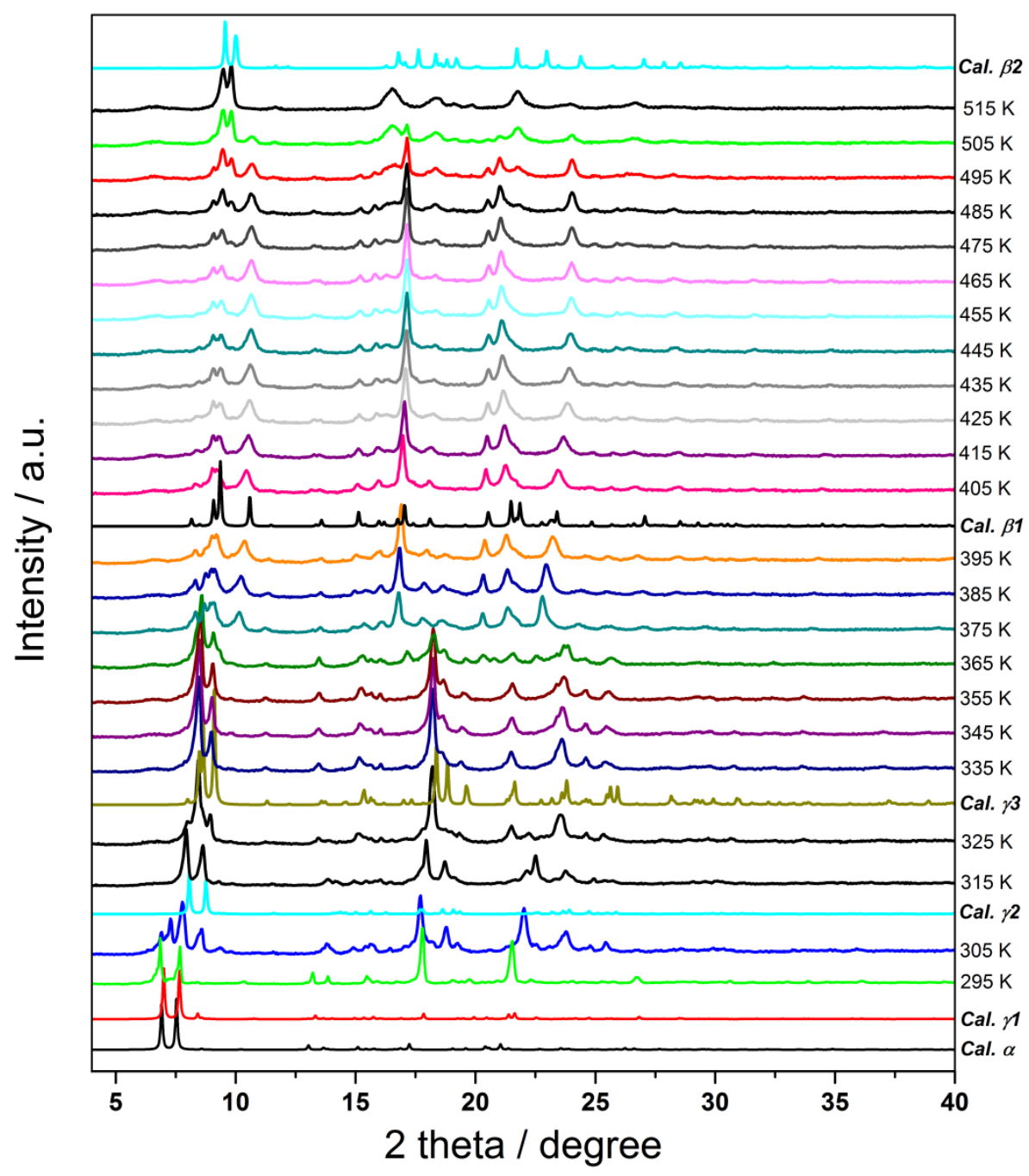

Figure S32. Variable temperature PXRD patterns of sample from 295 to $515 \mathrm{~K}$ under $\mathrm{N}_{2}$ at a step of $10 \mathrm{~K}$. The sample was obtained by putting the activated $\boldsymbol{\beta} 1$ phase at $95 \%$ relative humidity for 1 day. The phase transformation induced by $\mathrm{H}_{2} \mathrm{O}$ release almost matched with the similar structural evolution tendency observed for freshly synthesized samples. However, there seems to have an intermediate phase at $305 \mathrm{~K}$, i.e. a phase between $\gamma \mathbf{1}$ to $\boldsymbol{\gamma} \mathbf{2}$, although we have tried our best to get the structural details by SCXRD, we still failed after multiple attempts. 


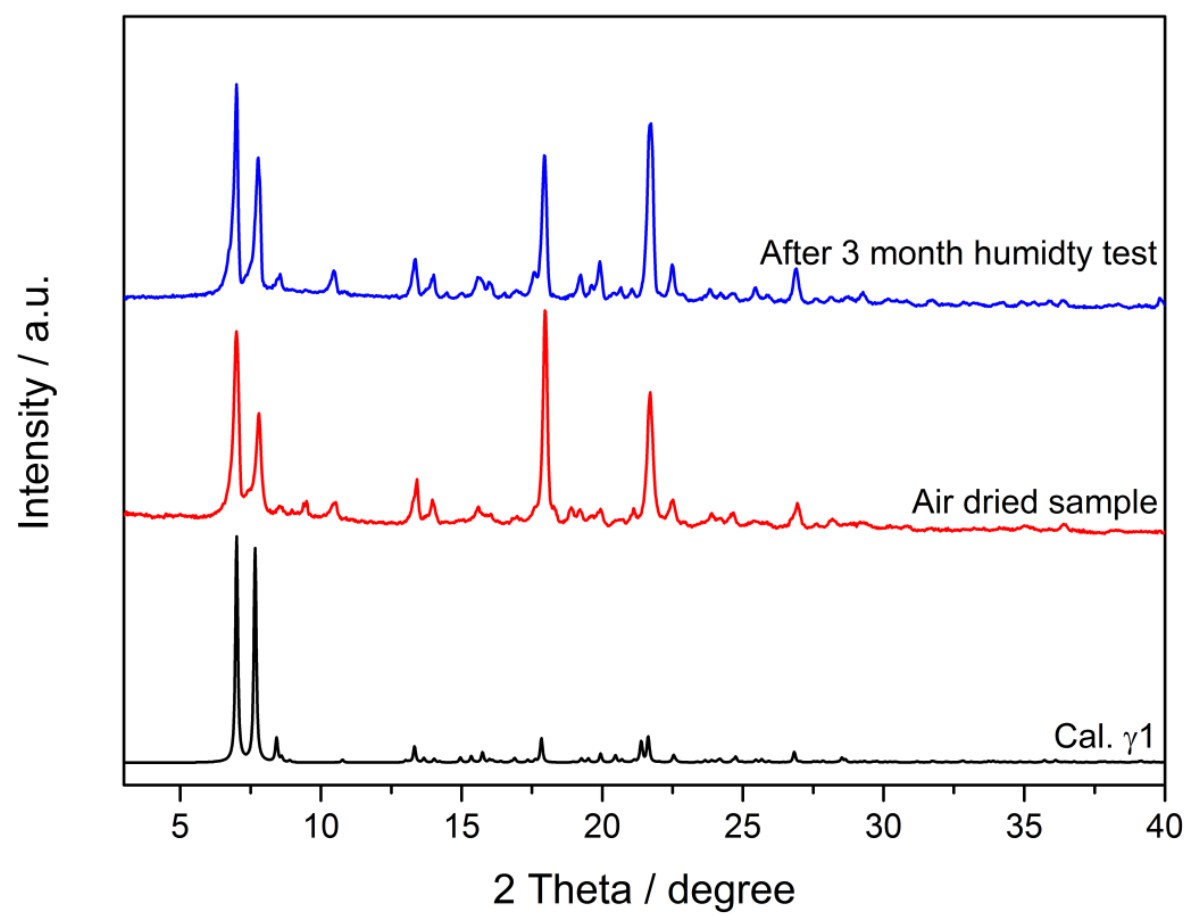

Figure S33. PXRD patterns for SIFSIX-23-Cu under $95 \%$ relative humidity at $40{ }^{\circ} \mathrm{C}$ for 3 months.

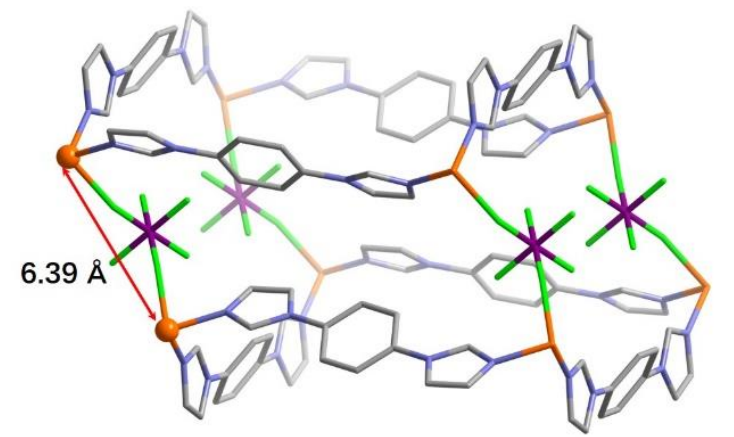

SIFSIX-23-Cu

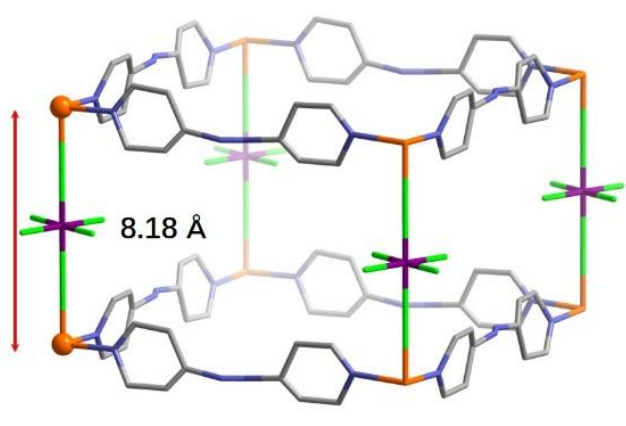

SIFSIX-14-Cu-i

Figure S34. Comparing the node-pillar-node distance in SIFSIX-23-Cu- $\boldsymbol{\alpha}$ and SIFSIX-14-Cu-i. Noting only one net (2-fold interpenetration) in SIFSIX-14-Cu-i is shown for clarity. The short distance observed in SIFSXI-23-Cu- $\boldsymbol{\alpha}$ contrasts with other reported SIFSIX nets, for example, SIFSXI-14-Cu-i, which exhibits a node-pillar-node length of $8.18 \AA$. The difference is ascribed to the special cis-bridging coordination mode in current work. The short $\mathrm{Cu}$-pillar- $\mathrm{Cu}$ distance leads to the reduced interlayer free space which limits the contact between water molecules and $\mathrm{Cu}$ centers. Additionally, the ubiquitous $\mathrm{C}-\mathrm{H}$...F hydrogen bonds between aromatic rings and inorganic pillars not only prevents the water molecules attacking the $\mathrm{Cu}$ centers (Table S4), but also "lock" the structure in such a manner that the inorganic pillar is trapped between metal nodes and is difficult to be displaced by water molecules. 
Table S6. Summary of switching metal-organic materials exhibiting closed-to-open structure transformation with uptake $>100 \mathrm{~cm}^{3} / \mathrm{g}$ [The FMOMs showing uptake $>200 \mathrm{~cm}^{3} / \mathrm{g}$ via closed-to-open switching have been highlighted in blue (3D) and green (2D)]

\begin{tabular}{|c|c|c|c|c|c|c|}
\hline \multicolumn{7}{|c|}{ Three-dimensional (3D) FMOMs } \\
\hline Materials & $\begin{array}{c}\text { Triggered } \\
\text { gas }\end{array}$ & $\begin{array}{c}\text { Saturated } \\
\text { Uptake } \\
\left(\mathrm{cm}^{3} / \mathrm{g}\right)\end{array}$ & $\begin{array}{l}\text { Gate } \\
\text { type }\end{array}$ & $\begin{array}{c}\text { The } \\
\text { pressure } \\
\text { of gate } \\
\text { opening }\end{array}$ & $\begin{array}{c}\text { The } \\
\text { pressure } \\
\text { of gate } \\
\text { closing }\end{array}$ & Ref. \\
\hline \multirow{3}{*}{ SIFSIX-23-Cu } & $\mathrm{CO}_{2}$ & $216(195 \mathrm{~K})^{\mathrm{a}}$ & multi-step & 0.004 bar & $<0.001$ bar & \multirow{3}{*}{$\begin{array}{l}\text { This } \\
\text { work }\end{array}$} \\
\hline & $\mathrm{CO}_{2}$ & $77(273 \mathrm{~K})^{\mathrm{a}}$ & single-step & $0.66 \mathrm{bar}$ & 0.38 bar & \\
\hline & $\mathrm{N}_{2}$ & $160(77 \mathrm{~K})^{\mathrm{a}}$ & single-step & 0.19 bar & $<0.001$ bar & \\
\hline \multirow{2}{*}{ X-pcu-5-Zn- $\beta$ (DMOF) } & $\mathrm{CO}_{2}$ & $254(195 \mathrm{~K})^{\mathrm{a}}$ & single-step & $\mathrm{P} / \mathrm{P}_{0}=0.30$ & $\mathrm{P} / \mathrm{P}_{0}=0.20$ & \multirow{4}{*}{$12^{19}$} \\
\hline & $\mathrm{CO}_{2}$ & $199(268 \mathrm{~K})^{\mathrm{b}}$ & single-step & 16 bar & 11 bar & \\
\hline \multirow{2}{*}{ X-pcu-5-Zn- $\gamma(\mathrm{DOMF})$} & $\mathrm{CO}_{2}$ & $256(195 \mathrm{~K})^{\mathrm{a}}$ & single-step & $\mathrm{P} / \mathrm{P}_{0}=0.36$ & $\mathrm{P} / \mathrm{P}_{0}=0.21$ & \\
\hline & $\mathrm{CO}_{2}$ & $212(268 \mathrm{~K})^{\mathrm{b}}$ & single-step & 19 bar & 11 bar & \\
\hline X-pcu-6-Zn- $\beta$ (DOMF) & $\mathrm{CO}_{2}$ & $245(195 \mathrm{~K})^{\mathrm{a}}$ & single-step & $\mathrm{P} / \mathrm{P}_{0}=0.17$ & $\mathrm{P} / \mathrm{P}_{0}=0.16$ & \multirow{3}{*}{$13^{20}$} \\
\hline $\mathrm{X}-\mathrm{pcu}-7-\mathrm{Zn}-\beta$ (DMOF) & $\mathrm{CO}_{2}$ & $267(195 \mathrm{~K})^{\mathrm{a}}$ & single-step & $\mathrm{P} / \mathrm{P}_{0}=0.33$ & $\mathrm{P} / \mathrm{P}_{0}=0.29$ & \\
\hline X-pcu-8-Zn- $\beta$ (DMOF) & $\mathrm{CO}_{2}$ & $243(195 \mathrm{~K})^{\mathrm{a}}$ & single-step & $\mathrm{P} / \mathrm{P}_{0}=0.39$ & $\mathrm{P} / \mathrm{P}_{0}=0.33$ & \\
\hline \multirow{2}{*}{ DUT-8 (Ni) (DMOF) } & $\mathrm{CO}_{2}$ & $590(196 \mathrm{~K})^{\mathrm{a}}$ & single-step & $\mathrm{P} / \mathrm{P}_{0}=0.4$ & $\mathrm{P} / \mathrm{P}_{0}=0.20$ & \multirow{2}{*}{$14^{21}$} \\
\hline & $\mathrm{N}_{2}$ & $650(77 \mathrm{~K})^{\mathrm{a}}$ & single-step & $\mathrm{P} / \mathrm{P}_{0}=0.1$ & $\mathrm{P} / \mathrm{P}_{0}<0.01$ & \\
\hline \multirow{2}{*}{$\mathrm{Zn}_{2}(\mathrm{tp})_{2}\left(\mathrm{~L}_{2}\right)(\mathrm{DMOF})$} & $\mathrm{CO}_{2}$ & $240(195 \mathrm{~K})^{\mathrm{a}}$ & multi-step & $\mathrm{P} / \mathrm{P}_{0}<0.05$ & $\mathrm{P} / \mathrm{P}_{0}<0.05$ & \multirow{2}{*}{$15^{22}$} \\
\hline & $\mathrm{O}_{2}$ & $250(77 \mathrm{~K})^{\mathrm{a}}$ & single-step & $\mathrm{P} / \mathrm{P}_{0}=0.05$ & $\mathrm{P} / \mathrm{P} 0<0.05$ & \\
\hline $\begin{array}{l}\text { MOF-508 analogue (DMOF) } \\
{\left[\mathrm{Zn}\left(\mathrm{C}_{20} \mathrm{H}_{12} \mathrm{O}_{4}\right)_{2}\left(\mathrm{C}_{10} \mathrm{H}_{8} \mathrm{~N}_{2}\right)\right]}\end{array}$ & $\mathrm{CO}_{2}$ & $188(298 \mathrm{~K})^{\mathrm{b}}$ & single-step & 25 bar & 10 bar & $16^{23}$ \\
\hline f-MOF-1b (DMOF) & $\mathrm{CO}_{2}$ & $107(195 \mathrm{~K})^{\mathrm{a}}$ & single-step & $\mathrm{P} / \mathrm{P}_{0}=0.44$ & $\mathrm{P} / \mathrm{P}_{0}<0.05$ & $17^{24}$ \\
\hline \multirow{2}{*}{ Co(bdp) } & $\mathrm{N}_{2}$ & $600(77 \mathrm{~K})^{\mathrm{a}}$ & multi-step & $\mathrm{P} / \mathrm{P}_{0}<0.01$ & $\mathrm{P} / \mathrm{P}_{0}<0.01$ & \multirow{4}{*}{$18^{25}$} \\
\hline & $\mathrm{CH}_{4}$ & $246(298 \mathrm{~K})^{\mathrm{b}}$ & single-step & $16 \mathrm{bar}$ & 7 bar & \\
\hline \multirow{2}{*}{ Fe(bdp) } & $\mathrm{N}_{2}$ & $600(77 K)^{\mathrm{a}}$ & multi-step & $\mathrm{P} / \mathrm{P}_{0}<0.01$ & $\mathrm{P} / \mathrm{P}_{0}<0.01$ & \\
\hline & $\mathrm{CH}_{4}$ & $295(298 \mathrm{~K})^{\mathrm{b}}$ & single-step & $\mathrm{P}=25$ bar & $\mathrm{P} \approx 9 \mathrm{bar}$ & \\
\hline \multirow{2}{*}{$\mathrm{X}$-dia-1-Ni } & $\mathrm{CO}_{2}$ & $325(195 \mathrm{~K})^{\mathrm{a}}$ & multi-step & $\mathrm{P} / \mathrm{P}_{0}<0.03$ & $\mathrm{P} / \mathrm{P}_{0}<0.01$ & \multirow{2}{*}{$19^{26}$} \\
\hline & $\mathrm{CH}_{4}$ & $222(298 \mathrm{~K})^{\mathrm{b}}$ & single-step & $\mathrm{P}=20 \mathrm{bar}$ & $\mathrm{P}<1$ bar & \\
\hline
\end{tabular}




\begin{tabular}{|c|c|c|c|c|c|c|}
\hline \multirow{2}{*}{ Cd-MOF } & $\mathrm{CO}_{2}$ & $130(195 \mathrm{~K})^{\mathrm{a}}$ & single-step & 0.34 bar & 0.08 bar & \multirow{2}{*}{$20^{27}$} \\
\hline & $\mathrm{CO}_{2}$ & $117(298 \mathrm{~K})^{\mathrm{b}}$ & single-step & $<8$ bar & $<2$ bar & \\
\hline \multirow{2}{*}{ [Zn(TCNQ-TCNQ)bpy] } & $\mathrm{O}_{2}$ & $268(77 \mathrm{~K})^{\mathrm{a}}$ & single-step & $\mathrm{P} / \mathrm{P}_{0}=0.34$ & $\mathrm{P} / \mathrm{P}_{0}<0.05$ & \multirow{2}{*}{$21^{28}$} \\
\hline & NO & $322(121 \mathrm{~K})^{\mathrm{a}}$ & single-step & $\mathrm{P} / \mathrm{P}_{0}=0.11$ & $\mathrm{P} / \mathrm{P}_{0}<0.05$ & \\
\hline flex-MOF(CN) & $\mathrm{CO}_{2}$ & 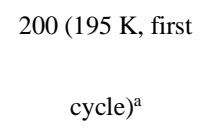 & multi-step & 0.41 bar & $<0.01$ bar & $22^{29}$ \\
\hline MIL-53(Sc) & $\mathrm{CO}_{2}$ & $291(195 \mathrm{~K})^{\mathrm{a}}$ & multi-step & 0.05 bar & $<0.01$ bar & $23^{30}$ \\
\hline rtl-[Cu(HIsa-az-dmpz)] & $\mathrm{CO}_{2}$ & $310(195 \mathrm{~K})^{\mathrm{a}}$ & single-step & 0.08 & $<0.01 \mathrm{bar}$ & $24^{31}$ \\
\hline $\mathrm{Zn}(\mathrm{GA})_{2}$ & $\mathrm{CO}_{2}$ & $132(195 \mathrm{~K})^{\mathrm{a}}$ & single-step & $\mathrm{P} / \mathrm{P}_{0}=0.03$ & $\mathrm{P} / \mathrm{P}_{0}<0.03$ & $25^{32}$ \\
\hline $\mathrm{Zn}(\mathrm{Gly}-\mathrm{Ala})_{2}$ & $\mathrm{CO}_{2}$ & $127(195 \mathrm{~K})^{\mathrm{a}}$ & single-step & $\mathrm{P} / \mathrm{P}_{0}=0.03$ & $\mathrm{P} / \mathrm{P}_{0}<0.03$ & $26^{33}$ \\
\hline \multicolumn{7}{|c|}{ Two-dimensional (2D) FMOMs } \\
\hline \multirow{2}{*}{ ELM-11 } & $\mathrm{N}_{2}$ & $340(77 \mathrm{~K})^{\mathrm{a}}$ & single-step & $\mathrm{P} / \mathrm{P}_{0}<0.10$ & $\mathrm{P} / \mathrm{P}_{0} \approx 0$ & \multirow{3}{*}{$27^{3}$} \\
\hline & $\mathrm{CO}_{2}$ & $240(195 \mathrm{~K})^{\mathrm{a}}$ & multi-step & $0.003 \mathrm{bar}$ & $<0.01$ bar & \\
\hline ELM-13 & $\mathrm{N}_{2}$ & $314(77 \mathrm{~K})^{\mathrm{a}}$ & single-step & $\mathrm{P} / \mathrm{P}_{0}=0.40$ & $\mathrm{P} / \mathrm{P}_{0} \approx 0$ & \\
\hline [Cd(bpndc)(bpy)] & $\mathrm{N}_{2}$ & $151(90 \mathrm{~K})^{\mathrm{a}}$ & single-step & $\mathrm{P} / \mathrm{P}_{0}=0.15$ & $\mathrm{P} / \mathrm{P}_{0}<0.01$ & $28^{35}$ \\
\hline \multirow{2}{*}{ CPM-325-Naph } & $\mathrm{N}_{2}$ & $216(77 \mathrm{~K})^{\mathrm{a}}$ & single-step & $\mathrm{P} / \mathrm{P}_{0}=0.27$ & $\mathrm{P} / \mathrm{P}_{0} \approx 0$ & \multirow{2}{*}{$29^{36}$} \\
\hline & $\mathrm{CO}_{2}$ & $190(195 \mathrm{~K})^{\mathrm{a}}$ & single-step & $\mathrm{P} / \mathrm{P}_{0}=0.03$ & $\mathrm{P} / \mathrm{P}_{0}<0.03$ & \\
\hline$\left[\mathrm{Cu}\left(\mathrm{CF}_{3} \mathrm{SO}_{3}\right)_{2}(\mathrm{bpp})_{2}\right]$ & $\mathrm{CO}_{2}$ & $153(195 \mathrm{~K})^{\mathrm{a}}$ & single-step & $\mathrm{P} / \mathrm{P}_{0}=0.60$ & $\mathrm{P} / \mathrm{P}_{0}=0.10$ & $30^{37}$ \\
\hline$[\mathrm{Ni}(\mathrm{bdc})(\mathrm{bphy})]$ & $\mathrm{CO}_{2}$ & $147(298 \mathrm{~K})^{\mathrm{b}}$ & single-step & 5 bar & I & $31^{38}$ \\
\hline sql-1-Co-NCS & $\mathrm{CO}_{2}$ & $136(195 \mathrm{~K})^{\mathrm{a}}$ & single-step & $\mathrm{P} / \mathrm{P}_{0}=0.10$ & $\mathrm{P} / \mathrm{P}_{0}=0.08$ & $32^{39}$ \\
\hline
\end{tabular}

Totally 17 FMOMs exhibiting gas-triggered closed-to-open switching with uptake > $200 \mathrm{~cm}^{3} / \mathrm{g}$ have been reported in the literatures, including the analogous structures with different ligands and metal ions. Among them, 3 FMOMs are two-dimensional (2D) while 14 are three-dimensional (3D). Among the 14 3D FMOMs, 7 (50\%) of them belong to the old-fashioned DMOF platform (paddle-wheel-based pillared-layered framework consisting of dicarboxylic ligand and neutral N-donor ligand (usually di-pyridine ligand)), which is well-known for the structural flexibility arising from the hinge-like motion associated with carboxylate coordination. The flexible coordination behavior of $\mathrm{sp}^{3}$ hybridized oxygen atom is crucial for the framework flexibility due to the non-directional and strong metal-oxygen 
coordination bonds. In fact, among the 14 examples of 3D FMOMs, 11 of them involve the carboxylate coordination. On the contrary, the binding direction of the $\mathrm{sp}^{2}$ nitrogen is highly restricted to the same direction as its lone electron pair. As a result, FMOMs constructed from pure neutral $\mathrm{N}$-donor ligands are very rare because the relatively weak and directional metal-N coordination bond, especially for 3D framework. The neutral N-donor ligands can be used to construct 2D FMOMs, for example 4,4'-bipyridine in ELM-11, because the main structure changes come from the relative movement between adjacent layers, while the request for the intra-layer metal-ligand interface distortion is not that much high.

\section{References}

(1) (a) Yang, G.-S.; Zang, H.-Y.; Lan, Y.-Q.; Wang, X.-L.; Jiang, C.-J.; Su, Z.-M.; Zhu, L.-D. Synthesis and characterization of two \{Mo6\}-based/templated metal - organic frameworks. CrystEngComm 2011, 13, 1461. (b) Fan, J.; Gan, L.; Kawaguchi, H.; Sun, W.-Y.; Yu, K.-B.; Tang, W.-X. Reversible Anion Exchanges between the Layered Organic - Inorganic Hybridized Architectures: Syntheses and Structures of Manganese(II) and Copper(II) Complexes Containing Novel Tripodal Ligands. Chem. - Eur. J. 2003, 9, 3965.

(2) APEX3, Version 2017.3-0, Bruker AXS Inc., Madison, Wisconsin, USA, 2017.

(3) SADABS, Version 2014/4, Bruker AXS Inc., Madison, Wisconsin, USA, 2014.

(4) XPREP, Version 2014/2, Bruker AXS Inc., Madison, Wisconsin, USA, 2014.

(5) Sheldrick, G. SHELXT - Integrated space-group and crystal-structure determination. Acta Cryst. A 2015, 71, 3.

(6) Sheldrick, G. Crystal structure refinement with SHELXL. Acta Cryst. C 2015, 71, 3.

(7) Dolomanov, O. V.; Bourhis, L. J.; Gildea, R. J.; Howard, J. A. K.; Puschmann, H. OLEX2: a complete structure solution, refinement and analysis program. J. Appl. Crystallogr. 2009, 42, 339.

(8) Spek, A. PLATON SQUEEZE: a tool for the calculation of the disordered solvent contribution to the calculated structure factors. Acta Cryst. $C$ 2015, 71, 9.

(9) Spek, A. Structure validation in chemical crystallography. Acta Cryst. D 2009, 65, 148.

(10) (a) Becke, A. D. Density - functional thermochemistry. I. The effect of the exchange - only gradient correction. J. Phys. Chem. 1992, 96, 2155. (b) Lee, C.; Yang, 
W.; Parr, R. G. Development of the Colle-Salvetti correlation-energy formula into a functional of the electron density. Physical Review B 1988, 37, 785.

(11) Frisch, M.; Trucks, G.; Schlegel, H.; Scuseria, G.; Robb, M.; Cheeseman, J.; Scalmani, G.; Barone, V.; Petersson, G.; Nakatsuji, H., Gaussian 16. Gaussian, Inc. Wallingford, CT: 2016.

(12) (a) Kresse, G.; Furthmüller, J. Efficiency of ab-initio total energy calculations for metals and semiconductors using a plane-wave basis set. Computational Materials Science 1996, 6, 15. (b) Kresse, G.; Furthmüller, J. Efficient iterative schemes for ab initio total-energy calculations using a plane-wave basis set. Physical Review B 1996, $54,11169$.

(13) Perdew, J. P.; Burke, K.; Ernzerhof, M. Generalized Gradient Approximation Made Simple. Phys. Rev. Lett. 1996, 77, 3865.

(14) (a) Steinmann, S. N.; Corminboeuf, C. A generalized-gradient approximation exchange hole model for dispersion coefficients. J. Phys. Chem. 2011, 134, 044117.

(b) Steinmann, S. N.; Corminboeuf, C. Comprehensive Benchmarking of a Density-Dependent Dispersion Correction. J. Chem. Theory Comput. 2011, 7, 3567.

(15) Blöchl, P. E. Projector augmented-wave method. Physical Review B 1994, 50, 17953.

(16) (a) Pack, J. D.; Monkhorst, H. J. "Special points for Brillouin-zone integrations"---a reply. Physical Review B 1977, 16, 1748. (b) Monkhorst, H. J.; Pack, J. D. Special points for Brillouin-zone integrations. Physical Review B 1976, 13, 5188.

(17) (a) Desiraju, G. R. Hydrogen Bridges in Crystal Engineering: Interactions without Borders. Acc. Chem. Res. 2002, 35, 565. (b) Alonso, J. L.; Antolínez, S.; Blanco, S.; Lesarri, A.; López, J. C.; Caminati, W. Weak $\mathrm{C}-\mathrm{H} \cdot \cdots \mathrm{O}$ and $\mathrm{C}-\mathrm{H} \cdot \cdots \mathrm{F}-\mathrm{C}$ Hydrogen Bonds in the Oxirane-Trifluoromethane Dimer. J. Am. Chem. Soc. 2004, 126, 3244. (c) Kryachko, E.; Scheiner, S. CH •. F Hydrogen Bonds. Dimers of Fluoromethanes. J. Phys. Chem. A 2004, 108, 2527. (d) Caminati, W.; López, J. C.; Alonso, J. L.; Grabow, J.-U. Weak CH - F Bridges and Internal Dynamics in the CH3F · CHF3 Molecular Complex. Angew. Chem. Int. Ed. 2005, 44, 3840.

(18) (a) Karagiaridi, O.; Lalonde, M. B.; Bury, W.; Sarjeant, A. A.; Farha, O. K.; Hupp, J. T. Opening ZIF-8: A Catalytically Active Zeolitic Imidazolate Framework of Sodalite Topology with Unsubstituted Linkers. J. Am. Chem. Soc. 2012, 134, 18790. (b) Lalonde, M. B.; Farha, O. K.; Scheidt, K. A.; Hupp, J. T. N-Heterocyclic Carbene-Like Catalysis by a Metal - Organic Framework Material. ACS Catal. 2012, 2,1550 .

(19) Zhu, A.-X.; Yang, Q.-Y.; Kumar, A.; Crowley, C.; Mukherjee, S.; Chen, K.-J.; Wang, S.-Q.; O' Nolan, D.; Shivanna, M.; Zaworotko, M. J. Coordination Network That Reversibly Switches between Two Nonporous Polymorphs and a High Surface Area Porous Phase. J. Am. Chem. Soc. 2018, 140, 15572.

(20) Zhu, A.-X.; Yang, Q.-Y.; Mukherjee, S.; Kumar, A.; Deng, C.-H.; Bezrukov, A. A.; Shivanna, M.; Zaworotko, M. J. Tuning the Gate-Opening Pressure in a Switching pcu Coordination Network, X-pcu-5-Zn, by Pillar-Ligand Substitution. Angew. Chem. Int. Ed. 2019, 58, 18212. 
(21) Klein, N.; Hoffmann, H. C.; Cadiau, A.; Getzschmann, J.; Lohe, M. R.; Paasch, S.; Heydenreich, T.; Adil, K.; Senkovska, I.; Brunner, E.; Kaskel, S. Structural flexibility and intrinsic dynamics in the $\mathrm{M} 2(2,6-\mathrm{ndc}) 2($ dabco $)(\mathrm{M}=\mathrm{Ni}, \mathrm{Cu}, \mathrm{Co}, \mathrm{Zn})$ metal - organic frameworks. J. Mater. Chem. 2012, 22, 10303.

(22) Seo, J.; Bonneau, C.; Matsuda, R.; Takata, M.; Kitagawa, S. Soft Secondary Building Unit: Dynamic Bond Rearrangement on Multinuclear Core of Porous Coordination Polymers in Gas Media. J. Am. Chem. Soc. 2011, 133, 9005.

(23) Engel, E. R.; Jouaiti, A.; Bezuidenhout, C. X.; Hosseini, M. W.; Barbour, L. J. Activation-Dependent Breathing in a Flexible Metal - Organic Framework and the Effects of Repeated Sorption/Desorption Cycling. Angew. Chem. Int. Ed. 2017, 56, 8874.

(24) Kanoo, P.; Haldar, R.; Reddy, S. K.; Hazra, A.; Bonakala, S.; Matsuda, R.; Kitagawa, S.; Balasubramanian, S.; Maji, T. K. Crystal Dynamics in Multi-stimuli-Responsive Entangled Metal - Organic Frameworks. Chem. - Eur. J. 2016, 22, 15864.

(25) Mason, J. A.; Oktawiec, J.; Taylor, M. K.; Hudson, M. R.; Rodriguez, J.; Bachman, J. E.; Gonzalez, M. I.; Cervellino, A.; Guagliardi, A.; Brown, C. M.; Llewellyn, P. L.; Masciocchi, N.; Long, J. R. Methane storage in flexible metal organic frameworks with intrinsic thermal management. Nature 2015, 527, 357.

(26) Yang, Q.-Y.; Lama, P.; Sen, S.; Lusi, M.; Chen, K.-J.; Gao, W.-Y.; Shivanna, M.; Pham, T.; Hosono, N.; Kusaka, S.; Perry IV, J. J.; Ma, S.; Space, B.; Barbour, L. J.; Kitagawa, S.; Zaworotko, M. J. Reversible Switching between Highly Porous and Nonporous Phases of an Interpenetrated Diamondoid Coordination Network That Exhibits Gate-Opening at Methane Storage Pressures. Angew. Chem. Int. Ed. 2018, 57, 5684.

(27) Yang, H.; Guo, F.; Lama, P.; Gao, W.-Y.; Wu, H.; Barbour, L. J.; Zhou, W.; Zhang, J.; Aguila, B.; Ma, S. Visualizing Structural Transformation and Guest Binding in a Flexible Metal - Organic Framework under High Pressure and Room Temperature. ACS Cent. Sci. 2018, 4, 1194.

(28) Shimomura, S.; Higuchi, M.; Matsuda, R.; Yoneda, K.; Hijikata, Y.; Kubota, Y.; Mita, Y.; Kim, J.; Takata, M.; Kitagawa, S. Selective sorption of oxygen and nitric oxide by an electron-donating flexible porous coordination polymer. Nat. Chem. 2010, $2,633$.

(29) Jeoung, S.; Lee, S.; Lee, J. H.; Lee, S.; Choe, W.; Moon, D.; Moon, H. R. Tuning of the flexibility in metal - organic frameworks based on pendant arm macrocycles. Chem. Commun. 2019, 55, 8832.

(30) Chen, L.; Mowat, J. P. S.; Fairen-Jimenez, D.; Morrison, C. A.; Thompson, S. P.; Wright, P. A.; Düren, T. Elucidating the Breathing of the Metal - Organic Framework MIL-53(Sc) with ab Initio Molecular Dynamics Simulations and in Situ X-ray Powder Diffraction Experiments. J. Am. Chem. Soc. 2013, 135, 15763.

(31) Millan, S.; Gil-Hernández, B.; Milles, E.; Gökpinar, S.; Makhloufi, G.; Schmitz, A.; Schlüsener, C.; Janiak, C. rtl-M-MOFs $(\mathrm{M}=\mathrm{Cu}, \mathrm{Zn})$ with a T-shaped bifunctional pyrazole-isophthalate ligand showing flexibility and S-shaped Type F-IV sorption isotherms with high saturation uptakes for $\mathrm{M}=\mathrm{Cu}$. Dalton Trans. 2019, 48, 8057. 
(32) Martí-Gastaldo, C.; Antypov, D.; Warren, J. E.; Briggs, M. E.; Chater, P. A.; Wiper, P. V.; Miller, G. J.; Khimyak, Y. Z.; Darling, G. R.; Berry, N. G.; Rosseinsky, M. J. Side-chain control of porosity closure in single- and multiple-peptide-based porous materials by cooperative folding. Nat. Chem. 2014, 6, 343.

(33) Rabone, J.; Yue, Y.-F.; Chong, S. Y.; Stylianou, K. C.; Bacsa, J.; Bradshaw, D.; Darling, G. R.; Berry, N. G.; Khimyak, Y. Z.; Ganin, A. Y.; Wiper, P.; Claridge, J. B.; Rosseinsky, M. J. An Adaptable Peptide-Based Porous Material. Science 2010, 329, 1053.

(34) Kajiro, H.; Kondo, A.; Kaneko, K.; Kanoh, H. Flexible Two-Dimensional Square-Grid Coordination Polymers: Structures and Functions. Int. J. Mol. Sci. 2010, $11,43$.

(35) Tanaka, D.; Nakagawa, K.; Higuchi, M.; Horike, S.; Kubota, Y.; Kobayashi, T. C.; Takata, M.; Kitagawa, S. Kinetic Gate-Opening Process in a Flexible Porous Coordination Polymer. Angew. Chem. Int. Ed. 2008, 47, 3914.

(36) Jin, J.; Zhao, X.; Feng, P.; Bu, X. A Cooperative Pillar - Template Strategy as a Generalized Synthetic Method for Flexible Homochiral Porous Frameworks. Angew. Chem. 2018, 130, 3799.

(37) Fukuhara, K.; Noro, S.-i.; Sugimoto, K.; Akutagawa, T.; Kubo, K.; Nakamura, T. Porous Coordination Polymer Polymorphs with Different Flexible Pores Using a Structurally Flexible and Bent 1,3-Bis(4-pyridyl)propane Ligand. Inorg. Chem. 2013, $52,4229$.

(38) Liu, X.-M.; Lin, R.-B.; Zhang, J.-P.; Chen, X.-M. Low-Dimensional Porous Coordination Polymers Based on 1,2-Bis(4-pyridyl)hydrazine: From Structure Diversity to Ultrahigh CO2/CH4 Selectivity. Inorg. Chem. 2012, 51, 5686.

(39) (a) Wang, S.-Q.; Yang, Q.-Y.; Mukherjee, S.; O’ Nolan, D.; Patyk-Kaźmierczak, E.; Chen, K.-J.; Shivanna, M.; Murray, C.; Tang, C. C.; Zaworotko, M. J. Recyclable switching between nonporous and porous phases of a square lattice (sql) topology coordination network. Chem. Commun. 2018, 54, 7042. (b) Wang, S.-Q.; Mukherjee, S.; Patyk-Kaźmierczak, E.; Darwish, S.; Bajpai, A.; Yang, Q.-Y.; Zaworotko, M. J. Highly Selective, High-Capacity Separation of o-Xylene from C8 Aromatics by a Switching Adsorbent Layered Material. Angew. Chem. 2019, 131, 6702. 